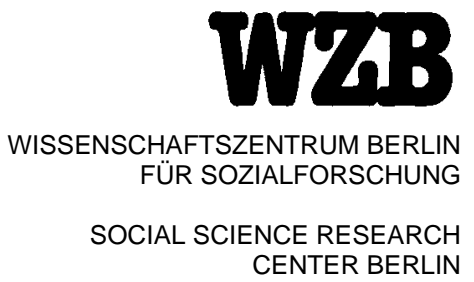

\author{
Susanne Prantl * \\ Matthias Almus ** \\ Jürgen Egeln *** \\ Dirk Engel ****
}

\begin{abstract}
Kreditvergabe durch Genossenschaftsbanken, Kreditbanken und Sparkassen: Eine empirische Analyse von Förderkrediten für junge, kleine Unternehmen
\end{abstract}

* Wissenschaftszentrum Berlin

** Great Lakes UK, London

*** Zentrum für Europäische Wirtschaftsforschung

$\star \star \star \star$ Rheinisch-Westfälisches Institut für

Wirtschaftsforschung

SP || $2008-14$

September 2008

ISSN Nr. $0722-6748$

Research Area

Markets and Politics

Research Unit

Competition and Innovation
Schwerpunkt II

Märkte und Politik

Abteilung

Wettbewerb und innovation 
Zitierweise/Citation:

Susanne Prantl, Matthias Almus, Jürgen Egeln und Dirk Engel, Kreditvergabe durch Genossenschaftsbanken, Kreditbanken und Sparkassen: Eine empirische Analyse von Förderkrediten für junge, kleine Unternehmen, Discussion Paper SP II 2008 - 14, Wissenschaftszentrum Berlin, 2008.

Wissenschaftszentrum Berlin für Sozialforschung gGmbH, Reichpietschufer 50, 10785 Berlin, Germany, Tel. (030) 25491 - 0 Internet: www.wzb.eu 


\title{
Kreditvergabe durch Genossenschaftsbanken, Kreditbanken und Sparkassen: Eine empirische Analyse von Förderkrediten für junge, kleine Unternehmen *
}

\author{
von Susanne Prantl, Matthias Almus, Jürgen Egeln und Dirk Engel
}

In diesem Beitrag untersuchen wir die Rolle von Genossenschaftsbanken, Kreditbanken und Sparkassen bei der Vergabe langfristiger Kredite an junge, kleine Unternehmen. Dies geschieht am Beispiel von Krediten aus öffentlichen Förderprogrammen, die in Deutschland einen substantiellen Anteil aller langfristigen Bankkredite an junge Unternehmen und KMU ausmachen und deren Allokation die drei Bankgruppen direkt involviert. Unsere empirischen Analysen auf Regions- und Unternehmensebene für die 1990er Jahre weisen darauf hin, dass Kreditbanken ihre Kreditvergabe an typische junge, kleine Unternehmen in diesem Zeitraum nicht ändern. Sie spielen schon Anfang der 1990er Jahre nur eine marginale Rolle. Im Gegensatz dazu tragen Genossenschaftsbanken und Sparkassen substantiell zur Kreditvergabe an junge, kleine Unternehmen bei. Von besonderem Interesse ist, dass wir für Genossenschaftsbanken und Sparkassen ähnlich starke, statistisch nicht unterscheidbare Effekte beobachten. Entsprechend legen unsere Ergebnisse nahe, dass regional operierende Banken mit dezentraler Organisationsform, nicht aber öffentlich-rechtliche Trägerschaft, für die beobachtete Kreditvergabe bedeutsam sind.

Schlagworte: Kreditvergabe durch Genossenschaftsbanken, Kreditbanken und Sparkassen; Finanzierung junger, kleiner Unternehmen; langfristige Kredite; öffentliche Förderprogramme; Regionalbanken; öffentlich-rechtliche Trägerschaft;

JEL-Klassifikation: G21; G28; L14; L22; L26; L33;

Für sehr hilfreiche Kommentare danken wir Lars-Hendrik Röller, Isabel Schnabel, Patrick Steinpass, Joachim Wagner, mehreren Teilnehmern des CEPR-ESSFM 2006, Studienzentrum Gerzensee und zwei anonymen Gutachtern. Bei Jochen Struck und Daniel Skambracks bedanken wir uns für zahlreiche Anregungen und die Bereitstellung von Datenmaterial der Deutschen Ausgleichsbank. Thorsten Doherr und Ulrike Böhme sind wir für ihre Unterstützung bei der Datenbankverknüpfung und der Editierung des Aufsatzes dankbar. Der Beitrag reflektiert nicht notwendigerweise die Meinung der genannten Arbeitgeber und verbleibende Unzulänglichkeiten gehen zu Lasten der Autoren. 


\section{ABSTRACT \\ Lending Decisions of Cooperative Banks, Private Credit Banks and Savings Banks: An Empirical Analysis of Subsidized Loans for Young and Small Firms}

by Susanne Prantl, Matthias Almus, Jürgen Egeln und Dirk Engel

In this paper we examine how German cooperative banks, (non-cooperative) private credit banks and savings banks contribute to the long-term loan financing of young and small firms. Bank loans, especially long-term bank loans, are often used by young and small firms in Germany. We focus on a specific type of loan. The assignment of these loans to firms involves cooperative banks, private credit banks or savings banks. The loans come from public subsidized loan programs and constitute a substantial part of all longterm bank loans to young firms and SME in Germany. We present empirical analyses for the 1990s based on county-level as well as firm-level data. We find that private credit banks did not change their lending to young and small firms during that period. Since the start of the 1990s, they have played only a minor role in start-up and small business lending. Cooperative and savings banks have had, in contrast, a strong, positive influence. One particularly relevant finding is that the lending activities of cooperative and savings banks turn out to be similarly strong and do not differ significantly. Taken together, our results imply that having banks that operate regionally with a decentralized organizational form, but not public ownership, is crucial to the observed lending activities. 


\section{$1 \quad$ Einleitung}

Für Unternehmensgründungen und junge, kleine Unternehmen mit Wachstumsplänen ist in Deutschland der Zugang zu externer Finanzierung, insbesondere zu langfristigen Bankkrediten, oft entscheidend für die Umsetzbarkeit von Gründungsideen oder Investitionsprojekten. Aus diesem Grund ist es von hohem Interesse, in welchem Ausmaß verschiedene Finanzintermediäre im dreigliedrigen Banksystem zur Kreditvergabe an junge Unternehmen beziehungsweise an kleine und mittlere Unternehmen (KMU) beitragen. In diesem Beitrag präsentieren wir umfangreiche, mikroökonometrische Evidenz zum Vergleich der Vergabe langfristiger Kredite an junge, kleine Unternehmen durch die drei Bankgruppen Genossenschaftsbanken, Kreditbanken und Sparkassen während der 1990er Jahre in Westdeutschland. ${ }^{1}$ Wir diskutieren zunächst Untersuchungen auf der Ebene von Stadt- und Landkreisen, dann präsentieren wir Analysen, die auf detaillierten Unternehmens-, Bankverbindungs- und Kreditinformationen für insgesamt 6.880 Unternehmen basieren. Vergleichende Evidenz dieser Art ist selten und wird in der anhaltenden Diskussion über die Beurteilung und mögliche Beeinflussung des Strukturwandels im Banksektor in Deutschland immer wieder gefordert (Engerer und Schrooten, 2004; Sachverständigenrat, 2004). Im Rahmen der Strukturdebatte wird die Bedeutung regional operierender Banken mit dezentraler Organisationsform für die Kreditvergabe an junge Unternehmen und KMU oft diskutiert. Ebenso nehmen die Rolle öffentlich-rechtlicher Trägerschaft von Banken und die Kontroverse um Reformüberlegungen für die Sparkassengruppe großen Raum ein. ${ }^{2}$ Zudem wird oftmals davon ausgegangen, dass Kreditbanken in der zweiten Hälfte der 1990er Jahre ihre Kreditvergabe an junge Unternehmen und KMU stark reduziert haben (Die Zeit, 2000; Engerer und Schrooten, 2004; Schindler und Neuberger, 2000).

Um die Rolle der drei Bankgruppen bei der Vergabe langfristiger Kredite $\mathrm{zu}$ untersuchen, nutzen wir in dieser Studie einen Unternehmensdatensatz, der auf eine zufällig gezogene Stichprobe aus dem ZEW Gründungspanel West zurückgeht. Diese Datenbank enthält Angaben zu mehr als zwei Millionen Unternehmen für die Jahre 1990 bis 1999. Die verwendeten Kreditinformationen stammen aus einer Datenbank der Deutschen Ausgleichsbank (DtA),

1 Wir verwenden im Folgenden den Begriff „Bankgruppe“ in Anlehnung an die Bankenstatistik der Deutschen Bundesbank.

Siehe hierzu unter anderem Brunner et al. (2004), Deutsche Bundesbank (2003), Economist (2006), Sachverständigenrat (2004) und die Diskussionsbeiträge von Bundesbank-Vorstandsmitglied Meister (BörsenZeitung, 2005), Fischer (2005), Möschel (2005), Vogelsang (2008) und Weber (2005). 
welche die insgesamt rund 776.000 Förderkreditbewilligungen der DtA im Zeitraum 1990 bis 1999 umfasst. $^{3}$ Diese Kreditdaten verwenden wir entweder auf der Ebene von Kreisregionen oder direkt auf Unternehmensebene, was aufgrund einer aufwendigen Datenbankverknüpfung möglich ist.

Bei langfristigen Krediten aus öffentlichen Förderprogrammen handelt es sich um eine spezielle Kreditart, die während der 1990er Jahre in Deutschland einen substantiellen Anteil aller langfristigen Bankkredite für junge Unternehmen und KMU darstellt. ${ }^{4}$ Für den beabsichtigten Vergleich der Kreditvergabe verschiedener Bankgruppen ist von zentraler Relevanz, dass sich sowohl Genossenschaftsbanken, Kreditbanken als auch Sparkassen gleichermaßen an der Allokation dieser Kreditart beteiligen können. Zudem handelt es sich um Kreditprodukte, deren Basismerkmale durch Förderprogrammkonditionen vorgegeben werden und somit bankunabhängig sind. Da Datenmaterial zu bankeigenen, langfristigen Krediten für diese Studie nicht vorliegt, ist zu diskutieren, ob und inwiefern unsere empirischen Ergebnisse Rückschlüsse auf das generelle Engagement der drei Bankgruppen bei der Vergabe von langfristigen Bankkrediten an junge, kleine Unternehmen zulassen. Wir erläutern in Abschnitt 2.2 im Detail, dass sich Banken bei Förderkrediten im Untersuchungszeitraum in Westdeutschland teilweise an der Übernahme des Kreditausfallrisikos beteiligen, Förderkredite häufig durch bankeigene Kredite ergänzt werden und im Wettbewerb stehende Banken rational agierenden Kunden Förderkredite aufgrund der günstigen Zins- und Tilgungskonditionen kaum vorenthalten können. Entsprechend gehen wir davon aus, dass Banken bei der Vergabe langfristiger Kreditfinanzierungen mit Förderkrediten ähnliche Entscheidungskriterien anlegen wie bei Finanzierungen, die ausschließlich bankeigene Kredite umfassen.

Mit unserer empirischen Analyse wollen wir erstens zeigen, wie sich Bankverbindungen zu Kreditbanken bei jungen, kleinen Unternehmen auf die Wahrscheinlichkeit für eine Bewilligung und auf die Höhe langfristiger Bankkredite auswirken. Wir untersuchen dies für Kredite aus öffentlichen Förderprogrammen und fokussieren auf Veränderungen des

Die wichtigsten Bundesprogramme wurden bis 2003 von der Deutschen Ausgleichsbank (DtA) verwaltet und durch hauseigene Programme ergänzt. Seit der Fusion zwischen der DtA und der Kreditanstalt für Wiederaufbau (KfW) wird dies in ähnlicher Weise von der KfW Mittelstandsbank fortgeführt.

4 Wir untersuchen in der vorliegenden Studie weder, wie das Angebot dieser Kreditform in Deutschland aus wirtschaftspolitischer Sicht zu beurteilen ist, noch müssen wir diesbezüglich eine konkrete Annahme treffen. Wir beschränken uns vielmehr darauf, die faktische Bedeutung und bestimmte Besonderheiten dieser Kreditform im Untersuchungszeitraum für den Vergleich der Rolle der drei Bankgruppen bei der Vergabe langfristiger Bankkredite auszunutzen. Zur Evaluierung von Wirkungen der jeweiligen Förderprogramme siehe z. B. Almus und Prantl (2002) oder Prantl (2008). 
Zusammenhangs während der 1990er Jahre, da oft angenommen wird, dass Kreditbanken ihre Kreditvergabe an KMU und junge Unternehmen im Verlauf der 1990er Jahre stark reduziert haben. Zweitens vergleichen wir die Effekte von Bankverbindungen zu Kreditbanken und zu regional operierenden Banken mit dezentraler Organisationsform, d. h. Genossenschaftsbanken oder Sparkassen. Drittens konzentrieren wir uns auf die Frage, ob und inwieweit sich die Rolle von Sparkassen und Genossenschaftsbanken bei der Kreditvergabe an junge, kleine Unternehmen unterscheidet. Hiermit gehen wir der Bedeutung unterschiedlicher Eigentümerstrukturen und öffentlicher Trägerschaft im Banksektor nach.

Die Ergebnisse unserer Analysen auf der Ebene von Kreisregionen stehen im Bezug zu einer Arbeit von Wengler (2006). Diese enthält empirische Analysen auf vergleichbar disaggregierter Regionsebene für Ostdeutschland in der zweiten Hälfte der 1990er Jahre zum Zusammenhang zwischen der kreditwirtschaftlichen Tätigkeit von Sparkassen, inklusive der Vermittlung von Förderkrediten, und dem kommunalen Raum. Die Sparkassentätigkeit wird mit der Aktivität von Kreditbanken verglichen. Im Gegensatz hierzu beziehen wir in unserer Arbeit auch Genossenschaftsbanken ein. Zudem können wir nicht nur Untersuchungen auf Regionsebene, sondern auch Analysen auf Unternehmensebene präsentieren. Diese knüpfen an die Literatur an, in der mit Unternehmensdaten Fragestellungen zur Finanzierung von jungen Unternehmen und KMU, zur Kreditvergabe durch Banken und zu Relationship Lending untersucht werden. Hierzu zählen z. B. die Arbeiten von Berger und Udell (1998, 2006), Berger et al. (2005, 2008), Degryse und Ongena (2005), Harhoff und Körting (1998), Lehman und Neuberger (2001), Neuberger und Räthke (2007), Petersen und Rajan (1995, 2002) oder Schulte (2002).

Im folgenden Abschnitt 2 diskutieren wir, in welchem Umfang sich KMU und junge Unternehmen in Deutschland mittels langfristiger Bankkredite finanzieren. Wir erläutern, welchen Anteil Genossenschaftsbanken, Kreditbanken und Sparkassen an der Allokation langfristiger Kredite haben und wie häufig diese aus öffentlichen Förderprogrammen stammen. Zur Kreditvergabe der drei Bankgruppen an junge, kleine Unternehmen leiten wir drei zu überprüfende Hypothesen ab. Wir beschreiben den Aufbau der empirischen Untersuchungen in Abschnitt 3 und stellen die empirischen Ergebnisse in Abschnitt 4 vor. In Abschnitt 5 fassen wir zusammen und enden mit Schlussfolgerungen. 


\subsection{Langfristige Bankkredite und Kreditallokation durch Genossenschaftsbanken,} Kreditbanken und Sparkassen

Im Vergleich zu größeren Unternehmen greifen KMU in Deutschland in höherem Maße auf Kreditfinanzierung, insbesondere auf langfristige Bankkredite, zurück. Für das Jahr 2005, beispielsweise, zeigen Auswertungen von etwa 60.000 Jahresabschlüssen im Jahresabschlussdatenpool der Deutschen Bundesbank und anderer Institute, dass die Anteile langfristiger Bankverbindlichkeiten an der Bilanzsumme bei kleinen Unternehmen mit einer Bilanzsumme unter 2 Mio. $€$ etwa 8,4-fach höher liegen als bei großen Unternehmen mit einer Bilanzsumme ab 50 Mio. $€$ und 2,9-fach (1,8-fach) höher als bei mittleren Unternehmen mit einer Bilanzsumme von 10 bis unter 50 Mio. $€$ (von 2 bis unter 10 Mio. $€$ ). Für andere Jahre im Zeitraum 1996 bis 2006 ergeben sich vergleichbare Unterschiede (Deutsche Bundesbank, 2008 und frühere Jahrgänge). $\mathrm{Zu}$ qualitativ ähnlichen Ergebnissen führt ein Vergleich der Medianwerte von Bankverbindlichkeitsquoten, die der Deutsche Sparkassen- und Giroverband aus Bilanzdaten kleiner, mittlerer und großer Unternehmen berechnet. ${ }^{5}$ Auch eine seit 2001 regelmäßig durchgeführte Befragung der $\mathrm{KfW}$ unterstreicht die Bedeutung langfristiger Bankkredite: Unternehmen zählen sie neben kurzfristigen Bankkrediten und Innenfinanzierung zu ihren wichtigsten Finanzierungsquellen. ${ }^{6}$

Langfristige Bankkredite sind sowohl für etablierte KMU als auch für junge Unternehmen wichtig. Junge Unternehmen sind meist klein und zählen somit bei den obigen Auswertungen zur Gruppe kleiner Unternehmen. Es ist aber von entscheidender Bedeutung, dass sich ihre Finanzierungssituation oft stark von der etablierter Unternehmen unterscheidet. Erstens ist die Informationssituation bei jungen, kleinen Unternehmen typischerweise in höherem Ausmaß intransparent bzw. opak als bei etablierten, größeren Unternehmen (Berger und Udell, 1998; Gompers und Lerner, 1999; Schulte, 2002, 2007). Es können weniger „harte“, d. h. leicht verifizierbare Unternehmensinformationen an Dritte, insbesondere potentielle Kreditgeber, vermittelt werden. Historische Daten zur Unternehmensaktivität, z. B. in Form von Bilanzen,

5 Für das Jahr 2005 z. B. ergeben sich basierend auf etwa 210.000 Firmenkundenbilanzen Verhältniszahlen von 3,3 und 1,8 beim Vergleich des Medianwerts für kleine Unternehmen (Umsatz bis 1 Mio. €) mit den Medianwerten für große Unternehmen (Umsatz ab 50 Mio. €) bzw. für mittlere Unternehmen. Ähnliches gilt auch für andere Jahre im Zeitraum 1995 bis 2006 (Deutscher Sparkassen- und Giroverband, 2008a, b und frühere Jahrgänge).

6 Detaillierte Auswertungen hierzu bieten die Dokumentationen der Befragungsrunde 2006 (KfW Bankengruppe, 2006) oder früherer Befragungsrunden. In jeder Runde wurden zwischen 40.000 und 60.000 Fragebögen über Wirtschaftsverbände an Unternehmen weitergeleitet und die Rücklaufquote lag jeweils bei etwa 10 Prozent. 
fehlen oder sind noch nicht aussagekräftig. Unternehmensgründer, die oft sowohl als Eigentümer als auch als Mitglied der Unternehmensführung (Eigentümermanager) auftreten, können meist keine bisherige, erfolgreiche Unternehmertätigkeit vorweisen. Kreditvergabeentscheidungen hängen entsprechend stark von „weichen“, d. h. schwer verifizierbaren, Informationen ab. Es bestehen substantielle Informationsasymmetrien, die zu adverser Selektion oder Moral Hazard führen können. Es kann zu Kreditrationierung kommen, insbesondere wenn weder Kreditsicherheiten, feste Kunde-Bank-Kreditbeziehungen (Relationship Lending), zusätzliche Kreditvertragsklauseln (Covenants) noch multiple Kreditgeber genutzt werden (Boot, 2000; Freixas und Rochet, 1997; Hartmann-Wendels et al., 2007). Zweitens sind alternative Finanzierungsinstrumente für junge, kleine Unternehmen in geringerem Ausmaß zugänglich, geeignet oder gewünscht als bei etablierten, größeren Unternehmen. Innenfinanzierung aus einbehaltenen Gewinnen ist in den ersten Jahren nach einer Gründung selten möglich, da noch keine oder nur geringe Gewinne erwirtschaftet werden. Gerade die Finanzierung von Anfangsinvestitionen, die relativ zum Unternehmensumfang groß sind, sollte langfristig angelegt sein; kurzfristige Bankkredite sind wenig geeignet. Eigentümermanager haben oft ein stark ausgeprägtes Unabhängigkeitsstreben und ein entsprechend geringes Interesse an externen Finanzierungsformen, die direkt mit der Abgabe von Kontrollrechten einhergehen, wie z. B. Beteiligungsfinanzierungen (Hutchinson, 1995; Berger und Udell, 1998).

Aufgrund der großen Bedeutung langfristiger Bankkredite für junge, kleine Unternehmen wollen wir untersuchen, welche Rolle Genossenschaftsbanken, Kreditbanken und Sparkassen bei der Allokation dieser Kreditform übernehmen. ${ }^{7}$ Zur ersten Information greifen wir in Tabelle 1 auf Angaben der Deutschen Bundesbank zu Beständen langfristiger Bankkredite an inländische Unternehmen und an das Handwerk zurück. Entsprechende Angaben zur jährlichen Kreditneuvergabe sind nicht verfügbar. Wir verwenden Daten für West- bzw.

Wir gehen im Folgenden insofern vom Status quo aus, als wir nicht berücksichtigen, ob eine stärkere Hinwendung zu einem Finanzsystem mit mehr marktbasierter externer Finanzierung anstelle von Kreditfinanzierung zusätzliche positive gesamtwirtschaftliche Wohlfahrtswirkungen implizieren könnte (siehe hierzu Allen und Gale, 2000; Rajan und Zingales, 2003). Allgemeine Darstellungen zum deutschen Finanzsystem bzw. zum Vergleich von Finanzsystemen bieten Allen und Gale (2000), Guinnane (2002), Hartmann-Wendels et al. (2007) und Rajan und Zingales (2003). 
Gesamtdeutschland im Zeitraum von 1987 bis $2005 .{ }^{8}$ Gemäß Tabelle 1, Panel 1 weist die Sparkassengruppe insgesamt in allen tabellierten Jahren, außer 1990, den höchsten Anteil am Bestand langfristiger Kredite der drei Bankgruppen an Unternehmen insgesamt auf. ${ }^{9}$ Zwischen 1987 und 1999 steigt der Anteil von 56,7 auf 58,2 Prozent, dann steigt er weiter auf 60,9 Prozent im Jahr 2005. Der Anteil der Sparkassen sinkt zwischen 1987 und 1999 von 25,5 auf 21,5 Prozent, erreicht im Jahr 2005 aber wieder den Wert des Jahres 1987. Der Anteil der Landesbanken liegt in allen Jahren über dem Sparkassenanteil, und zwar meist mit mehr als 10 Prozentpunkten. Nach der Sparkassengruppe folgen private Kreditbanken auf dem zweiten Rang, abgesehen vom Jahr 1990. ${ }^{10}$ In den Jahren 1987 und 1999 liegt ihr Anteil bei etwa 30 Prozent, anschließend sinkt er auf 27,5 Prozent im Jahr 2005. Der Anteil der Genossenschaftsbankgruppe variiert im Zeitablauf kaum, er liegt 1987 bei 13,1 Prozent und in späteren Jahren zwischen 11,0 und 11,8 Prozent. ${ }^{11}$ Eine deutlich höhere Bedeutung der Genossenschaftsbankgruppe zeigt sich in Tabelle 1, Panel 2 beim Bestand langfristiger Kredite der drei Bankgruppen im Handwerkssektor, zu dem viele kleine Unternehmen zählen. Der Anteil der Genossenschaftsbankgruppe liegt hier mit durchschnittlich 20 Prozent doppelt so hoch wie der Anteil privater Kreditbanken. Genossenschaftliche Zentralbanken sind als Spitzeninstitute selten direkt in KMU-Finanzierung involviert und spielen entsprechend fast keine Rolle. Die Sparkassengruppe weist - ebenso wie in Tabelle 1, Panel 1 - den höchsten Anteil auf und auch hier ist die Bedeutung der Spitzeninstitute gering. Der Anteil der Genossenschaftsbanken am Bestand langfristiger Kredite der drei Bankgruppen an das Handwerk sinkt zwischen 1987 und 1999 um 4,4 Prozentpunkte; der Anteil der Sparkassen steigt um 2 Prozentpunkte; in den folgenden Jahren bis 2005 setzen sich diese Entwicklungen fort.

Tabelle 1 hier einfügen.

8 Bei unseren empirischen Analysen in Abschnitt 4 konzentrieren wir uns auf Westdeutschland. Da die Deutsche Bundesbank bei den hier relevanten Zeitreihenangaben im Jahr 1990 von West- auf Gesamtdeutschland umstellt, müssen wir in Tabelle 1 ab 1990 ersatzweise auf Angaben für Gesamtdeutschland ausweichen. Die Werte für das Jahr 1990 im Panel 1, Tabelle 1 zeigen eine temporäre Anteilsverschiebung zwischen den drei Bankgruppen, die sich durch die Transformation des ostdeutschen Banksektors nach der Wiedervereinigung erklären lässt (Robins 2000; Lehmann et al. 2004).

9 Zur Sparkassengruppe zählen in Gesamtdeutschland im Jahr 2005463 Sparkassen und als Spitzeninstitute die Deutsche Girozentrale (DekaBank) sowie 12 Landesbanken (Deutsche Bundesbank, Bankstellenstatistik, http://www.bundesbank.de/bankenaufsicht/bankenaufsicht_dokumentation_statistiken.php).

10 Zur Kreditbankgruppe zählen in Gesamtdeutschland im Jahr 2005356 Kreditinstitute inkl. der Großbanken und der Zweigstellen ausländischer Banken.

11 Die Genossenschaftsbankgruppe umfasst in Gesamtdeutschland im Jahr 2005 1.262 Kreditgenossenschaften und zwei genossenschaftliche Zentralbanken als Spitzeninstitute. 


\subsection{Kredite aus öffentlichen Förderprogrammen und deren Allokation}

Langfristige Bankkredite an junge, kleine Unternehmen in Deutschland sind neben bankeigenen Krediten auch Kredite aus Förderprogrammen, die von der DtA bzw. der Nachfolgeinstitution KfW Mittelstandsbank verwaltet werden. ${ }^{12}$ In unserer empirischen Studie können wir detaillierte Daten der DtA zu Krediten aus Programmen zur Existenz- und Unternehmensgründungsförderung in den 1990er Jahren nutzen. Folgende Merkmale dieser speziellen Kreditart sind für unsere Untersuchung wichtig und werden in diesem Abschnitt genauer erläutert: Erstens machen Förderkredite im relevanten Zeitraum in Deutschland einen substantiellen Anteil aller langfristigen Bankkredite für junge Unternehmen und KMU aus. Zweitens können Genossenschaftsbanken, Kreditbanken und Sparkassen gleichermaßen an der Allokation dieser Kreditart mitwirken. Drittens handelt es sich um Kreditprodukte, deren Basismerkmale durch Förderprogrammkonditionen vorgegeben werden und somit nicht davon abhängen, welche Geschäftsbank in die Kreditvergabe involviert ist. Schließlich diskutieren wir, inwiefern unsere empirischen Ergebnisse Rückschlüsse auf das generelle Engagement der drei Bankgruppen bei der Vergabe von langfristigen Bankkrediten an junge, kleine Unternehmen zulassen.

In den Programmen der Deutschen Ausgleichsbank zur Existenz- und Unternehmensgründungsförderung wurden zwischen 1990 und 2002 etwa 450.000 Kredite mit einem Gesamtvolumen von fast $27 \mathrm{Mrd}$ € für westdeutsche Unternehmen bereitgestellt (DtA, 2001 und 2003). Da sich unsere empirischen Analysen im Abschnitt 4 auf Westdeutschland beziehen, wird in Abbildung 1 die Entwicklung der Fördertätigkeit der DtA für diesen Raum dargestellt. Der Kurvenverlauf reflektiert zum Teil die Variation von Unternehmensgründungszahlen im Konjunkturverlauf (KfW Bankengruppe et al., 2006). Zudem sinkt die Fördertätigkeit im Zeitraum 1991-1993 in Westdeutschland, weil gerade in dieser Zeit Fördermittel nach Ostdeutschland gelenkt wurden.

Abbildung 1 hier einfügen.

Förderkredite machen einen wesentlichen Anteil aller in Deutschland neu an junge Unternehmen und KMU vergebenen langfristigen Bankkredite aus. Dies zeigt z. B. die Relation zwischen dem jährlich neu vergebenen Förderkreditvolumen (Angaben für den Förderbereich Existenz- und Unternehmensgründung der DtA) und der jährlichen Veränderung des

12 Nach Angaben der DtA lag ihr Marktanteil im Förderbereich Existenz- und Unternehmensgründung während der 1990er Jahre bei etwa 90 Prozent (Almus und Prantl, 2002). 
Gesamtbestands langfristiger Bankkredite an inländische Unternehmen insgesamt (Angaben in der Bankenstatistik der Deutschen Bundesbank): Zwischen 1990 und 2002 liegt diese Relation durchschnittlich bei 24,4 Prozent. ${ }^{13}$ Die Deutsche Bundesbank geht in ihren Veröffentlichungen ebenfalls von einem hohen Förderkreditanteil aus (Deutsche Bundesbank, 1992). Eigene Auswertungen auf Basis einer repräsentativen Unternehmensstichprobe für die frühen 1990er Jahre zeigen, dass etwa ein Drittel der ostdeutschen und 10 Prozent der westdeutschen Unternehmensgründungen Förderkredite zur Gründungsfinanzierung einsetzten. ${ }^{14} \mathrm{Da}$ zur Gesamtheit aller Gründungen auch viele Mikrogründungen ohne hohen Kapitaleinsatz und ohne Kreditfinanzierung zählen, implizieren diese Quoten einen substantiellen Förderkreditanteil am jährlichen Gesamtvolumen der neu an Unternehmensgründungen vergebenen langfristigen Bankkredite.

Bei der Allokation langfristiger Kredite aus öffentlichen Förderprogrammen der DtA und nachfolgend der KfW Mittelstandsbank übernehmen Geschäftsbanken eine wichtige Funktion. Genossenschaftsbanken, Kreditbanken oder Sparkassen können sich gleichermaßen gemäß dem „Hausbankverfahren“ an der Förderkreditvergabe beteiligen. Unternehmen bewerben sich nicht direkt bei der Förderinstitution, sondern müssen eine Geschäftsbank finden, die ihren Antrag an die DtA/KfW weiterleitet. Im relevanten Zeitraum für unsere Analyse sind bei der DtA Unternehmensgründer antragsberechtigt, die fachlich und kaufmännisch für ihr Unternehmensprojekt qualifiziert sind, deren Investitionsvorhaben noch nicht begonnen hat, aussichtsreich ist und andernfalls unzureichend finanziert wäre. Typischerweise erhalten geförderte Unternehmen einen so genannten „Fördercocktail““ mit Krediten aus verschiedenen, kombinierbaren Programmen: oftmals einen ERP-Existenzgründungskredit und einen Kredit aus dem ERP-Eigenkapitalhilfeprogramm, ggf. auch noch einen ergänzenden DtAExistenzgründungskredit. ${ }^{15}$ Zudem wird die Gründungsfinanzierung eines geförderten Unternehmens oft noch durch bankeigene Kredite der Geschäftsbank ergänzt, die in die

13 Angaben zum jährlichen Gesamtvolumen der Neuvergabe langfristiger Kredite an junge, kleine Unternehmen liegen uns für den relevanten Zeitraum nicht vor. Die hier ersatzweise als Bezugsgröße herangezogene Veränderung des Gesamtbestands langfristiger Kredite umfasst sowohl Veränderungen durch Kreditneuaufnahmen als auch durch Kreditmodifikationen und -tilgungen und dieses Maß bezieht sich nicht auf junge, kleine Unternehmen, sondern auf alle inländischen Unternehmen insgesamt.

14 Siehe hierzu Prantl (2008). Ein ähnliches Ergebnis ergibt sich auch basierend auf dem in Abschnitt 3.2 beschriebenen Regionsdatensatz für Westdeutschland im Jahr 1999.

15 In den 1990er Jahren, unserem Untersuchungszeitraum, entfiel der überwiegende Anteil des Fördervolumens für Existenz- und Unternehmensgründungen auf die zwei „Existenzgründungsprogramme“, die durch die DtA verwaltet und durch das European Recovery Program (ERP) bzw. die DtA selbst finanziert wurden, und auf das ERP-Eigenkapitalhilfeprogramm (EKH). Die Programme „DtA-Betriebsmittel“ und „DtA-Startgeld“ wurden erst in der zweiten Hälfte der 1990er Jahre eingeführt. 
Förderkreditvergabe involviert ist. An der Förderkreditvergabe beteiligte Geschäftsbanken übernehmen folgende Aufgaben, für die sie von der DtA im Zeitraum unserer empirischen Analyse mit pauschal fixierten, risikounabhängigen Margen vergütet werden: die anfängliche Unternehmer- und Projektbeurteilung, die Bearbeitung des Förderkreditantrags, die Auszahlung der bewilligten Kreditsumme und die gesamte Kreditüberwachung, inklusive ggf. nötiger Sicherheitenbe- und -(ver)wertung. Darüber hinaus beteiligen sie sich - ohne zusätzliches Entgelt - auch teilweise an der Übernahme des Kreditausfallrisikos. ${ }^{16}$ Seitens der DtA werden die weitergeleiteten Förderkreditanträge hinsichtlich formaler Kriterien geprüft und in der Regel auch bewilligt. ${ }^{17}$

Mehrere Gründe, die wir im Folgenden erläutern, sprechen dafür, dass die Bedeutung der drei Bankgruppen bei der Förderkreditallokation eng mit deren Gesamtaktivität im Bereich der Finanzierung junger, kleiner Unternehmen korreliert. In die Förderkreditvergabe involvierte Geschäftsbanken beteiligen sich teilweise an der Übernahme des Kreditausfallrisikos und werden hierfür im Untersuchungszeitraum von der DtA nicht vergütet. Zudem vergeben diese Banken, wie schon erwähnt, begleitend zu Förderkrediten oft bankeigene Kredite. Entsprechend haben sie Anreize, bei einer Entscheidung über eine Kundenbeziehung und ein Finanzkonzept, das Förderkredite einschließt, ähnliche Maßstäbe bezüglich Unternehmensbonität und Projektqualität anzulegen wie bei einer Unternehmensfinanzierung ohne Förderkredite. Weiterhin müssen Banken, die junge, kleine Unternehmen als Kunden im Bereich Unternehmensfinanzierung gewinnen wollen und im Wettbewerb mit anderen Banken stehen, Förderkredite anbieten, weil deren Konditionen für Kreditnehmer sehr attraktiv sind ${ }^{18}$ und alle Banken diese Förderkredite anbieten können. Da junge, kleine Unternehmen in Deutschland

16 Kredite aus den Existenzgründungsprogrammen werden banküblich besichert und die involvierten Geschäftsbanken übernehmen die volle Haftung, sofern nicht zusätzlich Haftungsfreistellungen seitens der DtA, Bürgschaften des Bundes oder anderer Institutionen in Anspruch genommen werden. Letzteres trifft für Kredite in Westdeutschland weniger zu als für Kredite in Ostdeutschland, gerade in den Jahren nach der Wiedervereinigung. Bei einer Förderung im EKH-Programm, bei der es sich ebenfalls um einen langfristigen Kredit handelt, werden keine Sicherheiten verlangt. Der Kreditnehmer übernimmt die persönliche Haftung und der Bund bzw. die DtA tragen das Ausfallrisiko in voller Höhe. Siehe hierzu auch Deutsche Bundesbank (1992), Wengler (2006) und Woywode und Struck (2004).

17 Siehe z. B. Almus und Prantl (2002) und Prantl (2008) für weitere Erläuterungen.

18 In allen Programmen werden Kredite mit subventionierten Zinssätzen, tilgungsfreier Anfangsphase und sehr langen Laufzeiten angeboten. Für die besonders attraktiven Kredite aus dem EKH-Programm, die als Eigenkapitalsurrogat verstanden werden, beträgt beispielsweise in den alten Bundesländern Anfang der 1990er Jahre der Zinssatz für die ersten zwei Jahre null und steigt dann langsam an. Tilgungszahlungen werden erst nach dem zehnten Jahr fällig, die Laufzeit ist 20 Jahre. Der Zinssatz für einen typischen Kredit aus dem ERPExistenzgründungsprogramm in den alten Bundesländern Anfang der 1990er Jahre liegt im Durchschnitt etwa einen halben Prozentpunkt unterhalb des Interbankenzinssatzes, bis zu drei Jahre sind tilgungsfrei und die Laufzeit beträgt in mehr als 50 Prozent aller Fälle 10 Jahre (Bekanntmachungen im Bundesanzeiger; Prantl, 2008). 
ihre Kreditaufnahme zumeist auf ein Bankinstitut konzentrieren, können sich einzelne Banken auch nicht allein auf die Förderkreditvergabe oder allein auf die Vergabe ergänzender Kredite konzentrieren (Harhoff und Körting, 1998; Neuberger und Räthke, 2007).

Tabelle 2 hier einfügen.

Laut Tabelle 2 weisen Sparkassen bis 1992 und ab 1998 den höchsten Anteil am jährlich in Westdeutschland neu vergebenen Kreditvolumen aus DtA-Programmen zur Existenz- und Gründungsförderung auf. Dieser Rangplatz korrespondiert mit dem Ergebnis aus Tabelle 1 für die Anteile der Sparkassengruppe am Bestand langfristiger Kredite der drei Bankgruppen an Unternehmen insgesamt und an das Handwerk. Der Anteil schwankt vor 1998 um die 40 Prozentmarke, anschließend steigt er auf fast 52 Prozent im Jahr 2002. Die Genossenschaftsbanken nehmen meist Rangplatz zwei ein, Mitte der 1990er Jahre ist ihr Anteil allerdings höher als der Anteil der Sparkassen. Zwischen 1994 und 1996 liegt er über 45 Prozent. Kreditbanken rangieren, ebenso wie beim Anteil am langfristigen Kreditbestand der drei Bankgruppen im Handwerkssektor in Tabelle 1, Panel 2 an letzter Position. Der Anteil geht zwischen 1990 und 1998 von 25,0 auf 15,4 Prozent zurück und sinkt dann weiter auf 11,6 Prozent im Jahr 2002.

\subsection{Hypothesen zur Kreditvergabe durch Genossenschaftsbanken, Kreditbanken und Sparkassen}

Die Rangfolge der drei Bankgruppen, die sich in Tabelle 1, Panel 1 im betrachteten Zeitraum bei den Anteilen am Bestand langfristiger Kredite der drei Bankgruppen an Unternehmen insgesamt ergibt, korrespondiert mit der Rangfolge bei der Bankgruppengröße gemäß der Bilanzsumme: die Sparkassengruppe liegt an erster Stelle, gefolgt von der Kreditbankgruppe und dann der Genossenschaftsbankgruppe. ${ }^{19}$ Für die Rangfolgen im Handwerkssektor, der von kleinen Unternehmen dominiert wird (Tabelle 1, Panel 2), und bei der Neuvergabe von Förderkrediten für Existenz- und Unternehmensgründer (Tabelle 2) trifft dies hingegen nicht zu. Dieses Resultat legt entsprechend unterschiedliche Kreditvergabeentscheidungen der betrachteten Bankgruppen nahe. Hierzu leiten wir im Folgenden mehrere Hypothesen ab. In Abschnitt 4 schließt sich deren empirische Überprüfung für die Gruppe junger, kleiner Unternehmen auf der Basis von Förderkredit-, Unternehmens- und Regionsdaten an.

19 Siehe Deutsche Bundesbank (http://www.bundesbank.de/statistik/statistik_zeitreihen.php) zu Bilanzsummen. 
Kreditbanken in Deutschland arbeiten gewinnorientiert und konkurrieren im Zuge der Globalisierung verstärkt mit Banken anderer Länder. Dies gilt insbesondere seit der vollständigen Öffnung der Kapitalmärkte innerhalb der Europäischen Union (EU) im Jahr 1993 (Hartmann-Wendels et al., 2007). Die Ertragslage der Kreditbanken verschlechterte sich in der zweiten Hälfte der 1990er Jahre (KfW Bankengruppe et al., 2006) und sie reagierten mit verstärkten Bestrebungen, sich zunehmend auf besonders gewinnbringend erscheinende Geschäftsfelder zu konzentrieren. Den Druck zur Steigerung der Rentabilität und zur Konsolidierung beförderte auch, dass die heimischen Genossenschaftsbanken und Sparkassen während der 1990er Jahre gemessen an der Eigenkapitalrentabilität vor Steuern besser abschnitten als die Kreditbanken (Deutsche Bundesbank, 2000; Engerer und Schrooten, 2004). Einige (große) Kreditbanken begannen zudem Ende der 1990er Jahre, sich auf die Basel-IIRegulierung vorzubereiten. Insgesamt wird meist argumentiert, dass bei Kreditbanken die Bereitschaft zur Finanzierung der breiten Masse an KMU und jungen Unternehmen absank (Die Zeit 2000; Engerer und Schrooten, 2004; Schindler und Neuberger, 2000):

\section{Hypothese: Bei Kreditbanken sinkt ceteris paribus (c. p.) im Verlauf der 1990er Jahre die} Bereitschaft, langfristige Kredite, inklusive Förderkredite, an junge, kleine Unternehmen zu vergeben.

Komparative Vorteile für Kreditvergabeentscheidungen, die auf weichen, schwer verifizierbaren Informationen basieren, werden in der Literatur abgeleitet, die sich mit „Nähe“ zwischen Kreditgeber und -nehmer bzw. zwischen Kreditvergabeentscheidung und Informationssammlung beschäftigt. ${ }^{20}$ Zum einen können Bankmitarbeiter bei räumlicher Nähe zum Kreditnehmer kostengünstig persönliche Gespräche führen oder die Aktivitäten des Unternehmers, Unternehmens und lokalen Wirtschaftsumfelds überwachen. Dies erleichtert das Sammeln weicher, schwer verifizierbarer Informationen vor einer Entscheidung über eine Kreditvergabe und senkt die Kosten der Überwachung im Verlauf einer Kreditbeziehung (Monitoring). Beides kann gerade bei KMU und jungen Unternehmen relevant sein (Agarwal and Hauswald 2008; Berger und Udell, 1998, 2005; Petersen und Rajan, 2002). Zum anderen haben Bankmitarbeiter einen hohen Anreiz zur Sammlung kreditrelevanter Informationen, die

20 Die empirische Bedeutung dieses Zusammenhangs wird in der Literatur als groß angesehen. Berger und Udell (2006) und Petersen und Rajan (2002) erläutern aber auch, dass die Nutzung von weichen Informationen und Relationship Lending mit zunehmender Weiterentwicklung von Computer-, Kommunikations- und Kreditscoringtechnologien sinken kann und dann Nähe an Bedeutung verliert. Es soll auch nicht vernachlässigt werden, dass die Nutzung von weichen Informationen und Relationship Lending nicht nötig ist, wenn ein Unternehmen leicht kontrollierbare Sicherheiten einsetzen kann oder kreditwürdige Personen ausreichende Haftung übernehmen (Berger und Udell, 2006). 
weich und schwer verifizierbar sind, sofern sie auch direkt in die Kreditvergabeentscheidung involviert sind und diese Informationen entsprechend verwenden können. Anders ist die Situation in Banken, in denen Informationssammlung und Kreditentscheidung nicht nahe beieinander liegen, sondern organisatorisch getrennt auf unterschiedlichen Hierarchiestufen oder in verschiedenen Abteilungen stattfinden. Hier ergibt sich für Bankmitarbeiter eher ein Anreiz, harte Informationen zu sammeln, da diese im Gegensatz zu weichen Informationen leicht durch Dritte verifizierbar sind und somit gut innerhalb der Organisation weitergeleitet werden können. Dieser Anreiz wird verstärkt, wenn innerhalb der Bank ein interner Kapitalmarkt besteht. Dann kann ein Bankmitarbeiter erreichen, dass basierend auf den von ihm weitergeleiteten Informationen viele Kredite vergeben werden und dadurch seiner Bankeinheit Kapital zufließt, das andernfalls anderen Bankeinheiten zugeflossen wäre. Stein (2002) analysiert die diskutierte Bedeutung alternativer Bankorganisationsformen theoretisch, unterstützende empirische Evidenz hierzu zeigen insbesondere Berger et al. (2005) und Cole et al. (2004).

Insgesamt sollten Genossenschaften und Sparkassen eher komparative Vorteile haben als Kreditbanken, wenn weiche, schwer verifizierbare Informationen und Relationship Lending für eine Kreditvergabe essentiell sind. Die Kreditbankgruppe, welche unabhängig arbeitende Kreditbanken umfasst, weist eine eher geringe Anzahl an Bankstellen auf. ${ }^{21}$ Insbesondere in den Bankstellennetzen der Großbanken gibt es typischerweise mehrere Hierarchiestufen (Schnabel und Hakenes, 2007). Im Gegensatz dazu haben sowohl die Genossenschaftsbank- als auch die Sparkassengruppe eine Verbundstruktur, die jeweils zahlreiche, im Raum weit verteilte Bankstellen mit flacheren Hierarchien und Entscheidungsautonomie bei der Vergabe kleinerer und mittlerer Kredite umfasst - neben den hier nicht relevanten Spitzeninstituten.

Bei Genossenschaftsbanken und Sparkassen gibt es zudem historische Gründe für eine hohe Bereitschaft zur Kreditvergabe an KMU in der Geschäftsregion und auch an junge Unternehmen. Genossenschaftlich organisierte Banken entstanden im ländlichen oder kleingewerblichen Bereich als Selbsthilfeorganisationen und dienten zunächst ausschließlich der Förderung der Erwerbs- und Wirtschaftstätigkeit ihrer Mitglieder. Sie sind heute immer

21 Die Kreditbankgruppe umfasst in Gesamtdeutschland im Jahr 19906.890 Bankstellen (rechtlich selbstständige Kreditinstitute und deren Zweigstellen), im Jahr 1999 mit 7.182 etwas mehr und im Jahr 2005 noch 5.341 Bankstellen (ohne die Deutsche Postbank AG, die erst ab dem 1.1.2005 als Kreditbank zählt). Die Sparkassengruppe umfasst im Jahr 199020.128 Bankstellen, bis 1999 sinkt die Zahl um etwa 6 Prozent auf 18.913 und im Jahr 2005 verbleiben 15.005 Bankstellen. Im Jahr 1990 existieren in der Genossenschaftsbankgruppe 21.259 Bankstellen, im Jahr 1999 mit 17.856 etwa 16 Prozent weniger und im Jahr 2005 bestehen 14.028 Bankstellen (Deutsche Bundesbank, 2000, 2001 und 2006). 
noch regional verankert und stark regional orientiert. Sparkassen haben gemäß bundeslandspezifischer Sparkassengesetzgebung den öffentlichen Auftrag, im Geschäftsgebiet den lokal angesiedelten Mittelstand zu unterstützen. ${ }^{22}$

Zusammenfassend ähneln sich Genossenschaftsbanken und Sparkassen im Hinblick auf räumliche Nähe zum Kunden und dezentrale Organisation. Hieraus ergeben sich komparative Vorteile bei Kreditvergabeentscheidungen basierend auf weichen, schwer verifizierbaren Informationen und bei Relationship Lending, die gerade bei der Finanzierung junger, kleiner Unternehmen entscheidend sein können. Weiterhin besteht sowohl bei Sparkassen als auch bei Genossenschaftsbanken eine historisch bedingte Regions- und Mittelstandsorientierung. Entsprechend formulieren wir folgende Hypothese:

\section{Hypothese: Genossenschaftsbanken und Sparkassen weisen c. p. eine höhere Bereitschaft als} Kreditbanken auf, langfristige Kredite und somit auch Förderkredite an junge, kleine Unternehmen zu vergeben.

Im Gegensatz zu Kreditinstituten der Genossenschaftsbankgruppe sind solche der Sparkassengruppe Eigentum öffentlich-rechtlicher Träger, d. h. von Gemeinden, Kreisen, Zweckverbänden oder Ländern. Atkinson und Stiglitz (1980), beispielsweise, erläutern aus wohlfahrtsökonomischer Sicht, unter welchen Umständen öffentlich-rechtliche Unternehmen als Instrument zur Steigerung der Wohlfahrt dienen können. Auf Gerschenkron (1962) geht die Sichtweise zurück, dass öffentlich-rechtliche Banken im Falle eines unterentwickelten privaten Banksektors ökonomisches Wachstum fördern können. ${ }^{23}$ Bei Sparkassen haben öffentlichrechtliche Träger die direkte Kontrolle über die Einhaltung des gesetzlich verankerten, öffentlichen Auftrags zur Regions- und Mittelstandsförderung. Sofern dies die Umsetzung des Sparkassenauftrags, wie gewünscht, befördert, ist von einer besonders hohen Bereitschaft zur Kreditvergabe an KMU und junge Unternehmen auszugehen.

22 Sparkassen sind weiterhin damit beauftragt, die regionale Wirtschaftsentwicklung - über Mittelstandsfinanzierung hinausgehend - zu fördern, die Vermögensbildung und Kreditversorgung der Bevölkerung sicherzustellen und für die Finanzierung öffentlicher Aufgaben zu sorgen. Darauf gehen wir in dieser Arbeit zur Kreditvergabe an junge, kleine Unternehmen aber nicht weiter ein. Die historische Entwicklung des öffentlichen Auftrags der Sparkassen diskutiert beispielsweise Guinnane (2002). Aktuellere Einschätzungen geben Schindler und Neuberger (2000), Möschel (2005) oder der Sachverständigenrat (2004).

23 Neumann und Reichel (2006) oder Hakenes und Schnabel (2006) analysieren, unter welchen Bedingungen öffentlich-rechtliche Banken positive Wohlfahrtseffekte haben können. Auf mögliche Fehlentwicklungen in öffentlich-rechtlichen Unternehmen allgemein bzw. in öffentlich-rechtlichen Banken fokussieren hingegen Barth et al. (2004), La Porta et al. (2002) oder Shleifer und Vishny (1994). 
Während der 1990er Jahre ergaben sich für die Sparkassengruppe zudem aus den Haftungskonstrukten Gewährträgerhaftung und Anstaltslast Kostenvorteile. ${ }^{24}$ Für Sparkassen, die sich überwiegend durch relativ günstige Spareinlagen refinanzieren, waren während der 1990er Jahre beispielsweise die Kosten für Einlagensicherung aufgrund dieser Haftungsregelungen vergleichsweise niedrig (Engerer und Schrooten, 2004). Zudem konnten sie innerhalb des Haftungsverbundes der Sparkassengruppe davon profitieren, dass Landesbanken für Kredite, welche die Kapazität einer einzelnen Sparkasse übersteigen, günstige Refinanzierungsmittel ergänzend anboten (Deutsche Bundesbank, 2003; Sachverständigenrat, 2004). Auch nach der Übergangsfrist für die Eliminierung bzw. Änderung von Gewährträgerhaftung und Anstaltslast bleiben die Institute der Sparkassengruppe im Besitz öffentlicher Gebietskörperschaften mit Steuerhoheit und Beteiligung am Finanzausgleich. Entsprechend ist davon auszugehen, dass implizite Staatsgarantien auch dann weiterhin begünstigend wirken (Brunner et al., 2004; Möschel, 2005; Sachverständigenrat, 2004).

Ausgehend von den genannten Unterschieden zwischen Sparkassen und Genossenschaftsbanken, die aus der öffentlich-rechtlichen Trägerschaft der Sparkassen folgen, formulieren wir folgende Hypothese:

\section{Hypothese: Sparkassen zeigen in den 1990er Jahren im Vergleich zu Genossenschaftsbanken eine höhere Bereitschaft, langfristige Kredite, inklusive Förderkredite, an junge, kleine Unternehmen zu vergeben.}

3 Untersuchungsaufbau

\subsection{Spezifikation der Schätzmodelle}

Die Überprüfung der obigen Hypothesen zur Kreditvergabe durch Genossenschaftsbanken, Kreditbanken und Sparkassen nehmen wir in zwei Schritten vor.

Zunächst präsentieren wir Regressionen auf Regionsebene, in denen wir den Zusammenhang zwischen der Vergabe langfristiger Kredite an junge, kleine Unternehmen, am Beispiel von

24 Nachdem die Europäische Kommission Gewährträgerhaftung und Anstaltslast als unzulässige staatliche Beihilfen eingestuft hatte, vereinbarten die Kommission und die Bundesrepublik Deutschland in der Brüssler Verständigung vom 17. Juli 2001 die Streichung der Gewährträgerhaftung ab dem 18. Juli 2005 und bestimmte Übergangsregelungen für Verbindlichkeiten, die vor Juli 2005 entstanden sind. Bezüglich der Anstaltslast wurde folgende wesentliche Einschränkung ab dem 18. Juli 2005 beschlossen: Die öffentlich-rechtlichen Träger der Sparkassen und ihrer Spitzeninstitute können diese zukünftig nur noch gemäß den Beihilferegelungen des EUVertrages wirtschaftlich unterstützen und die Europäische Kommission kann intervenieren (Hartmann-Wendels et al., 2007; Sachverständigenrat, 2004; Schuster und Sohns, 2006). 
Förderkrediten der DtA, und der Präsenz der drei Bankgruppen in 325 westdeutschen Stadtund Landkreisen $\left(N_{R}\right)$ am Ende der 1990er Jahre analysieren. Wir spezifizieren ein OLSRegressionsmodell und modellieren wie folgt (Greene, 2008):

$$
y_{i}=\beta^{\prime} b_{i}+\gamma^{\prime} x_{i}+\varepsilon_{i} \quad \text { für alle } \quad i=1, \ldots, N_{R} \text {. }
$$

Als endogene Variable $Y$ verwenden wir entweder die logarithmierte Anzahl der Förderkreditzusagen oder das logarithmierte bewilligte Kreditvolumen im Kreis im Jahr 1999, $y_{i}$ bezeichnet die Wertausprägung für den Kreis $i$. Der Vektor $B$ umfasst die erklärenden Variablen zur regionalen Präsenz der einzelnen Bankgruppen. Weitere Regionalvariablen, die als Kontrollgrößen dienen, fassen wir im Vektor $X$ zusammen. Die jeweiligen Ausprägungen für den Kreis $i$ bezeichnen wir mit $b_{i}$ und $x_{i}$. Die zu schätzenden Parametervektoren sind $\beta$ und $\gamma$. Der Vektor der Fehlerterme ist $E$ und $\varepsilon_{i}$ ist die Wertausprägung für den Kreis $i$. Da die Nullhypothese homoskedastischer Fehlerterme im bevorzugten Schätzmodell R2 abgelehnt wird (siehe Zeile „Breusch-Pagan-Test $\left(\chi^{2}\right), \mathrm{H}^{0}$ : Homoskedastie“, Tabelle 3), weisen wir heteroskedastierobuste Standardfehler nach dem Huber-White-Verfahren aus.

Unsere Analysen auf Regionsebene können erste Hinweise auf bankgruppenspezifische Unterschiede bei der Kreditvergabe liefern, da die regional beobachtbaren Förderkreditzahlen und -summen von den Entscheidungen lokal angesiedelter Geschäftsbanken über ihre Beteiligung an der Förderkreditallokation beeinflusst werden. Allerdings lassen sich auf Regionsebene Effekte der Kreditvergabebereitschaft der drei Bankgruppen nicht eindeutig von anderen Effekten trennen, die trotz der Verwendung regionaler Kontrollvariablen die Ergebnisse für Maße regionaler Bankgruppenpräsenz mitbestimmen können. Unsere regionalen Bankvariablen werden eng mit dem regionalen Agglomerationsgrad und anderen regionalen Kontrollgrößen korrelieren. Des Weiteren können wir auf Regionsebene keine Informationen über unternehmensspezifische Bankbeziehungen verwenden und nicht direkt für Einflüsse anderer Unternehmensmerkmale kontrollieren.

Mittels detaillierter Mikrodaten für 6.880 Unternehmen $\left(N_{U}\right)$, die zwischen 1990 und 1993 gegründet wurden, können wir direkt die Zusammenhänge zwischen Bankverbindungen der Unternehmen und Kreditzusagewahrscheinlichkeiten sowie bewilligten Kreditvolumina untersuchen. Unsere zentralen Regressionen auf Unternehmensebene zur Erklärung der Kreditzusagewahrscheinlichkeit spezifizieren wir als Probit-Modelle, wobei wir den Erwartungswert der endogenen Variable $Y$ wie folgt konditional auf $B=b_{i}$ und $X=x_{i}$ modellieren (Maddala, 1983; Greene, 2008): 


$$
E\left(Y \mid B=b_{i}, X=x_{i}\right)=\operatorname{prob}\left(Y=1 \mid B=b_{i}, X=x_{i}\right)=\Phi\left(\left(\beta^{\prime} b_{i}+\gamma^{\prime} x_{i}\right) / \sigma\right) \quad \text { für alle } i=1, \ldots, N_{U} \text {. }
$$

Die endogene Variable $Y$ ist, gemäß der bevorzugten Definition, eine Indikatorvariable, die den Wert „1“ annimmt, wenn ein Unternehmen eine oder mehrere Förderkreditzusagen der DtA während der Gründungsphase (Jahr der Gründung plus zwei weitere Jahre) erhielt. Andernfalls nimmt $Y$ den Wert „0“ an. Der Vektor $B$ enthält die zentralen erklärenden Variablen, die unternehmensspezifische Bankverbindungen bei Genossenschaftsbanken, Kreditbanken oder Sparkassen anzeigen. Der Vektor $X$ umfasst unternehmens- und regionsspezifische Kontrollvariablen. Den Fehlerterm im latenten Modell spezifizieren wir zunächst

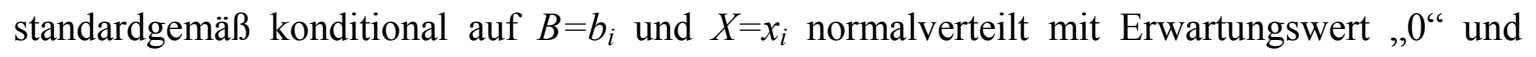
homoskedastischer Varianz $\sigma^{2}=1$, schätzen aber auch ein Modell, das multiplikative Heteroskedastie zulässt (Harvey 1976). $E(\bullet)$ bezeichnet den Erwartungswert und $\Phi(\bullet)$ die Verteilungsfunktion der Standardnormalverteilung. Die zu schätzenden Parametervektoren sind $\beta$ und $\gamma^{25}$

Die Robustheit unserer Ergebnisse untersuchen wir in zweierlei Hinsicht. Zum einen variieren wir die Vektoren $B$ und $X$ mit erklärenden Variablen und zum anderen die endogene Variable $Y$. Beispielsweise nutzen wir in den Regressionen auf Unternehmensebene einen Indikator, bei dem eine besondere Förderkreditart nicht berücksichtigt wird und Indikatoren mit alternativen Zeitabgrenzungen. Hierzu zählt auch ein Indikator basierend auf Kreditzusageinformationen für die Jahre 1990 bis 1999. Weiterhin verwenden wir in OLS- und Tobit-Regressionen zur Erklärung des bewilligten Kreditvolumens folgende kontinuierlich definierte Endogene: „ln(Förderkreditvolumen insgesamt pro Unternehmen während der Gründungsphase in $1.000 €+1$ )“ (siehe auch Abschnitt A.1 im Anhang).

\subsection{Datenquellen, Schätzstichproben und Messung von Variablen}

Das Datenmaterial für die empirischen Analysen wurde aus zwei umfangreichen Datenbanken zusammengestellt. Zum einen handelt es sich um das ZEW Gründungspanel West mit Daten zu mehr als zwei Millionen Unternehmen für den Zeitraum von 1990 bis 1999. Diese Datenbank wird seit 1990 in halbjährlichem Rhythmus mit Datenmaterial des Verbandes der Vereine Creditreform erweitert. Für jedes erfasste Unternehmen liegen detaillierte Angaben zu

25 Um die disproportionale Stratifizierung im verwendeten Datensatz zu berücksichtigen, setzen wir gewichtete Schätzverfahren ein und verwenden adäquate Testverfahren (Wooldridge, 2002). In Regressionen mit kreisspezifischen Variablen clustern wir die Standardfehler auf Kreisebene, d. h. wir lassen Korrelation zwischen Unternehmen aus der gleichen Kreisregion zu (Moulton, 1990). Weitere Angaben zu ökonometrischen Methoden finden sich im Anhang, Abschnitt A.1. 
Unternehmensmerkmalen, Eigentümern und Managern vor. ${ }^{26}$ Zum anderen konnten wir auf den Datenbestand der Deutschen Ausgleichsbank (DtA) zurückgreifen, der die Gesamtheit von etwa 776.000 Förderkreditbewilligungen der DtA im Zeitraum 1990 bis 1999 umfasst.

In den Regressionen zur Erklärung der Kreditvergabe auf Regionsebene in Abschnitt 4.1 verwenden wir die Daten der DtA zur Generierung der endogenen Variablen. Die erklärenden Variablen in diesen Regressionen basieren auf Kreisdaten zur Bankenbranche, zur Besiedlung, zum Volumen und zur Heterogenität des Gründungsgeschehens (Quellen: Deutsche Bundesbank, Bundesamt für Bauwesen und Raumordnung, ZEW Gründungspanel West). Die exakten Definitionen der Variablen und deskriptive Statistiken finden sich in Tabelle A.1 im Anhang.

Für die Regressionen auf Unternehmensebene in Abschnitt 4.2 können wir auf sehr detaillierte Unternehmensdaten zurückgreifen. Die Ausgangsbasis ist eine zufällig gezogene, repräsentative Stichprobe mit 12.000 Unternehmen aus dem ZEW Gründungspanel West. Für diese Stichprobe wurde das kodierte Datenmaterial von Creditreform durch eine Telefonbefragung ergänzt, umfassendes Textmaterial von Creditreform aufbereitet und eine aufwendige Verknüpfung mit der oben genannten Datenbank der DtA auf Unternehmensebene realisiert. In der empirischen Analyse verwenden wir hauptsächlich eine reduzierte Stichprobe mit 6.880 Unternehmen. ${ }^{27}$ Diese haben ein originäres Gründungsdatum zwischen 1990 und 1993, sind nicht vollständig an andere Unternehmen angebunden und decken sowohl alle Regionen Westdeutschlands als auch die Sektoren Verarbeitendes Gewerbe, Baugewerbe, Handel und die meisten Dienstleistungsindustrien ab.

Die endogenen Variablen in den Regressionen auf Unternehmensebene basieren auf der Verknüpfung von DtA- und ZEW-Daten. Für die erklärenden Variablen verwenden wir Informationen $\mathrm{zu}$ bankspezifischen und sonstigen Unternehmensmerkmalen. Hierzu zählen insbesondere Angaben zu Bankverbindungen bei Genossenschaftsbanken, Kreditbanken und Sparkassen, die Konto-, Kredit- oder andere Bankverbindungen zum Zeitpunkt der Unternehmensgründung darstellen und nicht nur Hauptbankverbindungen umfassen. Weiterhin berücksichtigen wir Merkmale der Bankenbranche und der Siedlungsstruktur am Unternehmensstandort (Quellen: Deutsche Bundesbank, Bundesamt für Bauwesen und

26 Creditreform ist die größte deutsche Kreditauskunftei und erhebt Daten proaktiv und auf Anfrage. Die ZEW Gründungspanels sind in Almus et al. (2002) ausführlich beschrieben.

27 Die Verknüpfung der DtA- und ZEW-Daten und die Reduktion der Ausgangs- auf die Schätzstichprobe werden in Abschnitt A.2.2 im Anhang genauer erläutert. 
Raumordnung). Tabelle A.2 im Anhang enthält die exakten Definitionen der Variablen und deskriptive Statistiken.

\section{$4 \quad$ Empirische Ergebnisse}

In Abschnitt 4.1 erläutern wir die Analysen auf Regionsebene, in Abschnitt 4.2 folgen die Analysen auf Unternehmensebene. Anschließend diskutieren wir in Abschnitt 4.3 die zentralen Schätzergebnisse in Bezug auf die Hypothesen aus Abschnitt 2.3 zur Kreditvergabe durch Genossenschaftsbanken, Kreditbanken und Sparkassen.

\subsection{Regressionsergebnisse basierend auf Regionsdaten}

In Tabelle 3 präsentieren wir die Ergebnisse für Regressionen gemäß Gleichung (1) in Abschnitt 3.1. In diesen Regressionen werden die logarithmierte Anzahl der Zusagen an DtAFörderkrediten im Kreis im Jahr 1999 und das logarithmierte Volumen der Kreditbewilligungen durch Variablen erklärt, die die regionale Präsenz von Sparkassen, Genossenschaftsbanken und Kreditbanken messen.

\section{Tabelle 3 hier einfügen.}

Für die erklärenden Variablen im bankgruppenspezifischen Vektor $B$ finden wir folgende, zentrale Schätzergebnisse. In allen Modellen R1 bis R3 weist die Sparkassendichte - definiert als , $\ln (($ Anzahl an Sparkassenbankstellen + 1) / Einwohnerzahl in 1.000 im Kreis, 1998) signifikant positive Koeffizienten auf. Signifikant positive Koeffizienten ergeben sich auch für die analog definierte Genossenschaftsbankdichte. Besonders $\mathrm{zu}$ betonen ist, dass sich die Koeffizienten für die Sparkassen- und die Genossenschaftsbankdichte in keinem der geschätzten Modelle signifikant voneinander unterscheiden (siehe Zeile „F-Test, $\mathrm{H}^{0}$ : $\beta^{\text {Spark.dichte }}=\beta^{\text {Gen.bankdichte، }}$ in Tabelle 3). Aufgrund der gewählten Modellspezifikation stellen die geschätzten Koeffizienten Elastizitäten dar und die quantitative Bedeutung einzelner Effekte kann direkt abgelesen werden. Zum Beispiel steigen Förderkreditzusagen c. p. um 2,23 Prozent (Modell R2), wenn die Sparkassendichte 10 Prozent zunimmt. Eine 1,39 Prozent höhere Anzahl an Förderkreditzusagen folgt, wenn die Genossenschaftsbankdichte um 10 Prozent erhöht wird. ${ }^{28}$ Die Koeffizienten für die Kreditbankdichte sind nie statistisch signifikant von Null verschieden und zudem ihrer Höhe nach quantitativ vernachlässigbar. Die statistischen Tests in

28 Variationen der Sparkassen- oder Genossenschaftsbankdichte um 10 Prozent sind realistisch angesichts der jeweiligen Standardabweichungen im Datensatz auf Regionsebene (siehe Tabelle A.1 im Anhang). 
Zeile „F-Test, $\mathrm{H}^{0}: \beta^{\text {Spark.dichte }}=\beta^{\text {Kreditbankdichte، }}$ zeigen, dass sich die Effekte der Sparkassendichte in allen Modellen signifikant auf dem 1\%-Niveau von denen der Kreditbankdichte unterscheiden. Die Effekte der Genossenschaftsbankdichte weichen in den Modellen R2 und R3 signifikant auf dem 5\%-Niveau von denen der Kreditbankdichte ab (siehe Zeile „F-Test, $\mathrm{H}^{0}$ : $\left.\beta^{\text {Gen.bankdichte }}=\beta^{\text {Kreditbankdichte، }}\right)$. Somit weisen Kreise mit höherer Dichte an Sparkassen- oder Genossenschaftsbankstellen gleichermaßen höhere Zusagezahlen und -volumina bei langfristigen Krediten an junge, kleine Unternehmen, in Form von DtA-Förderkrediten, auf. Im Gegensatz hierzu finden wir für die Kreditbankdichte weder statistisch signifikante noch quantitativ substantielle Effekte.

Die hier vorgestellten Schätz- und Testergebnisse zu bankgruppenspezifischen Variablen sind, wie der Vergleich der Modelle R2 und R3 zeigt, sehr robust bzgl. der getesteten Variation der endogenen Variable. Sie erweisen sich auch als stabil, wenn wir den Kontrollvektor $X$ verändern (Modell R1 versus Modell R2 oder R3). Die zu Normierungszwecken verwendete Variable „logarithmierte Anzahl der Gründungen im Kreis im Jahr 1999“ geht in allen Modellen mit signifikant positivem Schätzkoeffizienten ein. Gemäß der statistischen Tests in Zeile „F-Test, $H^{0}: \beta^{\text {Gründungszahl }=1 “}$ weichen diese Schätzkoeffizienten jeweils signifikant von eins ab. Der c. p. unterproportionale Zusammenhang ist plausibel, da nicht jeder Existenzgründer Förderkredite der DtA nachfragt und Kreditanträge nicht immer bewilligt werden. Bundeslandindikatoren (Basiskategorie: NRW) sind in allen Modellen gemeinsam

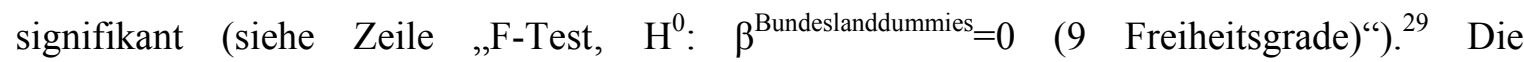
logarithmierte Einwohnerdichte, gemessen im Jahr 1998 auf Kreisebene, hat c. p. einen negativen Einfluss, der im Modell R1 auf dem 5\%-Niveau signifikant ist, aber nicht in den Modellen R2 und R3. Die Kontrollvariablen für Branchenkomposition und Größenverteilung des regionalen Gründungsaufkommens in den Modellen R2 und R3 zeigen, dass Kreise mit einem hohen Anteil an Gründungen im verarbeitenden Gewerbe c. p. signifikant höhere Förderkreditzusagezahlen und -volumina aufweisen. Für den Anteil an Gründungen in der Branche „sonstige Dienstleistungen“ ergibt sich hingegen ein signifikant negativer Effekt. Bei einem hohen Anteil an Gründungen mit zwei Mitarbeitern im Kreis resultieren c. p. deutlich mehr Förderkreditzusagen und höhere Kreditvolumina. Für den Anteil an Gründungen mit drei

29 West-Berlin ist nicht im Datensatz enthalten. Die Schätzergebnisse für die Bundeslandindikatoren können auf Anfrage zur Verfügung gestellt werden. Gleiches gilt für alle weiteren Schätzergebnisse, die im Folgenden erwähnt, aber aus Platzgründen nicht tabellarisch ausgewiesen werden. 
oder mehr Mitarbeitern finden wir ebenfalls einen signifikant positiven, aber etwas schwächer ausgeprägten Effekt.

Signifikant positive Schätzkoeffizienten für die logarithmierte Dichte der Sparkassen oder Genossenschaftsbanken, die signifikant vom Koeffizienten für die Kreditbankdichte abweichen, zeigen sich nicht nur in den Modellen R1 bis R3, sondern auch in Regressionen, in denen wir nur für die Normierungsvariable kontrollieren, d.h. für die logarithmierte Gründungszahl im Kreis. Analoge Ergebnisse finden wir auch in Regressionen mit nicht logarithmierten Dichtevariablen, sofern wir ein ausreißerrobustes Schätzverfahren einsetzen (Hamilton, 2006) oder den Kreis Düsseldorf, der eine unplausibel hohe Förderkreditzahl aufweist, ausschließen (Tabelle A.3 im Anhang).

Obige Ergebnisse liefern erste Indizien für Unterschiede und Gemeinsamkeiten der Kreditvergabe durch Sparkassen, Genossenschaftsbanken und Kreditbanken. Allerdings sind hohe Korrelationen regionaler Bankvariablen mit anderen regionalen Variablen (Tabelle A.4 im Anhang) und entsprechende Identifikationsprobleme $\mathrm{zu}$ beachten. Entsprechend vorsichtig interpretieren wir die Ergebnisse der Analysen auf Regionsebene, obwohl die zentralen bankgruppenspezifischen Resultate hinsichtlich aller getesteten Modelländerungen robust sind und Variance-Inflation-Faktoren in keinem der Modelle die üblichen Grenzwerte übersteigen (Chatterjee und Hadi, 2006). Weiterhin können auf Regionsebene, wie schon in Abschnitt 3.1 angesprochen, keine Informationen über unternehmensspezifische Bankbeziehungen verwendet werden. Es lässt sich auch nicht direkt für sonstige unternehmensspezifische Einflussfaktoren auf den Kreditvergabeprozess kontrollieren. Um den genannte Punkten zu begegnen, gehen wir im folgenden Abschnitt zu detaillierten Analysen mit Unternehmensdaten über.

\subsection{Regressionsergebnisse basierend auf Unternehmensdaten}

Auf Unternehmensebene können wir direkt analysieren, wie Bankverbindungen eines jungen, kleinen Unternehmens zu Sparkassen, Genossenschaftsbanken oder Kreditbanken und die Vergabe langfristiger Kredite in Form von Förderkrediten der DtA zusammenhängen.

In Tabelle 4 zeigen wir Schätzungen von Probit-Modellen zur Erklärung der Wahrscheinlichkeit einer Förderkreditzusage (Gleichung (2), Abschnitt 3.1) und ein einfaches OLS-Modell zur Erklärung des logarithmierten, bewilligten Kreditvolumens (Modell U3). Die Ergebnisse für die zentralen erklärenden Variablen im bankgruppenspezifischen Vektor $B$ sind wie folgt: Unternehmensgründungen, bei denen die Indikatorvariable „Bankverbindung bei Sparkasse“ Sparkassenverbindungen im Gründungsjahr anzeigt, erhalten c. p. während des 
Gründungsjahrs oder einem der beiden Folgejahre signifikant häufiger Zusagen für langfristige Kredite in Form von Förderkrediten der DtA bzw. höhere Zusagevolumina als Gründungen ohne solchen Sparkassenbezug. Für Bankverbindungen zu Genossenschaftsbanken ergeben sich auch signifikant positive Koeffizienten. Diese unterscheiden sich in keinem Modell signifikant von den Koeffizienten für Sparkassenverbindungen (siehe Zeile „ $\chi^{2}$-Test, $\mathrm{H}^{0}$ : $\beta^{\text {Spark.verb. }}=\beta^{\text {Gen.bankverb.، }}$ ). Der Indikator für Bankverbindungen $\mathrm{zu}$ einem Zentralinstitut der Sparkassen oder Genossenschaftsbanken hat in keinem Modell signifikante Koeffizienten. Dies ist plausibel, da die Spitzeninstitute selten direkt in die Finanzierung von KMU und jungen Unternehmen involviert sind. Von größerem Interesse sind die ebenfalls nicht signifikant von Null verschiedenen Koeffizienten für Kreditbankverbindungen, die in allen Modellen signifikant von den Sparkassen- und Genossenschaftsbankkoeffizienten abweichen (siehe Zeile , $\chi^{2}$-Test, $\mathrm{H}^{0}: \quad \beta^{\text {Spark.verb. }}=\beta^{\text {Kreditbankverb.، }}$ und Zeile,$\chi^{2}$-Test, $\left.H^{0}: \quad \beta^{\text {Gen.bankverb. }}=\beta^{\text {Kreditbankverb. } ،}\right)$. Insignifikante Koeffizienten finden wir für Kreditbankverbindungen, egal ob ein Unternehmen neben Kreditbankverbindungen auch Sparkassen- oder Genossenschaftsbankverbindungen unterhält oder nicht. ${ }^{30}$ Bei Kreditbankverbindungen der letzteren Kategorie kann das jeweilige Unternehmen keine Sparkasse oder Genossenschaftsbank als Hausbank haben.

Die Berechnung marginaler Effekte zeigt für die Bankverbindungsvariablen, dass die ökonomische Stärke der einzelnen Effekte das Muster der diskutierten statistischen Signifikanzen der Schätzkoeffizienten reflektiert (siehe Anhang A.1 und Tabelle A.5 im Anhang). Laut Probit-Modell U2, beispielsweise, steigt die Wahrscheinlichkeit, einen Förderkredit zu erhalten, bei Vorliegen einer Sparkassenverbindung signifikant um 2,1 Prozentpunkte, d. h. etwa 21 Prozent gegeben das Stichprobenmittel des Förderkreditindikators von 10,36 Prozent. Bei Vorliegen einer Genossenschaftsbankverbindung steigt sie signifikant in ähnlichem Ausmaß (2,4 Prozentpunkte bzw. 24 Prozent). Substantielle marginale Effekte für Sparkassen- oder Genossenschaftsbankverbindungen ergeben sich auch in den anderen Modellen. Die marginalen Effekte für Kreditbankverbindungen sind hingegen immer klein und nie signifikant von Null verschieden.

Tabelle 4 hier einfügen.

Um dies zu testen, verwenden wir neben dem Kontrollvektor $X$ aus Modell U2 einen Vektor $B$ mit den 4 bisher genannten Bankverbindungsvariablen und zusätzlich einer Indikatorvariable „Bankverbindung bei Kreditbank, aber nicht bei Sparkasse oder Genossenschaftsbank“. Die Koeffizienten, die sich basierend auf dieser Modellspezifikation für beide Teilgruppen der Kreditbankverbindungen ergeben, sind nicht signifikant von Null verschieden. 
Im Kontrollvektor $X$ verwenden wir in allen Modellen die unternehmensspezifische Bankverbindungsanzahl. Die Schätzkoeffizienten zeigen, dass die Wahrscheinlichkeit einer Förderkreditzusage und die zugesagten Kreditvolumina c. p. mit steigender Anzahl an Bankverbindungen zunehmen. ${ }^{31}$ Im Modell U1 ist der positive Koeffizient signifikant auf dem 10\%-Niveau. In den Modellen mit weiteren Unternehmensmerkmalen im Kontrollvektor $X$ sind die Koeffizienten aber jeweils meist insignifikant. Das Muster unserer Ergebnisse legt nahe, dass eine höhere Bankverbindungszahl im Modell U1 einen höheren Bedarf an Kreditfinanzierung auffängt, dies aber an Gewicht verliert, sobald wir u. a. für die Unternehmensgröße kontrollieren. In der Literatur zur Erklärung der Bankverbindungsanzahl gilt gerade die Unternehmensgröße als wichtiger Proxy für den Bedarf eines Unternehmens an Bankdienstleistungen und die Wahrscheinlichkeit, dass eine Bank diese nicht allein bereitstellt (Berger et al., 2008; Neuberger und Räthke, 2007; Ongena and Smith, 2000).

Als Regionsvariablen gehen im Kontrollvektor $X$ die Bankstellendichte, die Einwohnerdichte und Bundeslandindikatoren ein, wobei letztere in keinem Modell gemeinsam signifikant sind. ${ }^{32}$ Die Bankstellendichte am Unternehmensstandort, gemessen als Anzahl an Bankstellen pro 1.000 erwerbsfähige Einwohner im Kreis, hat in allen Modellen c. p. einen signifikant positiven Effekt. In Regionen mit hoher Bankstellendichte sollte die durchschnittliche räumliche Distanz zwischen einem Unternehmen und einer Bank, die an dieses Unternehmen Kredite vergibt, geringer sein als in anderen Regionen. Entsprechend der Diskussion in Abschnitt 2.3 und dort zitierter Literatur haben näher am Kunden angesiedelte Banken Vorteile bei der Sammlung weicher, schwer verifizierbarer Informationen sowie beim Monitoring und sind c. p. eher zur Kreditvergabe an junge, kleine Unternehmen bereit. Es liegt nahe, dass dies zur Erklärung unserer Regressionsergebnisse für die Bankstellendichte beiträgt. Zusätzlich sollte in Regionen mit hoher Bankstellendichte die durchschnittliche räumliche Distanz zwischen einer Bank, die letztlich einen Kredit vergibt, und ihren Wettbewerbern geringer sein als in anderen Regionen. Höherer ex ante Wettbewerb zwischen potentiellen Kreditgebern kann nach einem Modell von Boot und Thakor (2000) bei Banken den Anreiz zu

31 Wir erhalten qualitativ ähnliche Ergebnisse, wenn wir eine alternative Kodierung mit Dummyvariablen für Unternehmen mit zwei Bankverbindungen bzw. für solche mit drei und mehr Bankverbindungen verwenden.

32 Siehe Zeile , $\chi^{2}$-Test, $\mathrm{H}^{0}: \beta^{\text {Bundeslanddummies }}=0$ (7 Freiheitsgrade)“ in den Tabellen 4, 5 und 6 . Wir verwenden acht Indikatoren für Bundesländer. Als Basiskategorie dient Nordrhein-Westfalen. West-Berlin ist im Datensatz enthalten und folgende Länder werden zusammengefasst: 1) Hamburg, Bremen, Niedersachsen; 2) RheinlandPfalz, Saarland. 
Relationship Lending erhöhen. ${ }^{33}$ Zudem sollte die Bedeutung lokaler Bankmonopole mit Preisdiskriminierung zulasten von Kreditkunden mit geringen Transportkosten sinken (Degryse und Ongena, 2005). Beide Argumentationen sind konsistent mit unserer Beobachtung, dass die Finanzierungskonzepte von Unternehmensgründungen bei höherer Bankstellendichte eher langfristige Förderkredite mit niedrigen Zinssätzen und attraktiven Rückzahlungskonditionen einschließen.

Für die Einwohnerdichte finden wir in allen Modellen signifikant negative Koeffizienten, was sowohl mit unseren Ergebnissen auf Regionsebene in Abschnitt 4.1 korrespondiert, als auch mit den Ergebnissen der Regionsanalysen von Wengler (2006) für Ostdeutschland im Zeitraum 1996 bis 2000. ${ }^{34}$ Langfristige Kredite aus bundesweiten Programmen der DtA fließen c. p. eher in schwach besiedelte als in verdichtete Regionen, obwohl derartige Regionalförderung nicht als explizites Ziel der Programme formuliert ist. ${ }^{35}$

Die zentralen Schätz- und Testergebnisse für den Vektor $B$ bleiben robust, wenn wir den Kontrollvektor $X$ erweitern. $^{36}$ Ab Modell U2 berücksichtigen wir zusätzliche unternehmensspezifische Kontrollvariablen, um weitere Einflüsse auf die Förderkreditvergabe aufzufangen, die sich aus der Selbstselektion unter Gründerpersonen, aus der Kundenauswahl der in die Förderkreditvergabe involvierten Geschäftsbanken und aus den Vergaberichtlinien der hier relevanten DtA-Programme ergeben. ${ }^{37}$ Für Unternehmensgründungen, die sich

33 Siehe auch die Darstellung in Boot (2000). Petersen und Rajan (1995) fokussieren hingegen auf ex-post Wettbewerb.

34 Wengler (2006) findet negative, teils signifikant von Null verschiedene Schätzkoeffizienten für die logarithmierte Einwohnerdichte in Regressionen, in denen die von Sparkassen bzw. Kreditbanken neu vermittelten, logarithmierten DtA-Förderkreditzahlen bzw. -volumina normiert je Einwohner erklärt werden. In diesen Regressionen für 89 Sparkassengeschäftsgebiete in Ostdeutschland zwischen 1996 und 2000 kontrolliert Wengler auch für fixe Jahreseffekte und für das Bruttoinlandsprodukt pro Einwohner. In einer ähnlich spezifizierten Regression zur Erklärung des Unternehmenskreditbestands der Sparkassen pro Einwohner ergibt sich ebenfalls ein signifikant negativer Koeffizient für die Einwohnerdichte.

35 Für die negativen Schätzkoeffizienten der Kontrollvariable Einwohnerdichte sind zahlreiche angebots- oder nachfrageseitige Erklärungsansätze denkbar, die wir aus Platzgründen nicht weiter erläutern. Sie basieren jeweils auf unterschiedlichen Annahmen zu Unterschieden zwischen verdichteten und schwach besiedelten Regionen im Hinblick auf die Erfolgschancen junger Unternehmen, deren Finanzierungsrestriktionen und Informationsasymmetrien.

36 Konsistente Ergebnisse erhalten wir auch, wenn wir alle Variablen im Vektor $B$, aber keine Kontrollvariablen aus $X$ berücksichtigen bzw. bivariate Regressionen schätzen.

37 Das Pseudo R ${ }^{2}$ (McFadden's likelihood-ratio-index), das im Modell U1 etwa 3 Prozent beträgt, liegt im Modell U2 bei 9 Prozent. Dies entspricht dem Niveau vergleichbarer Untersuchungen und bleibt in den übrigen ProbitModellen stabil. Der Prozentsatz richtig prognostizierter Werte ist bei der Verwendung der Vorhersageregel , $\hat{\mathrm{y}}=1$ wenn $\mathrm{p}>\mathrm{F}^{*}$ und sonst $\hat{\mathrm{y}}=0^{\text {“ }}$ und des naiven Schwellenwerts von $\mathrm{F}^{*}=0.5$ immer sehr hoch, d. h. bei etwa 90 Prozent. Wenn wir den Anteil der selten auftretenden 1-Ausprägung als Schwellenwert verwenden $\left(\mathrm{F}^{*}=0,1\right)$, beträgt der Prozentsatz richtig prognostizierter Werte in allen Probit-Modellen zwischen 56 und 69 Prozent. 
teilweise im Besitz anderer Unternehmen befinden, erhalten wir c. p. eine signifikant geringere Wahrscheinlichkeit für Förderkreditzusagen und geringere Zusagevolumina als für Gründungen in der Referenzgruppe. Diese Ergebnisse stehen im Einklang mit der These, dass solche Unternehmensanbindungen den Zugang zu alternativen Finanzierungsquellen erleichtern und die Kreditnachfrage reduzieren. Weiterhin hat eine Vergaberichtlinie der DtA negative Ausstrahlung auf den Zugang zu Förderkrediten für teilweise angebundene Unternehmen: Gründungen mit einer vollständigen Anbindung an andere Unternehmen, z. B. Filialen, können keine Kredite aus den hier relevanten DtA-Programmen erhalten und wurden deshalb auch aus unserem Datensatz eliminiert (Abschnitt 3.2). Bei Teamgründungen und Gründungen von Unternehmern mit einem Meistertitel oder Hochschulabschluss sind c. p. die Wahrscheinlichkeit für Förderkreditzusagen und die bewilligten Kreditvolumina signifikant höher als bei Gründungen in den jeweiligen Referenzgruppen („Einzelgründung“, ,geringe Ausbildung/Lehrabschluss") ${ }^{38}$ Diese Ergebnisse können darauf zurückgeführt werden, dass Gründungsprojekte mit mehreren oder besser ausgebildeten Unternehmern höhere Erfolgschancen haben und die Entscheidungsträger in diesen Unternehmen eher Informationen über die attraktiven Konditionen der Förderkredite sammeln und korrekt verarbeiten (Bates, 1990, Cressy, 1996; Mata und Portugal, 2002). Die Schätzkoeffizienten für den Indikator der Unternehmen, für die uns keine Humankapitalangaben vorliegen, sind in allen Modellen sehr klein und nicht signifikant von Null verschieden. Da die meisten Unternehmen mit Humankapitalangaben zur Referenzgruppe zählen, ergibt sich somit kein Hinweis darauf, dass die selektive Verfügbarkeit von Humankapitalangaben zu verzerrten Schätzergebnissen führen würde. Unternehmen, die als BGB-Gesellschaft firmieren, haben c. p. signifikant seltener Förderkreditzusagen und niedrigere Zusagevolumina als Unternehmen in der Referenzgruppe (haftungsunbeschränkte Gewerbebetriebe, Einzelunternehmen, Personengesellschaften). Dies lässt sich damit erklären, dass diese Rechtsform häufig gewählt wird bei geringfügigen unternehmerischen Tätigkeiten mit geringem Kapitalbedarf und bei ex ante zeitlich befristeten Unternehmensprojekten, für die entsprechende Richtlinien der DtA keine Förderkreditvergabe zulassen. Für Unternehmen mit haftungsbeschränkten Rechtsformen $(\mathrm{GmbH}, \mathrm{AG})$ finden wir in allen Modellen negative Koeffizienten, die meist auch mindestens auf dem 10\%-Niveau signifikant sind. Dies ist plausibel, da das Vorliegen einer haftungsbeschränkten Rechtsform als Signal für Unternehmensrisiko interpretiert werden kann. Gerade für Unternehmensgründer, die ein riskantes Projekt umsetzen wollen, ergibt sich ein Anreiz, ihre Haftung zu beschränken.

38 Eine Ausnahme ist das insignifikante Ergebnis für den Teamgründungsindikator im Modell U3. 
Zudem zeigen Stiglitz und Weiss (1981) für eine Situation mit asymmetrischer Information und Haftungsbeschränkung, wie bei Kreditnehmern Anreize zur Risikoerhöhung entstehen können. Entsprechend liegt nahe, dass Banken an haftungsbeschränkte Unternehmen seltener Kredite vergeben bzw. ausschließlich komplexe Kreditverträge mit Kreditbesicherung und/oder Covenants anbieten (Boot, 2000; Hartmann-Wendels et al., 2007; Harhoff et al., 1998; Schulte, 1999). Indikatorvariablen für die Gründungskohorten 1990 bis 1993 und für die Wirtschaftszweigklassen sind jeweils gemeinsam signifikant (siehe hierzu die Testergebnisse in den Zeilen , $\chi^{2}$-Test, $H^{0}: \beta^{\text {Kohortendummies }}=0$ (3 Freiheitsgrade $)^{\text {“ }}$ und,$\chi^{2}$-Test, $H^{0}: \beta^{\text {Branchendummies }}=0$ (6 Freiheitsgrade)“ in den Tabellen 4, 5, und 6). ${ }^{39}$ Im Vergleich zu Einpersonenunternehmen sind bei Unternehmen mit mehr als einem Mitarbeiter zum Zeitpunkt der Gründung die Wahrscheinlichkeit für eine Förderkreditzusage und die Zusagevolumina höher. Der geschätzte Effekt für die logarithmierte Mitarbeiterzahl ist nicht-linear, erreicht sein Maximum in Modell U2 bei etwa vier Mitarbeitern und bleibt positiv bis zum 95\%-Quantil der Größenverteilung in der verwendeten Stichprobe. Das Ergebnis steht im Einklang mit unseren Ergebnissen in Abschnitt 4.1 und einer umfangreichen Literatur zur Rolle der Unternehmensgröße als Proxy für unternehmerische Kreditnachfrage, Erfolgschancen eines Unternehmens und potenzielle Kreditrestriktionen (Audretsch und Mahmood, 1995; Berger et al., 2008; Caves, 1998; Frank, 1988; Holtz-Eakin et al., 1994 a, b; Mata und Portugal, 1994; Ongena and Smith, 2000).

Tabelle 5 hier einfügen.

Unsere Ergebnisse für den Zusammenhang zwischen Bankverbindungen von Unternehmen und der Vergabe langfristiger Kredite in Form von Förderkrediten bleiben auch stabil, wenn wir die endogene Variable wie folgt modifizieren: Wir können erstens das logarithmierte, bewilligte Kreditvolumen als abhängige Variable in einem OLS-Modell (Tabelle 4, Modell U3), wie schon angesprochen, verwenden, oder in einem Tobit-Modell (Abschnitt A.1 und Modell U10 in Tabelle A.6 im Anhang). Robustheit ergibt sich zweitens, wenn wir in den Probit-Modellen in Tabelle 5 einen Indikator nur für Kreditzusagen im Gründungsjahr und dem folgenden Jahr verwenden (Modelle U4), oder für alle Zusagen bis Ende des Jahres 1999

39 Im Vergleich zu Unternehmen der Gründungskohorte 1990 (Basiskategorie) ist für Gründungen im Jahr 1991 in allen Modellen eine c. p. signifikant höhere und im Jahr 1993 eine signifikant niedrigere Förderwahrscheinlichkeit zu beobachten. Im Vergleich zur Basiskategorie „Einzelhandel“ zeigen sich, ähnlich wie in Abschnitt 4.1, für Unternehmen im verarbeitenden Gewerbe positive Koeffizienten. Diese sind auf dem 5\%-Niveau signifikant, sofern nicht für Kapitalintensität kontrolliert wird (Modell U7 in Tabelle 6). Gründungen im Großhandel, im Bereich „Verkehr und Nachrichtenvermittlung“ und in unternehmensnahen oder sonstigen Dienstleistungsindustrien haben eine signifikant niedrigere Wahrscheinlichkeit, Förderkredite zu erhalten, als Einzelhandelsgründungen. Der Effekt für das Baugewerbe bleibt meist insignifikant. 
(Modell U5). Somit zeigen die Regressionen auf Unternehmensebene, die alternativ auf Kreditdaten zwischen 1990 und 1995, 1994 oder 1999 basieren, und die Regressionen auf Regionsebene für 1999, dass unsere Ergebnisse während der 1990er Jahre stabil sind. Drittens sind unsere zentralen Schätz- und Testergebnisse im Modell U6 stabil, wenn die Endogene bei geförderten Unternehmen, die ausschließlich DtA-Förderkredite aus dem EigenkapitalhilfeProgramm erhielten, nicht mit „1“ kodiert wird. Die Konditionen dieses Programms sehen keine Einbindung der weiterleitenden Banken in die Übernahme des Ausfallsrisikos vor. Die Stabilität unserer Resultate bei Nichtberücksichtigung dieser Förderfälle ist insofern wichtig, als die Haftungseinbindung der in die Förderkreditallokation involvierten Geschäftsbanken eines der Argumente dafür ist, dass Banken bei der Vergabe der hier analysierten Förderkredite und bei der Vergabe bankeigener Kredite an die untersuchte Unternehmensgruppe ähnliche Entscheidungskriterien anlegen sollten (siehe Abschnitt 2.2).

In Tabelle 6 präsentieren wir drei weitere Modellvarianten. Die zentralen Schätz- und Testergebnisse zu Effekten von Bankverbindungen auf die Vergabe von Förderkrediten bleiben erhalten, wenn wir im Modell U7 für Kapitalintensität kontrollieren, gemessen als logarithmierter Kapitaleinsatz in tangible Investitionsgüter pro Mitarbeiter bei Unternehmensgründung. ${ }^{40}$ Lagrange-Multiplier Spezifikationstests nach Greene (2008) für das Modell U2 zeigen, dass die zentrale Annahme der Normalverteilung des Fehlerterms erfüllt ist $\left(\chi^{2}:\right.$ 2,61, p-Wert: 0,27), Homoskedastie des Fehlerterms jedoch in manchen Testvarianten verworfen werden muss. Im Modell U8 wird deshalb ein Probit-Modell geschätzt, das multiplikative Heteroskedastie zulässt (Harvey, 1976; Abschnitt A.1 im Anhang). Die Schätzergebnisse erweisen sich als robust.

Tabelle 6 hier einfügen.

Von besonderem Interesse ist das Modell U9, da wir mit dieser Modellspezifikation überprüfen wollen, ob sich unsere zentralen Ergebnisse für unternehmensspezifische Bankverbindungsindikatoren anstatt auf Unterschiede in der Kreditvergabebereitschaft der drei Bankgruppen auch direkt auf unterschiedliche regionale Konzentration der Bankstellennetze zurückführen ließen. Die Bankstellennetze der Kreditbanken fokussieren stärker auf Agglomerationsräume als die Bankstellennetze der Sparkassen oder Genossenschaftsbanken

Von einer kausalen Interpretation des signifikant positiven Effekts sehen wir ab, da gerade die Kapitalintensität in Regressionen zur Erklärung von Kreditvergabeentscheidungen endogen sein kann. Grundsätzlich könnte auch die Unternehmensgröße, d. h. die Mitarbeiterzahl zum Gründungszeitpunkt, endogen sein. Prantl (2008) zeigt jedoch, dass Förderkredite der DtA mittel- bzw. langfristig, aber nicht kurzfristig zu Beschäftigungseffekten bei geförderten Unternehmen führen. 
(Tabelle A.4 im Anhang). Entsprechend separieren wir zwischen zwei Regionstypen, d. h. wir erweitern den bisher verwendeten Vektor $B$ um Interaktionen zwischen einem Indikator für schwach besiedelte Regionen und den Variablen „Bankverbindung bei Sparkasse“ bzw. „Bankverbindung bei Genossenschaftsbank““41 Die Interaktionsterme im Modell U9 bleiben insignifikant (siehe auch das Modell U11 in Tabelle A.6 im Anhang mit kontinuierlichen Interaktionstermen und konsistenten Resultaten). Die Tests am unteren Tabellenende zeigen, dass sowohl in schwach besiedelten als auch in verdichteten Kreisregionen Sparkassen- sowie Genossenschaftsbankverbindungen positive Effekte haben. Es ergibt sich auch für beide Regionstypen, dass sich diese Effekte nicht signifikant voneinander unterscheiden, aber signifikant vom Effekt der Kreditbankanbindungen abweichen. Folglich können die hier im Mittelpunkt stehenden Regressionsergebnisse nicht darauf zurückgeführt werden, dass Unternehmensgründer in schwächer besiedelten Regionen aufgrund hoher Präsenz von Sparkassen und Genossenschaftsbanken häufiger Bankverbindungen zu Banken dieser Gruppen haben und unabhängig von den bestehenden Bankverbindungen langfristige Kredite aus DtAProgrammen verstärkt in diese Regionen fließen. Dies unterstützt unsere Ansicht, dass die berichteten Ergebnisse auf Unterschiede in der Kreditvergabebereitschaft der drei Bankgruppen zurückgehen.

\subsection{Diskussion der empirischen Resultate zur bankgruppenspezifischen Kreditvergabe}

Die Ergebnisse unserer empirischen Regressionsanalysen für bankgruppenspezifische Variablen bleiben robust beim Wechsel von Regions- zu Unternehmensdaten und bei allen getesteten Veränderungen des Analysezeitraums, der Schätzmethode und der Spezifikation endogener sowie erklärenden Variablen. Insgesamt zeigt sich eindeutig, dass Hypothese 2 aus Abschnitt 2.3 nicht verworfen wird, wohl aber die Hypothesen 1 und 3.

Um Hypothese $1 \mathrm{zu}$ testen, haben wir zunächst in Regressionen auf der Ebene westdeutscher Stadt- und Landkreise den Zusammenhang zwischen der regionalen Präsenz von Kreditbanken, gemessen anhand der Kreditbankstellendichte, und der Vergabe langfristiger Kredite, in Form von Förderkreditzusagezahlen bzw. -volumina, im Jahr 1999 untersucht. Es ergeben sich kleine, statistisch nicht signifikant von Null verschiedene Effekte. Regressionen auf Unternehmensebene zeigen, dass schon zu Beginn der 1990er Jahre bei jungen, kleinen Unternehmen in Westdeutschland die unternehmensspezifische Wahrscheinlichkeit einer

41 Der Indikator für schwach besiedelte Kreisregionen nimmt den Wert „1“ an, wenn die Bevölkerungsdichte am Unternehmensstandort unter bzw. am Stichprobenmedian (458 Einwohner pro km²) liegt, ansonsten „0“. 
Förderkreditzusage und die Höhe der vergebenen Kredite nicht dadurch beeinflusst werden, ob bei der Unternehmensgründung Bankverbindungen zu Kreditbanken bestehen. Die Ergebnisse auf Regions- und Unternehmensebene zusammennehmend, finden wir keine Hinweise auf eine statistisch signifikante, quantitativ relevante Veränderung des Kreditvergabeverhaltens von Kreditbanken im Falle von Förderkrediten für junge, kleine Unternehmen und lehnen Hypothese 1 aus Abschnitt 2.3 ab. Unsere Ergebnisse legen nahe, dass wir für junge, kleine Unternehmen eine Verschlechterung des Kreditzugangs und den vermuteten Rückzug der Kreditbanken im Verlauf der 1990er Jahre deshalb nicht nachweisen können, weil Kreditbanken im Kreditgeschäft mit solchen Unternehmen schon Anfang der 1990er Jahre kaum eine Rolle mehr spielten. Die Globalisierung auf Kapitalmärkten, die Konsolidierung im Banksektor und frühe Anpassungen an die Basel-II-Regulierung mögen dazu geführt haben, dass Kreditbanken während der 1990er Jahre ihre Kreditvergabe an größere, mittelständische Unternehmen substantiell verändert haben. Diese Unternehmensgruppe untersuchen wir hier aber nicht.

Im Einklang mit Hypothese 2 finden wir für die 1990er Jahre, dass junge, kleine Unternehmen, die bei ihrer Gründung über Bankverbindungen zu Sparkassen oder Genossenschaftsbanken verfügen, signifikant und substantiell häufiger Förderkredite bzw. höhere Kreditvolumina erhalten als Unternehmensgründungen ohne solche Bankverbindungen. Die signifikant positiven Koeffizienten für diese Bankverbindungen weichen auch systematisch von den kleinen, statistisch nicht signifikant von Null verschiedenen Koeffizienten für Bankverbindungen zu Kreditbanken ab. Auch unsere Ergebnisse auf Regionsebene für das Jahr 1999 korrespondieren mit den Ergebnissen auf Unternehmensebene. Insgesamt entsprechen die empirischen Ergebnisse unserer Erwartung, dass diese beiden Bankgruppen, die regional verankert sind und sich auf Bankkunden in ihrer Region konzentrieren, substantiell zur Kreditvergabe an KMU und junge Unternehmen beitragen. Entsprechend der Herleitung von Hypothese 2 in Abschnitt 2.3 lassen sich unsere Ergebnisse damit erklären, dass Sparkassen und Genossenschaftsbanken komparative Vorteile nutzen, die aufgrund räumlicher Nähe und dezentraler Organisationsform bei Kreditvergabeentscheidungen basierend auf weichen, schwer verifizierbaren Informationen und bei Relationship Lending entstehen. Weiterhin weisen beide Bankgruppen eine historisch vorgegebene Regions- und Mittelstandsorientierung auf.

Zur Überprüfung von Hypothese 3 testen wir, ob Unterschiede zwischen den Effekten bestehen, die sich für Sparkassen- und Genossenschaftsbankvariablen ergeben. Auf Unternehmensebene finden wir für die 1990er Jahre auch nach Kontrolle für zahlreiche 
regions- und unternehmensspezifische Merkmale, dass sich deren Wirkungen auf unternehmensspezifische Zusagewahrscheinlichkeiten von Förderkrediten oder auf bewilligte Kreditvolumina statistisch nicht unterscheiden. Analoge Testergebnisse resultieren auch auf Regionsebene für das Jahr 1999. Insgesamt ergeben sich also in unseren empirischen Untersuchungen zur Vergabe langfristiger Kredite in Form von Förderkrediten an junge, kleine Unternehmen keine Hinweise dafür, dass sich unterschiedliche Eigentümerstrukturen bei regional operierenden Banken mit dezentraler Organisationsform in unterschiedlichen Kreditvergabeentscheidungen niederschlagen. Die Kreditvergabe durch Sparkassen mit öffentlich-rechtlicher Trägerschaft, öffentlicher Beauftragung, öffentlich-rechtlicher Rechtsform und begünstigenden Haftungsregelungen während der 1990er Jahre und die Kreditvergabe durch privatwirtschaftlich organisierte Genossenschaftsbanken gleichen sich vielmehr.

\section{$5 \quad$ Zusammenfassung und Schlussfolgerungen}

In diesem Beitrag untersuchen wir die Rolle von Genossenschaftsbanken, Kreditbanken und Sparkassen bei der Vergabe langfristiger Kredite an junge, kleine Unternehmen. Dies geschieht am Beispiel langfristiger Kredite aus öffentlichen Förderprogrammen, die von der DtA verwaltet werden und einen hohen Anteil an allen langfristigen Bankkrediten für junge Unternehmen und KMU in Deutschland ausmachen. Sowohl Genossenschaftsbanken, Kreditbanken als auch Sparkassen sind in die Allokation dieser klar definierten Kreditart involviert. Wir argumentieren, dass Banken bei der Vergabe langfristiger Kreditfinanzierungen mit Förderkrediten ähnliche Entscheidungskriterien anlegen wie bei vollständig bankeigenen Finanzierungen. Gründe hierfür sind, dass Banken bei Förderkrediten im Untersuchungszeitraum in Westdeutschland oft einen Teil des Ausfallrisikos übernehmen, dass Förderkredite häufig durch bankeigene Kredite ergänzt werden und dass im Wettbewerb stehende Banken rational agierenden Kunden Förderkredite mit günstigen Zins- und Tilgungskonditionen kaum vorenthalten können. Für die empirischen Analysen verwenden wir detaillierte Mikrodaten aus den Jahren 1990 bis 1999 für 6.880 westdeutsche Unternehmen mit einem Gründungsdatum zwischen 1990 und 1993 und aggregierte Regionsdaten für das Jahr 1999 auf der Ebene westdeutscher Stadt- und Landkreise.

Basierend auf unseren Regressionsanalysen zur Vergabe langfristiger Kredite in Form von Förderkrediten an junge, kleine Unternehmen in Westdeutschland während der 1990er Jahre fassen wir unsere Ergebnisse wie folgt zusammen: 
1. Kreditbanken spielen im gesamten Zeitraum der 1990er Jahre eine gleichbleibend marginale Rolle bei der Vergabe langfristiger Kredite an junge, kleine Unternehmen in Westdeutschland, untersucht am Beispiel von Förderkrediten.

2. Regional operierende Banken mit dezentraler Organisationsform, d. h. Sparkassen und Genossenschaftsbanken, haben hingegen eine große Bedeutung, die substantiell über die der Kreditbanken hinausgeht.

3. Unterschiede bei der Kreditvergabe durch Sparkassen und Genossenschaftsbanken lassen sich trotz unterschiedlicher Eigentümerstrukturen und öffentlich-rechtlicher Trägerschaft der Sparkassen nicht nachweisen.

Die empirischen Ergebnisse unserer Studie sind von Interesse im Rahmen der anhaltenden Debatte über Restrukturierungen im deutschen Banksystem, in der Organisationen wie der Internationale Währungsfond, die Monopolkommission, der Sachverständigenrat und die Deutsche Bundesbank immer wieder Reformen für die Sparkassengruppe fordern und die Wettbewerbs- und Subventionskontrolle der EU seit Jahren entsprechend agiert. Besonders wichtig sind in diesem Kontext die robusten Hinweise der Regressionsanalysen darauf, dass Sparkassen und Genossenschaftsbanken, d. h. regional operierende Banken mit dezentraler Organisationsform, trotz unterschiedlicher Eigentümerstrukturen eine ähnlich substantielle Bedeutung bei der Kreditvergabe an junge, kleine Unternehmen zukommt. Unsere Ergebnisse stützen die Sichtweise, dass eine Reformierung der Eigentümerstrukturen von Sparkassen, die eine Abkehr von öffentlich-rechtlicher Rechtsform, öffentlich-rechtlicher Trägerschaft und begünstigenden Haftungsregelungen beinhaltet, nicht zu der oftmals befürchteten Reduktion der Kreditvergabe an junge Unternehmen und KMU führt, wenn eine zentrale Bedingung erfüllt wird: Regional operierende Banken mit dezentraler Organisationsform müssten ihre Bedeutung bei der Kreditvergabe an junge Unternehmen und KMU ähnlich wie bisher behalten oder andere Banken müssten in vergleichbarer Weise wirken.

Grundlegende Reformen öffentlich-rechtlicher Banken und Bankgruppen, wie sie in mehreren anderen europäischen Ländern in den letzten 20 bis 30 Jahren stattgefunden haben ${ }^{42}$ und in Deutschland möglicherweise bevorstehen, sind zweifelsohne komplexe Unterfangen. Beispielsweise ist davon auszugehen, dass die oben genannte Bedingung nur bei funktionierendem Wettbewerb im Kreditvergabebereich erfüllt werden kann. Detaillierte

42 Dort wurden Sparkassen zumeist in private Rechtsformen überführt, das Regionalprinzip gelockert und in unterschiedlichem Ausmaß Bankgeschäft, Politik und öffentliche Aufgabe entflochten. Dabei wurden oft auch grundlegende Reformen des Banksystems insgesamt implementiert (Brunner et al., 2004; Sachverständigenrat, 2004). 
Evidenz zum Wettbewerb bei der Kreditvergabe in Deutschland und Analysen unter Ausnutzung zurückliegender Reformen in anderen europäischen Ländern sind hier ergänzend heranzuziehen, um konkrete Reformmaßnahmen ableiten zu können. 
Abbildung 1: Kreditzusagen und bewilligtes Kreditvolumen im Förderbereich Existenz- und Unternehmensgründung der Deutschen Ausgleichsbank, Westdeutschland, 1990-2002

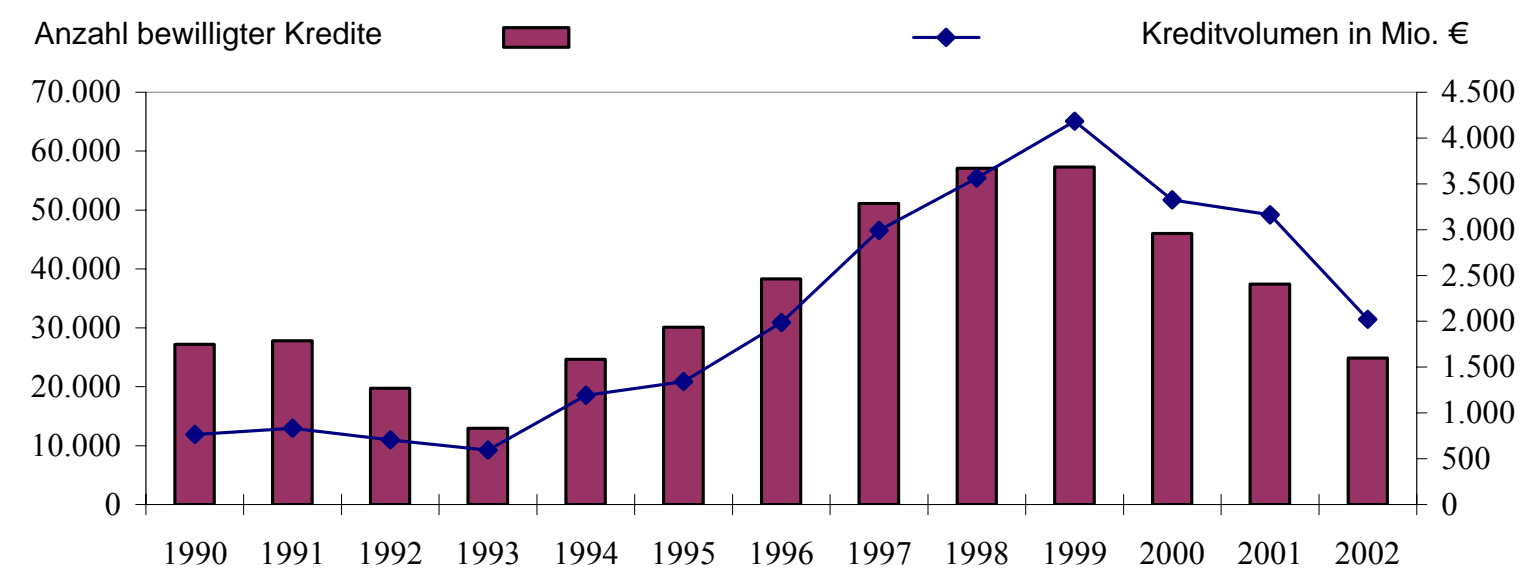

Quellen: $\quad$ Eigene Darstellung basierend auf Angaben der DtA Förderreporte 2001 und 2003. 
Tabelle 1: $\quad$ Panel 1: Anteile der Bankgruppen am Bestand langfristiger Bankkredite an Unternehmen insgesamt (in \%), West- bzw. Gesamtdeutschland, 1987-2005

\begin{tabular}{lccccccc}
\hline Bankgruppe & $\mathbf{1 9 8 7}$ & $\mathbf{1 9 9 0}$ & $\mathbf{1 9 9 3}$ & $\mathbf{1 9 9 6}$ & $\mathbf{1 9 9 9}$ & $\mathbf{2 0 0 2}$ & $\mathbf{2 0 0 5}$ \\
\hline Genossenschaftsbankgruppe insgesamt & 13,1 & 11,8 & 11,0 & 11,3 & 11,4 & 11,4 & 11,6 \\
davon: Genossenschaftsbanken & 9,7 & 7,7 & 7,8 & 8,1 & 7,3 & 7,8 & 8,9 \\
$\quad$ genossenschaftliche Zentralbanken & 3,4 & 4,1 & 3,2 & 3,2 & 4,1 & 3,7 & 2,7 \\
Kreditbankgruppe & 30,2 & 46,6 & 32,1 & 33,5 & 30,4 & 29,3 & 27,5 \\
Sparkassengruppe insgesamt & 56,7 & 41,5 & 56,9 & 55,1 & 58,2 & 59,3 & 60,9 \\
davon: Sparkassen & 25,5 & 20,0 & 23,0 & 22,0 & 21,5 & 23,2 & 25,5 \\
$\quad$ Landesbanken & 31,2 & 21,6 & 33,8 & 33,2 & 36,7 & 36,1 & 35,9 \\
\hline
\end{tabular}

Panel 2: Anteile der Bankgruppen am Bestand langfristiger Bankkredite an das Handwerk (in \%), West- bzw. Gesamtdeutschland, 1987-2005

\begin{tabular}{lccccccc}
\hline Bankgruppe & $\mathbf{1 9 8 7}$ & $\mathbf{1 9 9 0}$ & $\mathbf{1 9 9 3}$ & $\mathbf{1 9 9 6}$ & $\mathbf{1 9 9 9}$ & $\mathbf{2 0 0 2}$ & $\mathbf{2 0 0 5}$ \\
\hline Genossenschaftsbankgruppe insgesamt & 23,3 & 23,7 & 19,7 & 19,3 & 19,0 & 17,1 & 16,4 \\
davon: Genossenschaftsbanken & 23,2 & 21,5 & 19,6 & 19,1 & 18,8 & 17,0 & 16,3 \\
$\quad$ genossenschaftiche Zentralbanken & 0,1 & 2,2 & 0,1 & 0,2 & 0,2 & 0,2 & 0,1 \\
Kreditbankgruppe & 8,9 & 10,1 & 10,3 & 10,0 & 8,8 & 10,7 & 10,3 \\
Sparkassengruppe insgesamt & 67,8 & 66,3 & 70,0 & 70,7 & 72,2 & 72,2 & 73,3 \\
davon: Sparkassen & 63,9 & 62,1 & 64,7 & 66,0 & 65,9 & 65,8 & 68,4 \\
$\quad$ Landesbanken & 3,9 & 4,2 & 5,3 & 4,7 & 6,4 & 6,4 & 4,9 \\
\hline
\end{tabular}

Quellen: Eigene Berechnungen basierend auf Angaben der Deutschen Bundesbank zu Beständen langfristiger Kredite in Mill. $€$ jeweils im vierten Jahresquartal (http://www.bundesbank.de/statistik/statistik_zeitreihen.php).

Anmerkungen: Die Angaben für 1987 beziehen sich auf West-, die Angaben ab 1990 auf Gesamtdeutschland. Ein Anteilswert gibt an, welchen Anteil die jeweils betrachtete Bank(teil)gruppe am jeweiligen Kreditbestand der drei Bankgruppen hält. Der von sonstigen Banken (Banken mit Sonderauftrag, Realkreditinstitute) gehaltene Anteil am Kreditbestand aller Bankgruppen beträgt bei langfristigen Bankkrediten an Unternehmen insgesamt im betrachteten Zeitraum gleichbleibend etwa 30\% und bei langfristigen Bankkrediten an das Handwerk etwa $10 \%$.

Tabelle 2: $\quad$ Anteile der Bankgruppen am neu zugesagten Kreditvolumen im Förderbereich Existenz- und Unternehmensgründung der Deutschen Ausgleichsbank (in \%), Westdeutschland, 1990-2002

\begin{tabular}{lccccccc}
\hline Bankgruppe & $\mathbf{1 9 9 0}$ & $\mathbf{1 9 9 2}$ & $\mathbf{1 9 9 4}$ & $\mathbf{1 9 9 6}$ & $\mathbf{1 9 9 8}$ & $\mathbf{2 0 0 0}$ & $\mathbf{2 0 0 2}$ \\
\hline Genossenschaftsbanken & 35,8 & 39,2 & 45,5 & 47,6 & 40,0 & 36,0 & 36,5 \\
Kreditbanken & 25,0 & 18,0 & 14,6 & 14,1 & 15,4 & 13,0 & 11,6 \\
Sparkassen & 39,2 & 42,8 & 39,9 & 38,3 & 44,6 & 51,0 & 51,9 \\
\hline
\end{tabular}

Quellen: Eigene Darstellung basierend auf Jahresangaben der DtA Förderreporte 2000, 2001 und 2003.

Anmerkungen: An der Vergabe von DtA-Förderkrediten sind abgesehen von Einzelfällen nur Banken der hier aufgeführten Bankgruppen beteiligt. 
Tabelle 3: Determinanten der Vergabe von Förderkrediten aus DtA-Programmen Regressionsmodelle R1-R3 (Kreisdaten)

\begin{tabular}{|c|c|c|c|}
\hline \multirow{2}{*}{$\begin{array}{l}\text { Endogene Variable } \\
\text { Modell }\end{array}$} & \multicolumn{2}{|c|}{ Förderkreditzusagen (ln) } & \multirow{2}{*}{$\begin{array}{c}\begin{array}{c}\text { Förderkreditsumme } \\
\text { (ln) }\end{array} \\
\text { R3 } \\
\end{array}$} \\
\hline & $\mathbf{R} 1$ & R2 & \\
\hline Exogene Variable & $\begin{array}{c}\text { Parameter } \\
\text { (Standardfehler) }\end{array}$ & $\begin{array}{c}\text { Parameter } \\
\text { (Standardfehler) }\end{array}$ & $\begin{array}{c}\text { Parameter } \\
\text { (Standardfehler) }\end{array}$ \\
\hline \multicolumn{4}{|l|}{ Logarithmierte Dichte von ... } \\
\hline Sparkassenbankstellen & $\mathbf{0 , 2 0 7}(0,058)^{* * *}$ & $\mathbf{0 , 2 2 3}(0,058)^{* * *}$ & $\mathbf{0 , 2 4 2}(0,073)^{* * *}$ \\
\hline Genossenschaftsbankstellen & $\mathbf{0 , 1 4 4}(0,085)^{*}$ & $\mathbf{0 , 1 3 9}(0,075)^{*}$ & $\mathbf{0 , 1 8 8}(0,089)^{* *}$ \\
\hline Kreditbankstellen & $\mathbf{0 , 0 0 6}(0,049)$ & $\mathbf{- 0 , 0 4 3}(0,047)$ & $\mathbf{- 0 , 0 2 5}(0,053)$ \\
\hline Zahl der Gründungen (ln) & $\mathbf{0 , 8 0 6}(0,062)^{* * *}$ & $\mathbf{0 , 8 6 1}(0,052)^{* * *}$ & $\mathbf{0 , 8 6 4}(0,061)^{* * *}$ \\
\hline Einwohnerdichte $(\ln )$ & $\mathbf{- 0 , 1 3 6}(0,053)^{* *}$ & $\mathbf{- 0 , 0 7 9}(0,053)$ & $\mathbf{- 0 , 0 3 5}(0,070)$ \\
\hline \multicolumn{4}{|l|}{ Anteil neuer Unternehmen... } \\
\hline mit zwei Beschäftigten & 1 & $\mathbf{1 , 5 8 2}(0,504)^{* * *}$ & $\mathbf{1 , 6 0 5}(0,600)^{* * *}$ \\
\hline mit mehr als zwei Beschäftigten & / & $\mathbf{1 , 4 7 4}(0,378)^{* * *}$ & $\mathbf{1 , 0 3 9}(0,467)^{* *}$ \\
\hline im verarbeitenden Gewerbe & 1 & $2,495(1,131)^{* *}$ & $2,370(1,373)^{*}$ \\
\hline im Baugewerbe & / & $\mathbf{- 1 , 0 2 4}(0,738)$ & $\mathbf{0 , 6 8 7}(0,805)$ \\
\hline im Großhandel & / & $\mathbf{- 0 , 0 2 0}(1,115)$ & $\mathbf{0 , 0 2 7}(1,371)$ \\
\hline in Verkehr/Nachrichten & / & $\mathbf{0 , 9 4 6}(1,069)$ & $\mathbf{1 , 8 5 5}(1,217)$ \\
\hline in unternehmensnahen Dienstl. & l & $\mathbf{- 0 , 9 7 5}(0,801)$ & $\mathbf{0 , 0 7 4}(0,975)$ \\
\hline in sonstigen Dienstleistungen & / & $-\mathbf{1 , 5 6 6}(0,626)^{* *}$ & $\mathbf{- 1 , 3 4 7}(0,745)^{*}$ \\
\hline \multicolumn{4}{|l|}{ an allen neuen Unternehmen im Kreis } \\
\hline Konstante & $\mathbf{0 , 2 7 7}(0,350)$ & $\mathbf{- 0 , 4 5 5}(0,495)$ & $3,532(0,625)^{* * *}$ \\
\hline $\begin{array}{l}\text { Breusch-Pagan-Test }\left(\chi^{2}\right), \\
\mathrm{H}^{0} \text { : Homoskedastie }\end{array}$ & 2,66 & $7,25^{* * *}$ & 0,35 \\
\hline $\mathrm{F}-$ Test $, \mathrm{H}^{0}: \beta^{\text {Gründungszahl }}=1$ & $9,69^{* * *}$ & $7,19^{* * *}$ & $5,03^{* * *}$ \\
\hline $\mathrm{F}-\mathrm{Test}, \mathrm{H}^{0}: \beta^{\text {Bundeslanddummies }}=0$ & $10,02^{* * *}$ & $8,12^{* * *}$ & $10,65^{* * *}$ \\
\hline F-Test, $H^{0}: \beta^{\text {Spark.dichte }}=\beta^{\text {Gen.bankdichte }}$ & 0,33 & 0,68 & 0,19 \\
\hline $\mathrm{F}-\mathrm{Test}, \mathrm{H}^{0}: \beta^{\text {Spark.dichte }}=\beta^{\text {Kreditbankdichte }}$ & $8,57^{* * *}$ & $14,46^{* * *}$ & $10,24^{* * *}$ \\
\hline F-Test, $\mathrm{H}^{0}: \beta^{\text {Gen.bankdichte }=} \beta^{\text {Kreditbankdichte }}$ & 1,81 & $3,91^{* *}$ & $4,02^{* *}$ \\
\hline Zahl der Beobachtungen & 325 & 325 & 325 \\
\hline Korrigiertes $\mathbf{R}^{2}$ in \% & 68,22 & 73,56 & 68,17 \\
\hline
\end{tabular}

Quellen: Eigene Berechnungen basierend auf Daten der DtA, des ZEW, der Deutschen Bundesbank und des Bundesamts für Bauwesen und Raumordnung.

Anmerkungen: Die Tabelle enthält OLS-Schätzergebnisse. Die Standardfehler sind heteroskedastierobust nach dem Huber-White-Verfahren (Greene, 2008). ${ }^{* * *}\left(* *,{ }^{*}\right)$ zeigt Signifikanz auf dem $1(5,10) \%$-Niveau an. 
Tabelle 4: Determinanten der Vergabe von Förderkrediten aus DtA-Programmen Regressionsmodelle U1-U3 (Unternehmensdaten)

\begin{tabular}{|c|c|c|c|}
\hline \multirow{2}{*}{$\begin{array}{l}\text { Endogene Variable } \\
\text { Modell }\end{array}$} & \multicolumn{2}{|c|}{ Förderkreditindikator } & \multirow{2}{*}{$\begin{array}{c}\begin{array}{c}\text { Förderkreditsumme } \\
\text { (ln) }\end{array} \\
\text { U3 } \\
\end{array}$} \\
\hline & U1 & U2 & \\
\hline Exogene Variable & $\begin{array}{c}\text { Parameter } \\
\text { (Standardfehler) }\end{array}$ & $\begin{array}{c}\text { Parameter } \\
\text { (Standardfehler) }\end{array}$ & $\begin{array}{c}\text { Parameter } \\
\text { (Standardfehler) }\end{array}$ \\
\hline \multicolumn{4}{|l|}{ Bankverbindung bei ... } \\
\hline Sparkasse (S) & $\mathbf{0 , 1 3 8}(0,060)^{* *}$ & $\mathbf{0 , 1 3 9}(0,061)^{* *}$ & $\mathbf{0 , 0 8 3}(0,038)^{* *}$ \\
\hline Genossenschaftsbank (G) & $\mathbf{0 , 1 5 9}(0,053)^{* * *}$ & $\mathbf{0 , 1 5 7}(0,055)^{* * *}$ & $\mathbf{0 , 1 1 3}(0,033)^{* * *}$ \\
\hline S-/G-Zentralinstitut & $\mathbf{- 0 , 1 5 6}(0,140)$ & $\mathbf{- 0 , 1 9 5}(0,141)$ & $\mathbf{- 0 , 0 7 6}(0,068)$ \\
\hline Kreditbank & $\mathbf{- 0 , 0 2 3}(0,056)$ & $\mathbf{- 0 , 0 3 8}(0,058)$ & $\mathbf{- 0 , 0 0 2}(0,044)$ \\
\hline Anzahl der Bankverbindungen & $\mathbf{0 , 1 0 1}(0,054)^{*}$ & $\mathbf{0 , 0 8 8}(0,054)$ & $\mathbf{0 , 0 5 1}(0,030)^{*}$ \\
\hline Bankstellendichte & $\mathbf{0 , 1 2 4}(0,067)^{*}$ & $\mathbf{0 , 1 4 6}(0,071)^{* *}$ & $\mathbf{0 , 1 6 1}(0,059)^{* * *}$ \\
\hline Einwohnerdichte & $\mathbf{- 0 , 1 3 1}(0,033)^{* * *}$ & $\mathbf{- 0 , 1 0 7}(0,036)^{* * *}$ & $\mathbf{- 0 , 0 4 3}(0,016)^{* * *}$ \\
\hline Unternehmensbeteiligung & $1 \quad 1$ & $\mathbf{- 0 , 3 0 6}(0,134)^{* *}$ & $\mathbf{- 0 , 1 6 0}(0,067)^{* *}$ \\
\hline Teamgründung & / & $\mathbf{0 , 1 7 1}(0,077)^{* *}$ & $\mathbf{0 , 0 8 5}(0,053)$ \\
\hline Meister-/Hochschulabschluss & / & $\mathbf{0 , 3 4 5}(0,057)^{* * *}$ & $\mathbf{0 , 2 6 1}(0,048)^{* * *}$ \\
\hline fehlende Humankapitalangabe & / & $\mathbf{0 , 0 1 8}(0,055)$ & $\mathbf{0 , 0 0 6}(0,033)$ \\
\hline BGB-Gesellschaft & i & $\mathbf{- 0 , 2 0 7}(0,106)^{*}$ & $\mathbf{- 0 , 1 4 1}(0,069)^{* *}$ \\
\hline GmbH oder AG & / & $\mathbf{- 0 , 1 2 0}(0,070)^{*}$ & $\mathbf{- 0 , 0 5 6}(0,045)$ \\
\hline Mitarbeiterzahl (ln) & / & $\mathbf{0 , 1 8 5}(0,075)^{* *}$ & $\mathbf{0 , 1 5 3}(0,041)^{* * *}$ \\
\hline Mitarbeiterzahl (ln, quadriert) & $1 \quad 1$ & $\mathbf{- 0 , 0 6 8}(0,024)^{* * *}$ & $\mathbf{- 0 , 0 3 9}(0,011)^{* * *}$ \\
\hline Konstante & $\mathbf{- 1 , 6 9 9}(0,168)^{* * *}$ & $-\mathbf{1 , 6 1 3}(0,182)^{* * *}$ & $\mathbf{0 , 0 6 6}(0,111)$ \\
\hline$\chi^{2}$-Test, $H^{0}: \beta^{\text {Bundeslanddummies }}=0$ & 10,89 & 4,79 & 1,21 \\
\hline$\chi^{2}$-Test, $\mathrm{H}^{0}: \beta^{\text {Kohortendummies }}=0$ & l & $25,24^{* * *}$ & $8,48^{* * *}$ \\
\hline$\chi^{2}$-Test, $\mathrm{H}^{0}: \beta^{\text {Branchendummies }}=0$ & / & $128,60^{* * *}$ & $17,36^{* * *}$ \\
\hline$\chi^{2}$-Test, $H^{0}: \beta^{\text {Spark.verb. }}=\beta^{\text {Gen.bankverb. }}$ & 0,11 & 0,08 & 0,61 \\
\hline$\chi^{2}$-Test, $H^{0}: \beta^{\text {Spark.verb. }}=\beta^{\text {Kreditbankverb. }}$ & $5,58^{* *}$ & $6,39^{* *}$ & $3,30^{*}$ \\
\hline$\chi^{2}$-Test, $H^{0}: \beta^{\text {Gen.bankverb. }}=\beta^{\text {Kreditbankverb. }}$ & $7,97^{* * *}$ & $8,65^{* * *}$ & $5,89^{* *}$ \\
\hline Zahl der Beobachtungen & 6.880 & 6.880 & 6.880 \\
\hline Log likelihood-Wert & $-2.218,55$ & $-2.085,97$ & / \\
\hline Pseudo bzw. korrigiertes $R^{2}$ in \% & 3,13 & 8,92 & 5,88 \\
\hline
\end{tabular}

Quellen: Eigene Berechnungen basierend auf Daten der DtA, des ZEW, der Deutschen Bundesbank und des Bundesamts für Bauwesen und Raumordnung.

Anmerkungen: Die Modelle U1 und U2 sind Probit-Modelle. Das Modell U3 ist ein OLS-Modell und das korrespondierende Tobit-Modell U10 wird in Tabelle A.6 im Anhang gezeigt. Die Standardfehler sind robust, nach Kreisregionen geclustert und berücksichtigen die disproportional geschichtete Stichprobenziehungsregel. $* * *(* *, *)$ zeigt Signifikanz auf dem $1(5,10) \%$-Niveau an. 
Tabelle 5: Determinanten der Vergabe von Förderkrediten aus DtA-Programmen Varianten des Modells U2 in Tabelle 4 (Unternehmensdaten)

\begin{tabular}{|c|c|c|c|}
\hline \multirow[t]{2}{*}{ Endogene Variable } & \multicolumn{3}{|c|}{ Förderkreditindikator } \\
\hline & $\begin{array}{c}\text { verkürzter Zeitraum } \\
1990-1994\end{array}$ & $\begin{array}{c}\text { erweiterter Zeitraum } \\
1990-1999\end{array}$ & $\begin{array}{c}\text { Verengte } \\
\text { Kreditabgrenzung }\end{array}$ \\
\hline Modell & U4 & U5 & U6 \\
\hline Exogene Variable & $\begin{array}{c}\text { Parameter } \\
\text { (Standardfehler) }\end{array}$ & $\begin{array}{c}\text { Parameter } \\
\text { (Standardfehler) }\end{array}$ & $\begin{array}{c}\text { Parameter } \\
\text { (Standardfehler) }\end{array}$ \\
\hline \multicolumn{4}{|l|}{ Bankverbindung bei . } \\
\hline Sparkasse (S) & $\mathbf{0 , 1 5 7}(0,061)^{* * *}$ & $\mathbf{0 , 0 9 7}(0,060)$ & $\mathbf{0 , 1 1 4}(0,061)^{*}$ \\
\hline Genossenschaftsbank $(\mathrm{G})$ & $\mathbf{0 , 1 3 7}(0,057)^{* *}$ & $\mathbf{0 , 1 5 0}(0,054)^{* * *}$ & $\mathbf{0 , 1 4 0}(0,056)^{* *}$ \\
\hline S-/G-Zentralinstitut & $\mathbf{- 0 , 1 5 0}(0,140)$ & $\mathbf{- 0 , 2 3 9}(0,141)^{*}$ & $\mathbf{- 0 , 1 7 8}(0,141)$ \\
\hline Kreditbank & $\mathbf{- 0 , 0 0 8}(0,061)$ & $\mathbf{- 0 , 0 3 2}(0,057)$ & $\mathbf{- 0 , 0 2 7}(0,058)$ \\
\hline Anzahl der Bankverbindungen & $\mathbf{0 , 0 8 4}(0,055)$ & $\mathbf{0 , 0 8 1}(0,051)$ & $\mathbf{0 , 1 0 9}(0,054)^{* *}$ \\
\hline Bankstellendichte & $\mathbf{0 , 1 3 0}(0,074)^{*}$ & $\mathbf{0 , 1 2 1}(0,068)^{*}$ & $\mathbf{0 , 1 4 2}(0,076)^{*}$ \\
\hline Einwohnerdichte & $\mathbf{- 0 , 1 1 3}(0,035)^{* * *}$ & $\mathbf{- 0 , 1 2 0}(0,033)^{* * *}$ & $\mathbf{- 0 , 1 0 8}(0,034)^{* * *}$ \\
\hline Unternehmensbeteiligung & $\mathbf{- 0 , 4 1 7}(0,131)^{* * *}$ & $\mathbf{- 0 , 3 2 6}(0,130)^{* *}$ & $\mathbf{- 0 , 2 5 7}(0,135)^{*}$ \\
\hline Teamgründung & $\mathbf{0 , 1 6 4}(0,080)^{* *}$ & $\mathbf{0 , 2 1 4}(0,071)^{* * *}$ & $\mathbf{0 , 1 6 8}(0,076)^{* *}$ \\
\hline Meister-/Hochschulabschluss & $\mathbf{0 , 3 3 6}(0,059)^{* * *}$ & $\mathbf{0 , 3 3 0}(0,059)^{* * *}$ & $\mathbf{0 , 3 2 2}(0,058)^{* * *}$ \\
\hline fehlende Humankapitalangabe & $\mathbf{- 0 , 0 1 6}(0,057)$ & $\mathbf{- 0 , 0 0 4}(0,053)$ & $\mathbf{0 , 0 1 2}(0,056)$ \\
\hline BGB-Gesellschaft & $-\mathbf{0 , 2 3 7}(0,112)^{* *}$ & $\mathbf{- 0 , 2 5 7}(0,100)^{* * *}$ & $\mathbf{- 0 , 2 1 1}(0,113)^{*}$ \\
\hline GmbH oder AG & $\mathbf{- 0 , 1 2 1}(0,072)^{*}$ & $\mathbf{- 0 , 0 9 8}(0,064)$ & $\mathbf{- 0 , 1 4 5}(0,071)^{* *}$ \\
\hline Mitarbeiterzahl (ln) & $\mathbf{0 , 2 1 6}(0,081)^{* * *}$ & $\mathbf{0 , 1 9 8}(0,076)^{* * *}$ & $\mathbf{0 , 2 0 2}(0,078)^{* * *}$ \\
\hline Mitarbeiterzahl (ln, quadriert) & $\mathbf{- 0 , 0 8 0}(0,027)^{* * *}$ & $\mathbf{- 0 , 0 7 5}(0,025)^{* * *}$ & $\mathbf{- 0 , 0 7 2}(0,026)^{* * *}$ \\
\hline Konstante & $\mathbf{- 1 , 6 1 5}(0,184)^{* * *}$ & $\mathbf{- 1 , 4 9 8}(0,174)^{* * *}$ & $\mathbf{- 1 , 7 1 2}(0,186)^{* * *}$ \\
\hline$\chi^{2}$-Test, $H^{0}: \beta^{\text {Bundeslanddummies }}=0$ & 4,23 & 3,62 & 4,48 \\
\hline$\chi^{2}$-Test, $H^{0}: \beta^{\text {Kohortendummies }}=0$ & $28,10^{* * *}$ & $28,30^{* * *}$ & $22,10^{* * *}$ \\
\hline$\chi^{2}$-Test, $H^{0}: \beta^{\text {Branchendummies }}=0$ & $126,34^{* * *}$ & $130,18^{* * *}$ & $115,38^{* * *}$ \\
\hline$\chi^{2}$-Test, $H^{0}: \beta^{\text {Spark.verb. }}=\beta^{\text {Gen.bankverb. }}$ & 0,10 & 0,64 & 0,15 \\
\hline$\chi^{2}$-Test, $\mathrm{H}^{0}: \beta^{\text {Spark.verb. }}=\beta^{\text {Kreditbankverb. }}$ & $5,06^{* *}$ & $3,40^{*}$ & $4,14^{* *}$ \\
\hline$\chi^{2}$-Test, $H^{0}: \beta^{\text {Gen.bankverb. }}=\beta^{\text {Kreditbankverb. }}$ & $4,12^{* *}$ & $7,86^{* * *}$ & $6,04^{* *}$ \\
\hline Zahl der Beobachtungen & 6.880 & 6.880 & 6.880 \\
\hline Log likelihood-Wert & $-1.971,75$ & $-2.218,45$ & $-2017,57$ \\
\hline Pseudo $R^{2}$ in \% & 9,17 & 8,78 & 8,51 \\
\hline
\end{tabular}

Quellen: Eigene Berechnungen basierend auf Daten der DtA, des ZEW, der Deutschen Bundesbank und des Bundesamts für Bauwesen und Raumordnung.

Anmerkungen: Die Tabelle enthält Probit-Schätzergebnisse. Die Berechnung der endogenen Variable im Modell U4 basiert nur auf Kreditzusagen im Gründungsjahr und dem folgenden Jahr und im Modell U5 auf allen Zusagen bis Ende des Jahres 1999. Die endogene Variable im Modell U6 ist nicht mit „1“ kodiert, wenn ein gefördertes Unternehmen ausschließlich DtA-Förderkredite aus dem Eigenkapitalhilfe-Programm erhielt, dessen Programmkonditionen keine Einbindung der weiterleitenden Banken in die Übernahme des Ausfallsrisikos vorsehen. Die Standardfehler sind robust, nach Kreisregionen geclustert und berücksichtigen die disproportional geschichtete Stichprobenziehungsregel. $* * *(* *, *)$ zeigt Signifikanz auf dem $1(5,10) \%$ Niveau an. 
Tabelle 6: Determinanten der Vergabe von Förderkrediten aus DtA-Programmen Varianten des Models U2 in Tabelle 4 (Unternehmensdaten)

\begin{tabular}{|c|c|c|c|}
\hline \multirow{2}{*}{$\begin{array}{l}\text { Endogene Variable } \\
\text { Modell }\end{array}$} & \multicolumn{3}{|c|}{ Förderkreditindikator } \\
\hline & U7 & U8 & U9 \\
\hline Exogene Variable & $\begin{array}{c}\text { Parameter } \\
\text { (Standardfehler) }\end{array}$ & $\begin{array}{c}\text { Parameter } \\
\text { (Standardfehler) }\end{array}$ & $\begin{array}{c}\text { Parameter } \\
\text { (Standardfehler) }\end{array}$ \\
\hline \multicolumn{4}{|l|}{ Bankverbindung bei ... } \\
\hline Sparkasse (S) & $\mathbf{0 , 1 3 5}(0,062)^{* *}$ & $\mathbf{0 , 1 5 4}(0,074)^{* *}$ & $\mathbf{0 , 1 6 9}(0,085)^{* *}$ \\
\hline Genossenschaftsbank (G) & $\mathbf{0 , 1 5 3}(0,057)^{* * *}$ & $\mathbf{0 , 1 8 9}(0,066)^{* * *}$ & $\mathbf{0 , 1 5 9}(0,070)^{* *}$ \\
\hline $\mathrm{S} * \mathrm{D}$ (Einw.dichte $\leq$ Median $)$ & / & / & $\mathbf{- 0 , 0 5 5}(0,091)$ \\
\hline$G^{*} \mathrm{D}$ (Einw.dichte $\leq$ Median $)$ & $1 \quad 1$ & $1 \quad 1$ & $\mathbf{0 , 0 0 6}(0,080)$ \\
\hline S-/G-Zentralinstitut & $\mathbf{- 0 , 1 9 0}(0,142)$ & $\mathbf{- 0 , 2 1 2}(0,161)$ & $\mathbf{- 0 , 1 9 9}(0,141)$ \\
\hline Kreditbank & $\mathbf{- 0 , 0 3 0}(0,060)$ & $\mathbf{- 0 , 0 3 8}(0,068)$ & $\mathbf{- 0 , 0 4 1}(0,058)$ \\
\hline Anzahl der Bankverbindungen & $\mathbf{0 , 0 7 0}(0,055)$ & $\mathbf{0 , 0 8 6}(0,062)$ & $\mathbf{0 , 0 8 8}(0,054)$ \\
\hline Bankstellendichte & $\mathbf{0 , 1 3 3}(0,072)^{*}$ & $\mathbf{0 , 1 6 9}(0,082)^{* *}$ & $\mathbf{0 , 1 6 0}(0,078)^{* *}$ \\
\hline Einwohnerdichte & $\mathbf{- 0 , 1 1 1}(0,035)^{* * *}$ & $\mathbf{- 0 , 1 2 6}(0,041)^{* * *}$ & $\mathbf{- 0 , 1 1 9}(0,040)^{* * *}$ \\
\hline Unternehmensbeteiligung & $\mathbf{- 0 , 3 7 5}(0,136)^{* * *}$ & $\mathbf{- 0 , 3 9 8}(0,181)^{* *}$ & $\mathbf{- 0 , 3 0 6}(0,135)^{* *}$ \\
\hline Teamgründung & $\mathbf{0 , 1 8 3}(0,076)^{* *}$ & $\mathbf{0 , 2 8 6}(0,117)^{* *}$ & $\mathbf{0 , 1 7 1}(0,076)^{* *}$ \\
\hline Meister-/Hochschulabschluss & $\mathbf{0 , 3 2 7}(0,058)^{* * *}$ & $\mathbf{0 , 4 1 6}(0,074)^{* * *}$ & $\mathbf{0 , 3 4 4}(0,057)^{* * *}$ \\
\hline fehlende Humankapitalangabe & $\mathbf{0 , 0 4 1}(0,055)$ & $\mathbf{0 , 0 1 2}(0,065)$ & $\mathbf{0 , 0 1 8}(0,055)$ \\
\hline BGB-Gesellschaft & $\mathbf{- 0 , 1 9 7}(0,108)^{*}$ & $\mathbf{- 0 , 3 3 8}(0,142)^{* *}$ & $\mathbf{- 0 , 2 0 8}(0,106)^{* *}$ \\
\hline GmbH oder AG & $\mathbf{- 0 , 1 7 0}(0,072)^{* *}$ & $\mathbf{- 0 , 6 3 9}(0,257)^{* *}$ & $\mathbf{- 0 , 1 2 1}(0,070)^{*}$ \\
\hline Mitarbeiterzahl (ln) & $\mathbf{0 , 2 8 9}(0,077)^{* * *}$ & $\mathbf{0 , 1 9 5}(0,088)^{* *}$ & $\mathbf{0 , 1 8 5}(0,075)^{* *}$ \\
\hline Mitarbeiterzahl (ln, quadriert) & $\mathbf{- 0 , 0 8 3}(0,025)^{* * *}$ & $-\mathbf{0 , 0 7 1}(0,029)^{* *}$ & $\mathbf{- 0 , 0 6 8}(0,024)^{* * *}$ \\
\hline Kapitalintensität (ln) & $\mathbf{0 , 2 2 1}(0,029)^{* * *}$ & $1 \quad 1$ & $1 \quad 1$ \\
\hline Konstante & $-\mathbf{2 , 0 8 3}(0,195)^{* * *}$ & $\mathbf{- 1 , 6 1 4}(0,204)^{* * *}$ & $\mathbf{- 1 , 6 1 4}(0,182)^{* * *}$ \\
\hline 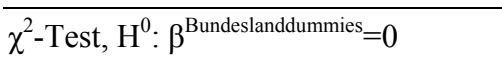 & 4,55 & 3,27 & 5,04 \\
\hline$\chi^{2}$-Test, $\mathrm{H}^{0}: \beta^{\text {Kohortendummies }}=0$ & $28,28^{* * *}$ & $12,87^{* *}$ & $25,32^{* * *}$ \\
\hline \multirow{2}{*}{$\chi^{2}$-Test, $H^{0}: \beta^{\text {Branchendummies }}=0$} & \multirow[t]{2}{*}{$136,21^{* * *}$} & \multirow[t]{2}{*}{$89,13^{* * *}$} & $129,22^{* * *}$ \\
\hline & & & Kreise mit E.dichte>Med: \\
\hline$\chi^{2}$-Test, $H^{0}: \beta^{\text {Spark.verb. }}=\beta^{\text {Gen.bankverb. }}$ & 0,08 & 0,22 & 0,01 \\
\hline$\chi^{2}$-Test, $H^{0}: \beta^{\text {Spark.verb. }}=\beta^{\text {Kreditbankverb. }}$ & $5,45^{* *}$ & $5,79^{* *}$ & $5,32^{* *}$ \\
\hline \multirow{2}{*}{$\chi^{2}$-Test, $H^{0}: \beta^{\text {Gen.bankverb. }}=\beta^{\text {Kreditbankverb. }}$} & \multirow[t]{2}{*}{$7,47^{* * *}$} & \multirow[t]{2}{*}{$8,77^{* * *}$} & $6,80^{* * *}$ \\
\hline & & & Kreise mit E.dichte $\leq$ Med.: \\
\hline$\chi^{2}$-Test, $H^{0}: \beta^{\text {Spark.verb. }}=\beta^{\text {Gen.bankverb. }}$ & l & 1 & 0,19 \\
\hline$\chi^{2}$-Test, $H^{0}: \beta^{\text {Spark.verb. }}=\beta^{\text {Kreditbankverb. }}$ & / & / & $4,00^{* *}$ \\
\hline$\chi^{2}$-Test, $H^{0}: \beta^{\text {Gen.bankverb. }}=\beta^{\text {Kreditbankverb. }}$ & 1 & 1 & $6,15^{* *}$ \\
\hline Zahl der Beobachtungen & 6.880 & 6.880 & 6.880 \\
\hline Log likelihood-Wert & $-2.049,96$ & $-2.080,88$ & $-2.085,66$ \\
\hline Pseudo $R^{2}$ in $\%$ & 10,49 & / & 8,94 \\
\hline
\end{tabular}

Quellen: Eigene Berechnungen basierend auf Daten der DtA, des ZEW, der Deutschen Bundesbank und des Bundesamts für Bauwesen und Raumordnung.

Anmerkungen: Die Modelle U7 und U9 sind homoskedastische Probit-Modelle und im Probit-Modell U8 wird multiplikative Heteroskedastie zugelassen (Harvey, 1976). Die Standardfehler sind robust, nach Kreisregionen geclustert und berücksichtigen die disproportional geschichtete Stichprobenziehungsregel. *** $(* *, *)$ zeigt Signifikanz auf dem $1(5,10) \%$-Niveau an. 
Allen, Franklin und Douglas Gale (2000), Comparing Financial Systems, MIT Press, Cambridge, MA.

Amemiya, Takeshi (1984), Tobit Models: A Survey, in: Journal of Econometrics, 24(1-2), S. 3-61.

Agarwal, Sumit und Robert Hauswald (2008), Distance and Private Information in Lending, Federal Reserve Bank of Chicago und American University, Februar 2008, mimeo.

Almus, Matthias, Susanne Prantl, Josef Brüderl, Konrad Stahl und Michael Woywode (2001), Die ZEW-Gründerstudie - Konzeption und Erhebung, Dokumentation Nr. 01-01, Zentrum für Europäische Wirtschaftsforschung, Mannheim.

Almus, Matthias und Susanne Prantl (2002), Die Auswirkungen öffentlicher Gründungsförderung auf das Überleben und Wachstum junger Unternehmen, in: Jahrbücher für Nationalökonomie und Statistik, 222(2), S. 161-185.

Almus, Matthias, Dirk Engel und Susanne Prantl (2002), Die Mannheimer Gründungspanels des Zentrums für Europäische Wirtschaftsforschung GmbH (ZEW), in: Fritsch, Michael und Reinhold Grotz (Hrsg.), Das Gründungsgeschehen in Deutschand, Physica, Heidelberg, S. 79102.

Atkinson, Anthony B. und Joseph E. Stiglitz (1980), Lectures on Public Economics, McGraw-Hill, London.

Audretsch, David B. und Talat Mahmood (1995), New Firm Survival: New Results Using a Hazard Function, in: Review of Economics and Statistics, 77(1), S. 97-103.

Barth, James R., Gerard Caprio Jr. und Ross Levine (2004), Bank Regulation and Supervision: What Works Best?, in: Journal of Financial Intermediation, 13(2), S. 205-248.

Bates, Timothy (1990), Entrepreneur Human Capital Inputs and Small Business Longevity, in: Review of Economics and Statistics, 72(4), S. 551-559.

Berger, Allen N., Nathan H. Miller, Mitchell A. Petersen, Raghuram G. Rajan und Jeremy C. Stein (2005), Does Function Follow Organizational Form? Evidence from the Lending Practices of Large and Small Banks, in: Journal of Financial Economics, 76(2), S. 237-269.

Berger, Allen N., Leora F. Klapper, Maria S. M. Peria, Rida Zaidal (2008), Bank Ownership Type and Banking Relationships, in: Journal of Financial Intermediation, 17(1), S. 37-62.

Berger, Allen N. und Gregory F. Udell (1998), The Economics of Small Business Finance: The Roles of Private Equity and Debt Markets in the Financial Growth Cycle, in: Journal of Banking and Finance, 22(6-8), S. 613-673.

Berger, Allen N. und Gregory F. Udell (2006), A More Complete Conceptual Framework for SME Finance, in: Journal of Banking and Finance, 30(11), S. 2945-2966.

Börsen-Zeitung (2005), Weitere Schritte der Öffnung wären wünschenswert - Interview von Bernd Wittkowski mit Bundesbank-Vorstandsmitglied Edgar Meister, Nr. 135, 16.7.2005, S. 5.

Boot, Arnoud W. A. (2000), Relationship Banking: What Do We Know?, in: Journal of Financial Intermediation, 9(1), S. 7-25.

Boot, Arnoud W. A. und Anjan V. Thakor (2000), Can Relationship Banking Survive Competition?, in: Journal of Finance, 55(2), S. 679-713. 
Brunner, Allan, Jörg Decressin, Daniel Hardy und Beata Kudela (2004), Germany's ThreePillar Banking System - Cross-Country Perspectives in Europe, Occasional Paper 233, International Monetary Fund, Washington DC.

Caves, Richard E. (1998), Industrial Organization and New Findings on the Turnover and Mobility of Firms, in: Journal of Economic Literature, 36(4), S. 1947-1982.

Cressy, Robert (1996), Are Business Startups Debt-Rationed?, in: Economic Journal, 106(438), S. 1253-1270.

Chatterjee, Samprit und Ali S. Hadi (2006), Regression Analysis by Example, 4. Auflage, John Wiley \& Sons, New York, US.

Cole, Rebel A., Lawrence G. Goldberg und Lawrence J. White (2004), Cookie-Cutter versus Character: The Micro Structure of Small Business Lending by Large and Small Banks, in: Journal of Financial and Quantitative Analysis, 39(2), S. 227-251.

Degryse, Hans und Steven Ongena (2005), Distance, Lending Relationships, and Competition, in: Journal of Finance, 60(1), S. 231-266.

Deutsche Ausgleichsbank DtA (2000-2003), Förderreport, Jahrgänge 2000-2003, Deutsche Ausgleichsbank, Bonn.

Deutsche Bundesbank (1992), Zinssubventionen und sonstige Finanzierungshilfen im geeinten Deutschland, Monatsbericht August 1992, 44(8), Frankfurt am Main, S. 22-29.

Deutsche Bundesbank (2000), Die Ertragslage der deutschen Kreditinstitute im Jahr 1999, Monatsbericht September 2000, 52(9), Frankfurt am Main, S. 47-79.

Deutsche Bundesbank (2001), Bankenstatistik, Statistisches Beiheft zum Monatsbericht 1, Dezember 2001, Frankfurt am Main.

Deutsche Bundesbank (2003), Bericht zur Stabilität des deutschen Finanzsystems, Monatsbericht Dezember 2003, 55(12), Frankfurt am Main, S. 5-53.

Deutsche Bundesbank (2006), Bankstellenbericht 2006, Frankfurt am Main, 24.07.2006.

Deutsche Bundesbank (2008), Verhältniszahlen aus Jahresabschlüssen deutscher Unternehmen von 2004 bis 2005, Statistische Sonderveröffentlichung 6, Februar 2008, Frankfurt am Main.

Deutscher Sparkassen- und Giroverband (2008a), Diagnose Mittelstand 2008, Sparkassen und Mittelstand - in der Region zuhause, gemeinsam in der Welt engagiert, Berlin.

Deutscher Sparkassen- und Giroverband (2008b), Diagnose Mittelstand 2008, Sparkassen und Mittelstand - in der Region zuhause, gemeinsam in der Welt engagiert, Statistischer Anhang, Berlin.

DIE ZEIT (2000), Blank ohne Bank, Nr. 23, 31.05.2000.

Economist, The (2006), Battles with Brussels, 29.06.2006, S. 71.

Engerer, Hella, und Mechthild Schrooten (2004), Untersuchung der Grundlagen und Entwicklungsperspektiven des Bankensektors in Deutschland (Dreisäulensystem), Gutachten im Auftrag des Bundesministeriums für Finanzen, Deutsches Institut für Wirtschaftsforschung, Berlin.

Fischer, Thomas R. (2005), Pauschale Diskussion über Säulenstruktur hilft nicht weiter, ifoSchnelldienst, 58(14), S.7-10. 
Frank, Murray Z. (1988), An Intertemporal Model of Industrial Exit, in: Quarterly Journal of Economics, 103(2), S. 333-344.

Freixas, Xavier und Rochet, Jean-Charles (1997), Microeconomics of Banking, MIT Press, Cambridge, MA.

Gerschenkron, Alexander (1962), Economic Backwardness in Historical Perspective, Harvard University Press, Cambridge, Massachusetts.

Gompers, Paul A. und Josh Lerner (1999), The Venture Capital Cycle, MIT Press, Cambridge, MA.

Greene, William H. (2008), Econometric Analysis, 6. Auflage, Prentice Hall, London.

Guinnane, Timothy W. (2002), Delegated Monitors, Large and Small: Germany's Banking System, 1800-1914, in: Journal of Economic Literature, 40(1), S. 73-124.

Hakenes, Hendrik und Isabel Schnabel (2006), The Threat of Capital Drain: A Rationale for Public Banks?, MPI-Preprint 2006-11, April 2006.

Harhoff, Dietmar und Timm Körting (1998), Lending Relationships in Germany - Empirical Evidence from Survey Data, in: Journal of Banking \& Finance, 22(10-11), S. 1317-1353.

Harhoff, Dietmar, Stahl, Konrad und Michael Woywode (1998), Legal Form, Growth and Exit of West German Firms - Empirical Results for Manufacturing, Construction, Trade and Service Industries, in: Journal of Industrial Economics, 46(4), S. 453-488.

Hartmann-Wendels, Thomas, Andreas Pfingsten und Martin Weber (2007), Bankbetriebslehre, 4. Auflage, Springer-Verlag, Berlin.

Hamilton, Lawrence C. (2006), Statistics with Stata, 6. Auflage Brooks/Cole Cengage Learning Belmont, CA.

Harvey, Andrew C. (1976), Estimating Regression Models with Multiplicative Heteroscedasticity, in: Econometrica, 44(3), S. 461-465.

Holtz-Eakin, Douglas, David Joulfaian und Harvey S. Rosen. (1994a), Entrepreneurial Decisions and Liquidity Constraints, in: RAND Journal of Economics, 25(2), S. 334-347.

Holtz-Eakin, Douglas, David Joulfaian und Harvey S. Rosen. (1994b), Sticking It Out: Entrepreneurial Survival and Liquidity Constraints, in: Journal of Political Economy, 102(1), S. 53-75.

Hutchinson, Robert W. (1995), The Capital Structure and Investment Decisions of the Small Owner-Managed Firm: Some Exploratory Issues, in: Small Business Economics, 7(3), S. 231239.

KfW Bankengruppe, Creditreform, IfM, RWI und ZEW (2006), Konjunkturaufschwung bei anhaltendem Problemdruck - Mittelstandsmonitor 2006, KfW Bankengruppe, Frankfurt am Main.

KfW Bankengruppe (2006), Unternehmensfinanzierung: Banken entdecken den Mittelstand neu. Kreditzugang für kleine Unternehmen bleibt schwierig. - Unternehmensbefragung 2006, September 2006, KfW Bankengruppe, Frankfurt am Main.

La Porta, Rafael, Florencio Lopez-De-Silanes und Andrei Shleifer (2002), Government Ownership of Banks, in: Journal of Finance, 57(1), S. 265-301.

Lehmann, Erik und Doris Neuberger (2001), Do Lending Relationships Matter? Evidence from Bank Survey Data in Germany, in: Journal of Economic Behaviour and Organisation, 45(4), S. 339-359. 
Lehmann, Erik, Neuberger, Doris und Solvig Räthke (2004), Lending to Small and MediumSized Firms: Is there an East-West Gap in Germany?, in: Small Business Economics, 23(1), S. 23-39.

Maddala, G. S. (1983), Limited-Dependent and Qualitative Variables in Econometrics, Cambridge University Press, Cambridge.

Mata, José und Pedro Portugal (1994), Life Duration of New Firms, in: Journal of Industrial Economics, 42(3), S. 227-245.

Mata, José und Pedro Portugal (2002), The Survival of New Domestic and Foreign-Owned Firms, in: Strategic Management Journal, 23(4), S. 323-343.

Möschel, Wernhard (2005), Reformbedarf des deutschen Bankensektors, ifo Schnelldienst, 58(23), S. 3-6.

Moulton, Brent R. (1990), An Illustration of a Pitfall in Estimating the Effects of Aggregate Variables on Micro Units, in: Review of Economics and Statistics, 72(2), S. 334-338.

Neuberger, Doris und Solvig Räthke (2007), Microenterprises and Multiple Bank Relationships: The Case of Professionals, in: Small Business Economics, forthcoming.

Neumann, Manfred und Richard Reichel (2006), Struktur der deutschen Bankwirtschaft: Das Dreisäulenmodell ist zeitgemäß, in: Jahrbuch für Wirtschaftswissenschaften, 57(3), S. 247-272.

Ongena, Steven und David C. Smith (2000), What Determines the Number of Bank Relationships? Cross-Country Evidence, in: Journal of Financial Intermediation, 9(1), S. 26-56.

Petersen, Mitchell A. und Raghuram G. Rajan (1995), The Effect of Credit Market Competition on Lending Relationships, in: Quarterly Journal of Economics, 110(2), S. 407-443.

Petersen, Mitchell A. und Raghuram G. Rajan (2002), Does Distance Still Matter? The Information Revolution in Small Business Lending, in: Journal of Finance, 57(6), S. 25332570 .

Prantl, Susanne (2003), Bankruptcy and Voluntary Liquidation: Evidence for New Firms in East and West Germany after Unification, ZEW Discussion Paper No. 03-72, Mannheim.

Prantl, Susanne (2008), The Role of Policies Supporting New Firms, Wissenschaftszentrum Berlin, mimeo.

Rajan, Raghuram G. und Luigi Zingales (2003), Banks and Markets: The Changing Character of European Finance, University of Chicago, mimeo.

Robins, Gregg S. (2000), Banking in Transition: East Germany after Unification, Macmillan Press LTD, London.

Sachverständigenrat zur Begutachtung der gesamtwirtschaftlichen Entwicklung (2004), Das Deutsche Bankensystem: Befunde und Perspektiven in: Erfolge im Ausland Herausforderungen im Inland, Jahresgutachten 2004/2005, Wiesbaden.

Schindler, Michael und Doris Neuberger (2000), Ist der öffentliche Auftrag im deutschen Sparkassensektor zeitgemäß?, Thünen-Reihe Angewandter Volkswirtschaftstheorie, Working Paper No. 26, Rostock.

Schnabel, Isabel und Hendrik Hakenes (2007), Regionale Banken in einer globalisierten Welt, Kredit und Kapital, 40(3), 2007, S. 351-380.

Schulte, Reinhard (1999), Das Risikoverhalten von Banken gegenüber Existenzgründungen, in: Ridinger, Rudolf und Peter Weiss (Hrsg.), Existenzgründungen und dynamische Wirtschaftsentwicklung, Duncker und Humblot, Berlin, S. 95-119. 
Schulte, Reinhard (2002), Finanzierungs- und wachstumstheoretische Aspekte der Frühentwicklung von Unternehmungen und deren empirische Analyse, Habilitationsschrift, Universität Dortmund.

Schulte, Reinhard (2007), Kapitalstrukturentwicklung in der Frühentwicklungsphase von Existenzgründungen, in: Betriebswirtschaftliche Forschung und Praxis, 59(3), S. 217-231.

Schuster, Detlev und Marcus Sohns (2006), Zur Veräußerung von Sparkassen, in: Zeitschrift für Bankrecht und Bankwirtschaft, 2006(5), S. 342-354.

Shleifer, Andrei und Robert W. Vishny (1994), Politicians and Firms, in: The Quarterly Journal of Economics, 109(4), S. 995-1025.

Stein, Jeremy C. (2002), Information Production and Capital Allocation: Decentralized versus Hierarchical Firms, in: Journal of Finance, 57(5), S. 1891-1921.

Stiglitz, Joseph und Andrew Weiss (1981), Credit Rationing in Markets with Imperfect Information, in: American Economic Review, 71(3), S. 393-410.

Vogelsang, Harald (2008), Die Drei-Säulen-Struktur hat sich in der Krise bewährt, BörsenZeitung, 19.07.2008, Nr. 138, S. 4.

Weber, Manfred (2005), Reformen dringend geboten, ifo-Schnelldienst, 58(14), S. 3-6.

Wengler, Martin O. (2006), Wechselwirkungen zwischen der finanzintermediatorischen Tätigkeit kommunaler Kreditinstitute und dem kommunalen Raum, Sonderheft 6/2006, Institut für Wirtschaftsforschung Halle, Halle (Saale).

Wooldridge, Jeffrey M. (2002), Econometric Analysis of Cross Section and Panel Data, The MIT Press, Cambridge, MA.

Woywode Michael und Jochen Struck (2004), Zu den Ursachen des Erfolgs staatlich geförderter Unternehmen: Ergebnisse einer aktuellen empirischen Untersuchung, in: $K f W$ Bankengruppe (Hrsg.), Was erfolgreiche Unternehmen ausmacht - Erkenntnisse aus Wissenschaft und Praxis, Physica-Verlag, Heidelberg, S. 89-137. 
Anhang

\section{A.1 Ökonometrische Methoden \\ A.1.1 Probit-Modell mit multiplikativer Heteroskedastie}

Im Modell U8 in Tabelle 6 weichen wir von der Standardspezifikation für Probit-Modelle ab, bei welcher der Fehlerterm im latenten Modell als konditional auf $B=b_{i}$ und $X=x_{i}$ normalverteilt mit Erwartungswert „, 0 “ und homoskedastischer Varianz $\sigma^{2}=1$ modelliert wird. Stattdessen lassen wir multiplikative Heteroskedastie zu und modellieren den Erwartungswert des Förderkreditindikators $Y$ konditional auf $B=b_{i}, X=x_{i}$ und $Z=z_{i}$ (Harvey 1976):

$$
\begin{aligned}
& E\left(Y \mid B=b_{i}, X=x_{i}, Z=z_{i}\right)=\operatorname{prob}\left(Y=1 \mid B=b_{i}, X=x_{i}, Z=z_{i}\right) \\
& =\Phi\left(\left(\beta^{\prime} b_{i}+\gamma^{\prime} x_{i}\right) / \sigma_{i}\right)=\Phi\left(\left(\beta^{\prime} b_{i}+\gamma^{\prime} x_{i}\right) / \exp \left(\zeta^{\prime} z_{i}\right)\right)
\end{aligned}
$$

Die Varianz des Fehlerterms wird nicht auf 1 normiert, sondern hängt wie folgt von $Z=z_{i}$ $\mathrm{ab}$ :

$$
\sigma_{i}^{2}=\left(\exp \left(\zeta^{\prime} z_{i}\right)\right)^{2}
$$

In den Vektor $Z$ werden die zwei Variablen aus $X$ aufgenommen, die im Modell U2 in Tabelle 4 eine Ablehnung der Nullhypothese „Homoskedastie des Fehlerterms“ verursachen. Dies sind: „GmbH oder AG“ und „Gründungskohorte 1993“.

\section{A.1.2 Tobit-Modell}

In Tabelle 4 weisen wir die OLS-Regressionsergebnisse für das Modell U3 mit der kontinuierlichen Endogenen „ln(Förderkreditvolumen insgesamt pro Unternehmen während der Gründungsphase in $1000 €+1$ )“ aus. Diese Variable nimmt oft den Wert „,“ an und kann als beobachtbare Endogene in einem Modell mit der zensiert beobachtbaren, latenten Endogenen „Neigung zur Kreditvergabe seitens der Bankkreditanbieter" angesehen werden. Diese latente Endogene kann grundsätzlich auch negative Werte annehmen, die aber nicht beobachtbar sind. Entsprechend ist die latente Endogene am Nullpunkt der Verteilung zensiert und es wird anstelle der Wertausprägung selbst der Grenzwert „0“ beobachtet. In diesem Fall führt die Schätzung einfacher OLS-Regressionen $\mathrm{zu}$ verzerrten, inkonsistenten Koeffizientenschätzern. Konsistente Koeffizientenschätzer lassen sich hingegen mit zensierten Regressionsmodellen bzw. Tobit-Modellen erzielen. ${ }^{1}$ Tobit-Regressionsergebnisse zeigen wir in der Spalte „Modell U10“ in Tabelle A.6.

Siehe hierzu insbesondere Amemiya (1984). Greene (2008) vergleicht OLS- und Tobit-Schätzergebnisse und berichtet, dass die marginalen Effekte basierend auf Tobit-Schätzergebnissen in praktischen Anwendungen häufig nur wenig von den geschätzten OLS-Koeffizienten abweichen. Dies gilt auch für die Schätzergebnisse zu den Bankverbindungsvariablen in Tabelle 4, Modell U3 und Tabelle A.6, Modell U10 (siehe die Fußnote unter Tabelle A.6 für marginale Effekte des Tobit-Modells U10). 
Im Tobit-Modell gilt für den Erwartungswert der beobachtbaren Förderkreditvariable $Y$ konditional auf $B=b_{i}$ und $X=x_{i}$ (Greene, 2008):

$$
E\left(Y \mid B=b_{i}, X=x_{i}\right)=\Phi\left(\left(\beta^{\prime} b_{i}+\gamma^{\prime} x_{i}\right) / \sigma\right)\left(\beta^{\prime} b_{i}+\gamma^{\prime} x_{i}+\sigma \lambda_{i}\right) \quad \text { für alle } i=1, \ldots, N_{U} \text {. }
$$

wobei $\lambda_{i}=\varphi\left(\left(\beta^{\prime} b_{i}+\gamma^{\prime} x_{i}\right) / \sigma\right) / \Phi\left(\left(\beta^{\prime} b_{i}+\gamma^{\prime} x_{i}\right) / \sigma\right){ }^{2} \Phi(\bullet)$ bezeichnet die Verteilungsfunktion und $\varphi(\bullet)$ die Dichtefunktion der Standardnormalverteilung. $\mathrm{Zu}$ schätzen sind die Parametervektoren $\beta$ und $\gamma$ sowie die Varianz $\sigma$.

\section{A.1.3 Berechnung marginaler Effekte}

In Tabelle A.5 weisen wir für jede bankbezogene Variable in den Probit-Modellen in den Tabellen 4, 5 und 6 den Effekt aus, den die marginale Veränderung der kontinuierlichen Variable bzw. die diskrete Veränderung der Indikatorvariable bei Konstanz aller übrigen Variablen in den Vektoren $B$ und $X$ auf die endogene Variable $Y$ ausübt. Diese Effekte haben wir am Mittel- bzw. Anteilswert aller Variablen in $B$ und $X$ berechnet. Marginale Effekte für kontinuierliche Erklärende sind beispielsweise im homoskedastischen Probit-Modell wie folgt definiert (Greene, 2008):

$$
\delta E\left(Y \mid B=b_{i}, X=x_{i}\right) / \delta K=\varphi\left(\beta^{\prime} b^{M}{ }_{i}+\gamma^{\prime} x^{M}{ }_{i}\right) \eta
$$

wobei $K$ für den Teilvektor kontinuierlicher Variablen aus $B$ und $X$ steht, $\eta$ für den Vektor der zu $K$ gehörenden Schätzparameter aus $\beta$ und $\gamma$. Die Vektorwerte mit den Mittel- bzw. Anteilswerten der erklärenden Variablen in $B$ und $X$ sind mit $b^{M}{ }_{i}$ und $x^{M}{ }_{i}$ bezeichnet.

Für das in Tabelle A.6 ausgewiesene Tobit-Modell mit Zensierungspunkt Null gelten für kontinuierliche Erklärende folgende marginale Effekte auf die beobachtbare Endogene $Y$ (Greene, 2008):

$$
\delta E\left(Y \mid B=b_{i}, X=x_{i}\right) / \delta K=\Phi\left(\left(\beta^{\prime} b^{M}{ }_{i}+\gamma^{\prime} x^{M}{ }_{i}\right) / \sigma\right) \eta .
$$

2 Bei zensierten Regressionsmodellen bzw. Tobit-Modellen handelt es sich um Modelle, in denen die gleichen Schätzparameter verwendet werden, um zu modellieren, wie der Beitrag zensierter und unzensierter Beobachtungen in der Schätzfunktion von den exogenen Variablen abhängt. Die Anwendbarkeit komplexerer Modelle diskutiert beispielsweise Maddala (1983). 


\section{A.2 Daten und Deskription}

\section{A.2.1 Daten für die Analyse auf Regionsebene und Deskription}

Tabelle A.1: Deskription für den Datensatz auf Regionsebene

\begin{tabular}{|c|c|c|}
\hline $\begin{array}{l}\text { Kontinuierliche } \\
\text { Variable }\end{array}$ & Definition & $\begin{array}{l}\text { Mittelwert } \\
\text { (Standardabw.) }\end{array}$ \\
\hline Förderkreditzusagen & $\begin{array}{l}\text { Anzahl der im Jahr } 1999 \text { von der DtA bewilligten } \\
\text { Kredite auf Stadt- bzw. Landkreisebene }\end{array}$ & $173,90(481,86)$ \\
\hline Förderkreditsumme & $\begin{array}{l}\text { Kreditvolumen der im Jahr } 1999 \text { bewilligten DtA- } \\
\text { Förderkredite in } 1.000 € \text { auf Kreisebene }\end{array}$ & $\begin{array}{l}12.788,67 \\
(52.644,42)\end{array}$ \\
\hline Sparkassendichte & $\begin{array}{l}\text { Sparkassenbankstellen je } 1.000 \text { Einwohner im Kreis, } \\
1998\end{array}$ & $0,304(0,146)$ \\
\hline Genossenschaftsbankdichte & $\begin{array}{l}\text { Genossenschaftsbankstellen je } 1.000 \text { Einwohner im } \\
\text { Kreis, } 1998\end{array}$ & $0,346(0,222)$ \\
\hline Kreditbankdichte & Kreditbankstellen je 1.000 Einwohner im Kreis, 1998 & $0,079(0,062)$ \\
\hline Zahl der Gründungen & Unternehmensgründungszahl im Kreis, 1999 & $612,23(798,06)$ \\
\hline Einwohnerdichte & $\begin{array}{l}\text { Einwohnerzahl im Kreis in } 1.000 \text { Einwohner pro } \\
\text { Fläche in qkm, } 1998\end{array}$ & $0,571(0,704)$ \\
\hline \multicolumn{3}{|l|}{ Anteil neuer Unternehmen ... } \\
\hline mit einem Beschäftigten & $\begin{array}{l}\text { Anteil der Gründungen mit einem Beschäftigten an } \\
\text { allen Unternehmensgründungen im Kreis, } 1999\end{array}$ & $0,549(0,089)$ \\
\hline mit zwei Beschäftigten & Anteil der Gründungen mit 2 Beschäftigten & $0,224(0,043)$ \\
\hline $\begin{array}{l}\text { mit mehr als zwei } \\
\text { Beschäftigten }\end{array}$ & Anteil der Gründungen mit mehr als 2 Beschäftigten & $0,226(0,072)$ \\
\hline im verarbeitenden Gewerbe & Anteil der Gründungen im verarbeitenden Gewerbe & $0,070(0,025)$ \\
\hline im Baugewerbe & Anteil der Gründungen im Baugewerbe & $0,137(0,043)$ \\
\hline im Großhandel & Anteil der Gründungen im Großhandel & $0,090(0,027)$ \\
\hline im Einzelhandel & Anteil der Gründungen im Einzelhandel & $0,254(0,048)$ \\
\hline in Verkehr/Nachrichten & $\begin{array}{l}\text { Anteil der Gründungen im Sektor Verkehr und } \\
\text { Nachrichtenübermittlung }\end{array}$ & $0,057(0,020)$ \\
\hline in unternehmensnahen Dienstl. & $\begin{array}{l}\text { Anteil der Gründungen in unternehmensnahen } \\
\text { Dienstleistungen }\end{array}$ & $0,166(0,053)$ \\
\hline $\begin{array}{l}\text { in sonstigen Dienstleistungen } \\
\text {... an allen neuen Unternehmen } \\
\text { im Kreis, } 1999\end{array}$ & Anteil der Gründungen in sonstigen Dienstleistungen & $0,227(0,049)$ \\
\hline
\end{tabular}

Anmerkung: Angaben für den Datensatz mit 325 westdeutschen Stadt- und Landkreisen.

\section{A.2.2 Daten für die Analyse auf Unternehmensebene und Deskription}

\section{Verknüpfung von DtA- und ZEW-Daten}

Für die Regressionen auf Unternehmensebene verwenden wir eine Ausgangsstichprobe mit 12.000 Unternehmen aus dem ZEW Gründungspanel West (Almus et al., 2001; Prantl, 2003), die mit Förderinformationen aus einer Datenbank der Deutschen Ausgleichsbank verknüpft wurden. Im ersten Schritt der aufwendigen Verknüpfungsprozedur wurde ein computergestütztes, heuristisches String-Such-Verfahren eingesetzt, um für alle verfügbaren Datensätze zu Unternehmen in der ZEW-Stichprobe die Ähnlichkeit zu jedem einzelnen 
Kreditdatensatz in der DtA-Datenbank zu bestimmen (Almus und Prantl, 2002; Prantl, 2008). Für diesen Ähnlichkeitsabgleich wurden folgende Informationen verwendet: Geburtsdaten von Unternehmenseigentümern, Namensangaben von Unternehmen sowie Eigentümern und Angaben zu Unternehmens- sowie Personenadressen (Orts- und Straßennamen, Postleitzahlen) inklusive registrierter Adressänderungen. Im zweiten Schritt wurden per Computer erzeugte Verknüpfungen akzeptiert, sofern diese eine manuelle Überprüfung passierten, in die auch Angaben zur Unternehmensrechtsform und Industriezugehörigkeit eingingen. Nach Testauswertungen konnten allerdings solche computerbasierte Verknüpfungen, bei denen Name, Geburtsdatum und mindestens zwei von drei Adresselementen übereinstimmten, ohne weitere Prüfung direkt übernommen werden. Insbesondere die Verwendung von Geburtsdaten und das zweistufige Verfahren führen zu einer qualitativ hochwertigen Verknüpfung. Deskriptive Analysen zeigen, dass Stichprobenverteilungen der Förderkredite nach Bundesländern, Förderprogrammen und im Zeitablauf mit den entsprechenden Verteilungen in der Grundgesamtheit der DtA-Datenbank eng übereinstimmen.

\section{Reduktion der Ausgangs- auf die Schätzstichprobe und zugehörige Testregressionen}

Die zufällig gezogene, repräsentative Ausgangsstichprobe mit 12.000 Unternehmen aus dem ZEW Gründungspanel West wurde auf die für diese Arbeit relevante Unternehmenspopulation eingeschränkt und um die Unternehmen bereinigt, für die benötigte Einzelangaben fehlen. Die einzelnen Reduktionsschritte sind:

1. 1.607 Unternehmen mit Gründungsdaten vor dem 1. Januar 1990 wurden eliminiert, da die DtA-Datenbasis nur Kreditinformationen für die Jahre 1990 bis 1999 enthält.

2. 941 unselbständige Unternehmenseinheiten, Teilzeitbetriebe, vollständig an andere Unternehmen angebundene Gründungen oder Holding-Gesellschaften wurden ausgeschlossen, weil diese keine DtA-Kredite aus den hier berücksichtigten Programmen erhalten können.

3. 9 Unternehmen entfielen wegen inkonsistenter Verknüpfungen zur DtA-Datenbank.

4. 1.065 Unternehmen wurden aufgrund fehlender unternehmensspezifischer Basisvariablen eliminiert.

5. 1.498 Unternehmen ohne Angaben zum Kapitaleinsatz bei der Gründung entfielen.

Die beiden letztgenannten Eliminationsschritte implizieren keine Selektionsprobleme, welche für die in dieser Arbeit interessierenden Forschungsfragen relevant sind. So erweisen sich die Ergebnisse der Regressionen in Abschnitt 4.2 ohne Kontrolle für Unternehmensmerkmale bzw. Kapitalintensität bei Verwendung der größeren Schätzstichproben als robust. Wird Modell U1 für 9.443 statt für 6.880 Beobachtungen geschätzt (d. h. Anwendung der Reduktionsschritte 1 bis 3 in der obigen Auflistung), sind die Schätzkoeffizienten (Standardfehler) für Bankverbindungen zu Sparkassen 0,109** $(0,050)$, zu Genossenschaftsbanken $0,114^{* *}(0,048)$ und zu Kreditbanken -0,057 (0,049). Die Schätzung des Modells U2 mit 8.378 Beobachtungen (d. h. Anwendung der Reduktionsschritte 1 bis 4) liefert als Schätzkoeffizienten (Standardfehler) für Bankverbindungen zu Sparkassen 0,096* (0,051), zu Genossenschaftsbanken 0,131 ${ }^{* * *}(0,050)$ und zu Kreditbanken -0,061 $(0,054)$. 
Anhang

Tabelle A.2: Deskription für den Datensatz auf Unternehmensebene

\begin{tabular}{|c|c|c|}
\hline $\begin{array}{l}\text { Kontinuierliche } \\
\text { Variable }\end{array}$ & Definition & $\begin{array}{l}\text { Mittelwert } \\
\text { (Standardabw.) }\end{array}$ \\
\hline Förderkreditsumme & $\begin{array}{l}\text { Förderkreditvolumen insgesamt pro Unternehmen in } 1.000 € \mathrm{im} \\
\text { Gründungsjahr oder den ersten } 2 \text { Jahren danach }\end{array}$ & $6,918(34,227)$ \\
\hline Anzahl der Bankverbindungen & $\begin{array}{l}\text { Angabe, ob zum Gründungszeitpunkt eine, zwei, drei oder mehr } \\
\text { Bankverbindungen zu Genossenschaftsbanken, Kreditbanken und } \\
\text { Sparkassen bestehen }\end{array}$ & $2,663(0,504)$ \\
\hline Bankstellendichte & $\begin{array}{l}\text { Anzahl der Bankstellen in 1990/erwerbsfähige Einwohner im Alter } \\
\text { von } 18 \text { bis } 65 \text { Jahren in } 1.000 \text { in 1992, Kreisebene }\end{array}$ & $0,995(0,451)$ \\
\hline Einwohnerdichte & Einwohnerzahl in 1.000 pro Kreisfläche in qkm, 1992 & $1,079(1,143)$ \\
\hline Kapitalintensität & Investitionssumme in $1.000 €$ in tangible Güter/Mitarbeiterzahl & $14,133(16,117)$ \\
\hline Mitarbeiterzahl & erste Beschäftigungsangabe & $3,709(14,596)$ \\
\hline Indikatorvariable & Definition & Anteil in \% \\
\hline Förderkreditindikator & $\begin{array}{l}\text { 1: DtA-Förderung im Gründungsjahr oder den ersten zwei Jahren } \\
\text { danach; 0: sonst }\end{array}$ & 10,36 \\
\hline Sparkassenverbindung & 1: Sparkassenbankverbindung bei Gründung; 0 : sonst & 62,87 \\
\hline Genossenschaftsbankverbindung & 1: Genossenschaftsbankverbindung bei Gründung; 0 :sonst & 54,21 \\
\hline $\begin{array}{l}\text { Bankverbindung bei einem } \\
\text { Zentralinstitut der Sparkassen-/ } \\
\text { Genossenschaftsbankgruppe }\end{array}$ & $\begin{array}{l}\text { 1: Bankverbindung bei einem Zentralinstitut der Sparkassen-/ } \\
\text { Genossenschaftsbankgruppe bei Gründung; 0: sonst }\end{array}$ & 5,02 \\
\hline Kreditbankverbindung & 1: Kreditbankverbindung bei Gründung; 0 : sonst & 75,13 \\
\hline $\begin{array}{l}\text { Beteiligung eines anderen } \\
\text { Unternehmens }\end{array}$ & $\begin{array}{l}\text { 1: mind. ein Unternehmenseigner ist ein Unternehmen, aber nicht } \\
\text { alle; } 0 \text { : keine Unternehmensbeteiligung }\end{array}$ & 5,71 \\
\hline Teamgründung & 1: mehr als ein Unternehmensgründer; 0 : sonst & 24,03 \\
\hline Meister-/ Hochschulabschluss & 1: Meister-/Hochschulabschluss; 0: sonst & 18,84 \\
\hline geringe Ausbildung/ Lehrabschluss & 1: geringfügige Ausbildung oder Lehrabschluss; 0: sonst & 41,89 \\
\hline fehlende Humankapitalangabe & 1: keine Humankapitalangabe vorhanden; 0 : sonst & 39,26 \\
\hline $\mathrm{GmbH}$ oder $\mathrm{AG}$ & 1: GmbH oder AG; 0 : sonst & 37,57 \\
\hline Gewerbebetrieb, EU, OHG oder KG & 1: Gewerbebetrieb/Einzelunternehmen, Personengesellschaft; 0 : sonst & 53,22 \\
\hline BGB-Gesellschaft & 1: BGB-Gesellschaft; 0: sonst & 9,21 \\
\hline verarbeitendes Gewerbe & 1: verarbeitendes Gewerbe; 0 : sonst & 12,00 \\
\hline Baugewerbe & 1: Baugewerbe; 0: sonst & 12,68 \\
\hline Großhandel & 1: Großhandel; 0: sonst & 12,27 \\
\hline Einzelhandel & 1: Einzelhandel; 0: sonst & 26,69 \\
\hline Verkehr/Nachrichten & 1: Verkehr und Nachrichtenübermittlung; 0 : sonst & 5,74 \\
\hline unternehmensnahe Dienstleistungen & 1: unternehmensnahe Dienstleistungen; 0: sonst & 14,67 \\
\hline sonstige Dienstleistungen & 1: sonstige Dienstleistungen; 0: sonst & 15,95 \\
\hline Gründungskohorte 1990 & 1: Gründungen mit Gründungsdatum im Jahr 1990; 0: sonst & 30,83 \\
\hline Gründungskohorte 1991 & 1: Gründungen mit Gründungsdatum im Jahr 1991; 0: sonst & 23,22 \\
\hline Gründungskohorte 1992 & 1: Gründungen mit Gründungsdatum im Jahr 1992; 0: sonst & 19,15 \\
\hline Gründungskohorte 1993 & 1: Gründungen mit Gründungsdatum im Jahr 1993; 0: sonst & 26,80 \\
\hline
\end{tabular}

Anmerkungen: Gewichtete Angaben für den Datensatz mit 6.880 Unternehmen zur Berücksichtigung der disproportional geschichteten Stichprobenziehungsregel. Alle erklärenden Variablen werden zum Zeitpunkt der Unternehmensgründung oder im darauf folgenden Jahr gemessen, sofern obige Tabelle keine abweichenden Angaben enthält. Im Falle von Teamgründungen basiert die Humankapitalkodierung auf den Informationen zum hauptbeteiligten Unternehmer. Sofern keine Beteiligungsinformationen vorliegen, werden die Angaben für den ältesten Unternehmer verwendet. 


\section{A.3 Ergänzende empirische Ergebnisse}

Tabelle A.3: Determinanten der Vergabe von Förderkrediten aus DtA-Programmen Varianten des Modells R2 (Kreisdaten)

\begin{tabular}{|c|c|c|c|}
\hline \multirow{2}{*}{$\begin{array}{l}\text { Endogene Variable } \\
\text { Modell }\end{array}$} & \multicolumn{3}{|c|}{ Förderkreditzusagen (ln) } \\
\hline & R4 & R5 & R6 \\
\hline \multirow{3}{*}{ Exogene Variable } & & $\begin{array}{l}\text { ausreißerrobustes } \\
\text { Schätzverfahren }\end{array}$ & $\begin{array}{l}\text { Stichprobe ohne den } \\
\text { Kreis Düsseldorf }\end{array}$ \\
\hline & Parameter & Parameter & Parameter \\
\hline & (Standardfehler) & (Standardfehler) & (Standardfehler) \\
\hline \multicolumn{4}{|l|}{ Dichte von ... } \\
\hline Sparkassenbankstellen & $\mathbf{0 , 8 2 7}(0,219)^{* * *}$ & $\mathbf{0 , 7 1 0}(0,205)^{* * *}$ & $\mathbf{0 , 7 2 7}(0,200)^{* * *}$ \\
\hline Genossenschaftsbankstellen & $\mathbf{0 , 6 7 5}(0,217)^{* * *}$ & $\mathbf{0 , 4 8 2}(0,153)^{* * *}$ & $\mathbf{0 , 5 1 3}(0,154)^{* * *}$ \\
\hline Kreditbankstellen & $\mathbf{0 , 4 2 5}(0,990)$ & $\mathbf{- 0 , 3 6 1}(0,531)$ & $\mathbf{- 0 , 4 8 6}(0,519)$ \\
\hline Zahl der Gründungen (ln) & $\mathbf{0 , 8 6 2}(0,053)^{* * *}$ & $\mathbf{0 , 8 1 8}(0,041)^{* * *}$ & $\mathbf{0 , 8 3 4}(0,047)^{* * *}$ \\
\hline Einwohnerdichte & $\mathbf{- 0 , 0 8 5}(0,049)^{*}$ & $\mathbf{- 0 , 0 6 9}(0,048)$ & $\mathbf{- 0 , 0 8 1}(0,049)^{*}$ \\
\hline \multicolumn{4}{|l|}{ Anteil neuer Unternehmen... } \\
\hline mit zwei Beschäftigten & $\mathbf{1 , 6 7 8}(0,510)^{* * *}$ & $\mathbf{1 , 7 1 3}(0,498)^{* * *}$ & $1,758(0,501)^{* * *}$ \\
\hline mit mehr als zwei Beschäftigten & $\mathbf{1 , 2 9 3}(0,351)^{* * *}$ & $\mathbf{1 , 1 0 0}(0,309)^{* * *}$ & $\mathbf{1 , 1 5 6}(0,331)^{* * *}$ \\
\hline im verarbeitenden Gewerbe & $3,016(1,108)^{* * *}$ & $3,375(1,075)^{* * *}$ & $3,013(1,071)^{* * *}$ \\
\hline im Baugewerbe & $\mathbf{- 0 , 1 1 0}(0,862)$ & $\mathbf{- 0 , 1 2 3}(0,700)$ & $\mathbf{- 0 , 5 0 6}(0,778)$ \\
\hline im Großhandel & $\mathbf{0 , 2 6 6}(1,188)$ & $\mathbf{- 0 , 6 5 1}(0,838)$ & $\mathbf{- 0 , 6 4 4}(0,857)$ \\
\hline in Verkehr/Nachrichten & $\mathbf{1 , 4 6 2}(1,099)$ & $\mathbf{1 , 8 1 8}(1,047)^{*}$ & $\mathbf{1 , 1 3 1}(1,053)$ \\
\hline in unternehmensnahen Dienstl. & $\mathbf{- 0 , 8 5 3}(0,827)$ & $-\mathbf{1 , 4 0 7}(0,606)^{* *}$ & $-1,393(0,652)^{* *}$ \\
\hline in sonstigen Dienstleistungen & $-\mathbf{1 , 4 3 3}(0,683)^{* *}$ & $-1,253(0,633)^{* *}$ & $-\mathbf{1 , 5 7 9}(0,658)^{* *}$ \\
\hline \multicolumn{4}{|l|}{ an allen neuen Unternehmen im Kreis } \\
\hline Konstante & $-1,444(0,668)^{* *}$ & $\mathbf{- 0 , 9 6 2}(0,457)^{* * *}$ & $\mathbf{- 0 , 9 0 7}(0,451)^{* *}$ \\
\hline $\begin{array}{l}\text { Breusch-Pagan-Test }\left(\chi^{2}\right), \\
\mathrm{H}^{0}: \text { Homoskedastie }\end{array}$ & $6,20^{* *}$ & / & $11,06^{* * *}$ \\
\hline $\mathrm{F}-$ Test $, \mathrm{H}^{0}: \beta^{\text {Gründungszahl }}=1$ & $6,73^{* * *}$ & $19,48^{* * *}$ & $12,30^{* *}$ \\
\hline F-Test, $\mathrm{H}^{0}: \beta^{\text {Bundeslanddummies }}=0$ & $7,83^{* * *}$ & $6,76^{* * *}$ & $14,15^{* * *}$ \\
\hline F-Test $, H^{0}: \beta^{\text {Spark.dichte }}=\beta^{\text {Gen.bankdichte }}$ & 0,25 & 0,57 & 0,53 \\
\hline F-Test $, H^{0}: \beta^{\text {Spark.dichte }}=\beta^{\text {Kreditbankdichte }}$ & 0,18 & $3,39^{*}$ & $4,53^{* *}$ \\
\hline F-Test, $\mathrm{H}^{0}: \beta^{\text {Gen.bankdichte }=} \beta^{\text {Kreditbankdichte }}$ & 0,09 & $2,73^{*}$ & $3,86^{*}$ \\
\hline Zahl der Beobachtungen & 325 & 325 & 324 \\
\hline Korrigiertes $\mathbf{R}^{2}$ in \% & 73,05 & / & 76,18 \\
\hline
\end{tabular}

Quellen: Eigene Berechnungen basierend auf Daten der DtA, des ZEW, der Deutschen Bundesbank und des Bundesamts für Bauwesen und Raumordnung.

Anmerkungen: In der Tabelle werden Schätzungen mit nicht logarithmierten Bankdichtevariablen gezeigt. Für die OLS-Regressionen R4 und R6 werden heteroskedastierobuste Standardfehler nach dem Huber-WhiteVerfahren angegeben (Greene, 2008). Im Modell R5 wird ein ausreißerrobustes Schätzverfahren eingesetzt (Hamilton, 2006). *** (**, *) zeigt Signifikanz auf dem $1(5,10) \%$-Niveau an. 
Tabelle A.4: Mittelwerte von Bankstellendichten in Kreisgruppen mit unterschiedlichem Verdichtungsgrad

\begin{tabular}{cccccc}
\hline $\begin{array}{c}\text { Quartil der } \\
\text { Einwohnerdichte }\end{array}$ & $\begin{array}{c}\text { Anzahl der } \\
\text { Kreise }\end{array}$ & $\begin{array}{c}\text { Einwohner- } \\
\text { dichte }\end{array}$ & $\begin{array}{c}\text { Sparkassen- } \\
\text { dichte }\end{array}$ & $\begin{array}{c}\text { Genossenschafts- } \\
\text { bankdichte }\end{array}$ & $\begin{array}{c}\text { Kreditbank- } \\
\text { dichte }\end{array}$ \\
\hline 1 & 83 & 0,101 & 0,391 & 0,555 & 0,045 \\
2 & 80 & 0,171 & 0,353 & 0,425 & 0,048 \\
3 & 81 & 0,409 & 0,287 & 0,278 & 0,072 \\
4 & 81 & 1,611 & 0,182 & 0,124 & 0,152 \\
\hline
\end{tabular}

Quellen: Eigene Berechnungen für die 325 Stadt- und Landkreise im Regionsdatensatz basierend auf Daten der Deutschen Bundesbank und des Bundesamts für Bauwesen und Raumordnung. 
Tabelle A.5: Determinanten der Vergabe von Förderkrediten aus DtA-Programmen Marginale Effekte für Probit-Modelle (Unternehmensdaten)

\begin{tabular}{|c|c|c|c|}
\hline \multirow{2}{*}{$\begin{array}{l}\text { Endogene Variable } \\
\text { Modell }\end{array}$} & \multicolumn{3}{|c|}{ Förderkreditindikator } \\
\hline & \multicolumn{2}{|c|}{ U1 } & \\
\hline Exogene Variable & \multicolumn{3}{|c|}{ Marginale Effekte (Standardfehler) } \\
\hline \multicolumn{4}{|l|}{ Bankverbindung bei ... } \\
\hline Sparkasse (S) & \multicolumn{2}{|c|}{$\mathbf{0 , 0 2 3}(0,010)^{* *}$} & $\mathbf{0 , 0 2 1}(0,009)^{* *}$ \\
\hline Genossenschaftsbank (G) & \multicolumn{2}{|c|}{$\mathbf{0 , 0 2 7}(0,009)^{* * *}$} & $\mathbf{0 , 0 2 4}(0,008)^{* * *}$ \\
\hline S-/G-Zentralinstitut & \multicolumn{2}{|c|}{$\mathbf{- 0 , 0 2 4}(0,020)$} & $\mathbf{- 0 , 0 2 7}(0,017)$ \\
\hline Kreditbank & \multicolumn{2}{|c|}{$\mathbf{- 0 , 0 0 4}(0,010)$} & $\mathbf{- 0 , 0 0 6}(0,009)$ \\
\hline Anzahl der Bankverbindungen & \multicolumn{2}{|c|}{$\mathbf{0 , 0 1 7}(0,009)^{*}$} & $\mathbf{0 , 0 1 3}(0,008)$ \\
\hline Bankstellendichte & \multicolumn{2}{|c|}{$\mathbf{0 , 0 2 1}(0,011)^{*}$} & $\mathbf{0 , 0 2 2}(0,011)^{* *}$ \\
\hline Modell & U4 & U5 & U6 \\
\hline Exogene Variable & & e Effekte (Standard. & \\
\hline \multicolumn{4}{|l|}{ Bankverbindung bei ... } \\
\hline Sparkasse (S) & $\mathbf{0 , 0 2 2}(0,008)^{* * *}$ & $\mathbf{0 , 0 1 6}(0,010)^{*}$ & $\mathbf{0 , 0 1 7}(0,009)^{*}$ \\
\hline Genossenschaftsbank (G) & $\mathbf{0 , 0 1 9}(0,008)^{* *}$ & $\mathbf{0 , 0 2 5}(0,009)^{* * *}$ & $\mathbf{0 , 0 2 1}(0,008)^{* *}$ \\
\hline S-/G-Zentralinstitut & $\mathbf{- 0 , 0 1 9}(0,016)$ & $-\mathbf{0 , 0 3 4}(0,017)^{* *}$ & $\mathbf{- 0 , 0 2 3}(0,016)$ \\
\hline Kreditbank & $\mathbf{- 0 , 0 0 1}(0,009)$ & $\mathbf{- 0 , 0 0 5}(0,010)$ & $\mathbf{- 0 , 0 0 4}(0,009)$ \\
\hline Anzahl der Bankverbindungen & $\mathbf{0 , 0 1 2}(0,008)$ & $\mathbf{0 , 0 1 3}(0,008)$ & $\mathbf{0 , 0 1 6}(0,008)^{* *}$ \\
\hline Bankstellendichte & $\mathbf{0 , 0 1 8}(0,011)^{*}$ & $\mathbf{0 , 0 2 0}(0,011)^{*}$ & $\mathbf{0 , 0 2 1}(0,011)^{*}$ \\
\hline Modell & U7 & U8 & U9 \\
\hline Exogene Variable & \multicolumn{3}{|c|}{ Marginale Effekte (Standardfehler) } \\
\hline \multicolumn{4}{|l|}{ Bankverbindung bei ... } \\
\hline Sparkasse (S) & $\mathbf{0 , 0 2 0}(0,009)^{* *}$ & $\mathbf{0 , 0 1 8}(0,008)^{* *}$ & $\mathbf{0 , 0 2 5}(0,012)^{* *}$ \\
\hline Genossenschaftsbank (G) & $\mathbf{0 , 0 2 3}(0,008)^{* * *}$ & $\mathbf{0 , 0 2 2}(0,008)^{* * *}$ & $\mathbf{0 , 0 2 4}(0,010)^{* *}$ \\
\hline $\mathrm{S} * \mathrm{D}$ (Einw.dichte $\leq$ Median $)$ & / & l & $\mathbf{- 0 , 0 0 8}(0,014)$ \\
\hline$G^{*} \mathrm{D}($ Einw.dichte $\leq$ Median $)$ & $1 \quad 1$ & / & $\mathbf{0 , 0 0 1}(0,012)$ \\
\hline S-/G-Zentralinstitut & $\mathbf{- 0 , 0 2 5}(0,016)$ & $\mathbf{- 0 , 0 2 3}(0,015)$ & $\mathbf{- 0 , 0 2 7}(0,017)$ \\
\hline Kreditbank & $\mathbf{- 0 , 0 0 5}(0,009)$ & $\mathbf{- 0 , 0 0 5}(0,008)$ & $\mathbf{- 0 , 0 0 6}(0,009)$ \\
\hline Anzahl der Bankverbindungen & $\mathbf{0 , 0 1 0}(0,008)$ & $\mathbf{0 , 0 1 0}(0,008)$ & $\mathbf{0 , 0 1 4}(0,008)$ \\
\hline Bankstellendichte & $\mathbf{0 , 0 2 0}(0,011)^{*}$ & $\mathbf{0 , 0 2 0}(0,010)^{* *}$ & $\mathbf{0 , 0 2 5}(0,012)^{* *}$ \\
\hline
\end{tabular}

Quellen: Eigene Berechnungen basierend auf Daten der DtA, des ZEW, der Deutschen Bundesbank und des Bundesamts für Bauwesen und Raumordnung.

Anmerkungen: In der Tabelle werden marginale Effekte für die Probit-Modelle U1, U2, U4 - U9 in den Tabellen 4, 5, und 6 angegeben. Die Standardfehler sind robust, nach Kreisregionen geclustert und berücksichtigen die disproportional geschichtete Stichprobenziehungsregel. *** (**,*) zeigt Signifikanz auf dem $1(5,10) \%$-Niveau an. 
Tabelle A.6: Determinanten der Vergabe von Förderkrediten aus DtA-Programmen Varianten von Modellen in Tabelle 4 und Tabelle 6 (Unternehmensdaten)

\begin{tabular}{|c|c|c|}
\hline Endogene Variable: & Förderkreditsumme (ln) & Förderkreditindikator \\
\hline Modell & ${\mathrm{U} 10^{3}}^{3}$ & U11 \\
\hline \multirow[t]{2}{*}{ Exogene Variable } & Parameter & Parameter \\
\hline & (Standardfehler) & (Standardfehler) \\
\hline \multicolumn{3}{|l|}{ Bankverbindung bei ... } \\
\hline Sparkasse (S) & $\mathbf{0 , 8 3 0}(0,366)^{* *}$ & $\mathbf{0 , 1 4 4}(0,074)^{*}$ \\
\hline Genossenschaftsbank (G) & $\mathbf{0 , 9 7 5}(0,329)^{* * *}$ & $\mathbf{0 , 2 2 7}(0,068)^{* * *}$ \\
\hline $\mathrm{S} *$ Einwohnerdichte & & $\mathbf{0 , 0 0 0 1}(0,068)$ \\
\hline $\mathrm{G}^{*}$ Einwohnerdichte & & $\mathbf{- 0 , 0 7 5}(0,048)$ \\
\hline S-/G-Zentralinstitut & $\mathbf{- 1 , 1 4 6}(0,855)$ & $\mathbf{- 0 , 1 9 5}(0,140)$ \\
\hline Kreditbank & $\mathbf{- 0 , 1 8 4}(0,351)$ & $\mathbf{- 0 , 0 3 1}(0,057)$ \\
\hline Anzahl der Bankverbindungen & $\mathbf{0 , 5 6 5}(0,326)^{*}$ & $\mathbf{0 , 0 8 7}(0,054)$ \\
\hline Bankstellendichte & $\mathbf{0 , 9 4 7}(0,424)^{* *}$ & $\mathbf{0 , 1 3 2}(0,072)^{*}$ \\
\hline Einwohnerdichte & $\mathbf{- 0 , 6 4 6}(0,220)^{* * *}$ & $\mathbf{- 0 , 0 7 7}(0,064)$ \\
\hline Unternehmensbeteiligung & $\mathbf{- 1 , 7 6 6}(0,837)^{* *}$ & $\mathbf{- 0 , 3 0 4}(0,135)^{* *}$ \\
\hline Teamgründung & $\mathbf{0 , 9 4 6}(0,454)^{* *}$ & $\mathbf{0 , 1 7 2}(0,076)^{* *}$ \\
\hline Meister-/Hochschulabschluss & $\mathbf{2 , 0 7 8}(0,332)^{* * *}$ & $\mathbf{0 , 3 4 4}(0,057)^{* * *}$ \\
\hline fehlende Humankapitalangabe & $\mathbf{0 , 1 2 8}(0,329)$ & $\mathbf{0 , 0 1 7}(0,055)$ \\
\hline BGB-Gesellschaft & $-\mathbf{1 , 1 9 2}(0,639)^{*}$ & $\mathbf{- 0 , 2 0 7}(0,106)^{*}$ \\
\hline $\mathrm{GmbH}$ oder $\mathrm{AG}$ & $\mathbf{- 0 , 6 0 4}(0,425)$ & $\mathbf{- 0 , 1 2 1}(0,070)^{*}$ \\
\hline Mitarbeiterzahl (ln) & $\mathbf{1 , 2 4 4}(0,444)^{* * *}$ & $\mathbf{0 , 1 8 8}(0,075)^{* *}$ \\
\hline Mitarbeiterzahl (ln, quadriert) & $\mathbf{- 0 , 4 1 8}(0,145)^{* * *}$ & $\mathbf{- 0 , 0 6 9}(0,024)^{* * *}$ \\
\hline Konstante & $\mathbf{- 1 0 , 1 3 7}(1,141)^{* * *}$ & $\mathbf{- 1 , 6 4 2}(0,185)^{* * *}$ \\
\hline$\chi^{2}$-Test, $\mathrm{H}^{0}: \beta^{\text {Bundeslanddummies }}=0$ & 0,67 & 4,68 \\
\hline$\chi^{2}$-Test, $H^{0}: \beta^{\text {Kohortendummies }}=0$ & $8,31^{* * *}$ & $25,45^{* * *}$ \\
\hline$\chi^{2}$-Test, $\mathrm{H}^{0}: \beta^{\text {Branchendummies }}=0$ & $23,37^{* * *}$ & $128,31^{* * *}$ \\
\hline$\chi^{2}$-Test, $H^{0}: \beta^{\text {Spark.verb. }}=\beta^{\text {Gen.bankverb. }}$ & 0,14 & 0,91 \\
\hline$\chi^{2}$-Test, $H^{0}: \beta^{\text {Spark.verb. }}=\beta^{\text {Kreditbankverb. }}$ & $5,93^{* *}$ & $4,40^{* *}$ \\
\hline$\chi^{2}$-Test, $H^{0}: \beta^{\text {Gen.bankverb. }}=\beta^{\text {Kreditbankverb. }}$ & $8,35^{* * *}$ & $10,48^{* * *}$ \\
\hline Zahl der Beobachtungen & 6.880 & 6.880 \\
\hline Log likelihood-Wert & -3664.70 & $-2.084,63$ \\
\hline Pseudo $R^{2}$ in $\%$ & 5,32 & 8,98 \\
\hline
\end{tabular}

Quellen: Eigene Berechnungen basierend auf Daten der DtA, des ZEW, der Deutschen Bundesbank und des Bundesamts für Bauwesen und Raumordnung.

Anmerkungen: Das Modell U10 ist ein Tobit-Modell, das Modelle U11 ist ein Probitmodell. Die Standardfehler sind robust, nach Kreisregionen geclustert und berücksichtigen die disproportional geschichtete Stichprobenziehungsregel. *** $\left(* *,{ }^{*}\right)$ zeigt Signifikanz auf dem $1(5,10) \%$-Niveau an.

3 Basierend auf der Tobit-Schätzung U10 ergeben sich folgende marginale Effekte (Standardfehler) auf den unkonditionalen Erwartungswert der beobachtbaren Endogenen: Bankverbindungen zu Sparkassen: 0,071 ${ }^{* *}$ (0,031), Bankverbindungen $\mathrm{zu}$ Genossenschaftsbanken: 0,085 $5^{* * *}(0,029)$, Bankverbindungen zu S-/GZentralinstituten: $-0,087$ (0,055), Bankverbindungen $\mathrm{zu}$ Kreditbanken: -0,016 ${ }^{* *}(0,032)$, Anzahl der Bankverbindungen: $0,050^{*}(0,029)$. Das Stichprobenmittel der logarithmierten, in 1.000 gemessenen und um 1 erhöhten Förderkreditvariable ist 0,385. 
Bücher des Schwerpunkts Märkte und Politik

Books of the Research Area Markets and Politics

Mark Gradstein, Kai A. Konrad (Eds.)

Institutions and Norms in Economic Development

2007, MIT Press

Johannes Münster

Mobbers, Robbers, and Warriors

2007, Shaker Verlag

Kai A. Konrad, Beate Jochimsen (Eds.)

Der Föderalstaat nach dem Berlin-Urteil

2007, Peter Lang Verlag

Kai A. Konrad, Beate Jochimsen (Eds.)

Finanzkrise im Bundesstaat

2006, Peter Lang Verlag

Robert Nuscheler

On Competition and Regulation in Health Care

Systems

2005, Peter Lang Verlag

Pablo Beramendi

Decentralization and Income Inequality

2003, Madrid: Juan March Institute

Thomas R. Cusack

A National Challenge at the Local Level: Citizens, Elites and Institutions in Reunified Germany

2003, Ashgate

Sebastian Kessing

Essays on Employment Protection

2003, Freie Universität Berlin

http://www.diss.fu-berlin.de/2003/202

Daniel Krähmer

On Learning and Information in Markets and

Organizations

2003, Shaker Verlag

Tomaso Duso

The Political Economy of the Regulatory Process:

An Empirical Approach

Humboldt-University Dissertation, 2002, Berlin,

http://edoc.hu-berlin.de/dissertationen/duso-tomaso-

2002-07-17/PDF/Duso.pdf

Bob Hancké

Large Firms and Institutional Change. Industrial Renewal and Economic Restructuring in France 2002, Oxford University Press

Andreas Stephan

Essays on the Contribution of Public Infrastruc-

ture to Private: Production and its Political

Economy

2002, dissertation.de

Peter A. Hall, David Soskice (Eds.)

Varieties of Capitalism

2001, Oxford University Press

Hans Mewis

Essays on Herd Behavior and Strategic Delegation

2001, Shaker Verlag
Andreas Moerke

Organisationslernen über Netzwerke - Die

personellen Verflechtungen von Führungsgremien japanischer Aktiengesellschaften

2001, Deutscher Universitäts-Verlag

Silke Neubauer

Multimarket Contact and Organizational Design

2001, Deutscher Universitäts-Verlag

Lars-Hendrik Röller, Christian Wey (Eds.)

Die Soziale Marktwirtschaft in der neuen

Weltwirtschaft, WZB Jahrbuch 2001

2001, edition sigma

Michael Tröge

Competition in Credit Markets: A Theoretic

Analysis

2001, Deutscher Universitäts-Verlag

Torben Iversen, Jonas Pontusson, David Soskice

(Eds.)

Unions, Employers, and Central Banks

2000, Cambridge University Press

Tobias Miarka

Financial Intermediation and Deregulation:

A Critical Analysis of Japanese Bank-Firm-

Relationships

2000, Physica-Verlag

Rita Zobel

Beschäftigungsveränderungen und

organisationales Lernen in japanischen

Industriengesellschaften

2000, Humboldt-Universität zu Berlin

http://dochost.rz.hu-berlin.de/dissertationen/zobel-rita-

2000-06-19

Jos Jansen

Essays on Incentives in Regulation and Innovation

2000, Tilburg University

Ralph Siebert

Innovation, Research Joint Ventures, and

Multiproduct Competition

2000, Humboldt-Universität zu Berlin

http://dochost.rz.hu-berlin.de/dissertationen/siebert-

ralph-2000-03-23/

Damien J. Neven, Lars-Hendrik Röller (Eds.)

The Political Economy of Industrial Policy in

Europe and the Member States

2000, edition sigma

Jianping Yang

Bankbeziehungen deutscher Unternehmen: Investitionsverhalten und Risikoanalyse 2000, Deutscher Universitäts-Verlag 
Kai A. Konrad

Jo Seldeslachts Joseph A. Clougherty Pedro Pita Barros

Stijn Goeminne Benny Geys

Carine Smolders

Hilde Coffé Benny Geys

Lutz Engelhardt

Beate Jochimsen Robert Nuscheler

Thomas R. Cusack Torben Iversen David Soskice

Lutz Engelhardt

Benny Geys Jan Vermeir

Kristien Werck Bruno Heyndels Benny Geys

Benny Geys

Tomaso Duso Enrico Pennigs Jo Seldeslachts
Strategy in Contests - an Introduction

Remedy for Now but Prohibit for Tomorrow:

The Deterrence Effects of Merger Policy Tools

Political Fragmentation and Projected Tax

Revenues: Evidence from Flemish Municipalities

Measuring the Bridging Nature of Voluntary

Organizations: A Note on the Importance of Association Size

Der Entry Standard der Frankfurter Wertpapierbörse als Nachfolger des Neuen Marktes: Zwei Versuche institutioneller Innovation in Deutschland

The Political Economy of the German Länder Deficits

Economic Interests and the Origins of Electoral Systems

Arbeits- und Kapitalmarktstruktur als Determinanten von Frühphasen-Wagniskapitalinvestitionen

Taxation and Presidential Approval:

Separate Effects from Tax Burden and Tax Structure Turbulence?

The Impact of 'Central Places' on Spatial Spending Patterns: Evidence from Flemish Local Government Cultural Expenditures

How to Make Head or Tail of 'Bridging' and 'Bonding'?: Addressing the Methodological Ambiguity

The Dynamics of Research Joint Ventures: A Panel Data Analysis
SP || 2007 - 01

SP || $2007-02$

SP II $2007-03$

SP || $2007-04$

SP || $2007-05$

SP || $2007-06$

SP || $2007-07$

SP || $2007-08$

SP || $2007-09$

SP || 2007 - 10

SP || $2007-11$

SP || $2007-12$ 


\section{DISCUSSION PAPERS 2008}

Dan Kovenock Brian Roberson

Dan Kovenock Brian Roberson

Vito Tanzi

Kai A. Konrad Kjell Erik Lommerud

Benny Geys Jan Vermeir

Benny Geys Jan Vermeir

Kai A. Konrad

Dan Kovenock

Johannes Münster

Kai A. Konrad Dan Kovenock

Kai A. Konrad

Florian Morath

Joseph Clougherty Anming Zhang

Jonathan Beck

Susanne Prantl Matthias Almus Jürgen Egeln Dirk Engel
Inefficient Redistribution and Inefficient

Redistributive Politics

Coalitional Colonel Blotto Games with Application to the Economics of Alliances

The Future of Fiscal Federalism

Love and Taxes - and Matching Institutions

Party Cues and Yardstick Voting

The Political Cost of Taxation:

New Evidence from German Popularity Ratings

The Alliance Formation Puzzle and Capacity

Constraints

Repeated Contests with Asymmetric Information

Competition for FDI with Vintage Investment and Agglomeration Advantages

Non-binding Minimum Taxes May Foster Tax Competition

Strategic Information Acquisition and the Mitigation of Global Warming

Domestic Rivalry and Export Performance: Theory and Evidence from International Airline Markets

Diderot's Rule

Kreditvergabe durch Genossenschaftsbanken, Kreditbanken und Sparkassen: Eine empirische Analyse von Förderkrediten für junge, kleine Unternehmen
SP II $2008-01$

SP II $2008-02$

SP II $2008-03$

SP II $2008-04$

SP II $2008-05$

SP || $2008-06$

SP || $2008-07$

SP || $2008-08$

SP || $2008-09$

SP || $2008-10$

SP || $2008-11$

SP II $2008-12$

SP || $2008-13$

SP || $2008-14$ 
Bei Ihren Bestellungen von WZB-Papers schicken

Sie bitte unbedingt einen an Sie adressierten Auf-

kleber mit sowie je paper eine Briefmarke im Wert

von 0,51 Euro oder einen "Coupon Reponse Inter-

national " (für Besteller aus dem Ausland)
Please send a self addressed label and postage stamps in the amount of 0.51 Euro or a "CouponReponse International" (if you are ordering from outside Germany) for each WZB-paper requested

\section{Absender / Return Address:}

Wissenschaftszentrum Berlin

für Sozialforschung

Presse- und Informationsreferat

Reichpietschufer 50

D-10785 Berlin-Tiergarten

Hiermit bestelle ich folgende(s) Discussion paper(s):
Please send me the following Discussion paper(s): 